Minimização de Conjuntos de Casos de Teste para Máquinas de Estados Finitos

Lúcio Felippe de Mello Neto 

SERVIÇO DE PÓS-GRADUAÇÃO DO ICMC-USP

Data de Depósito: 19 de março de 2008

Assinatura:

\title{
Minimização de Conjuntos de Casos de Teste para Máquinas de Estados Finitos
}

\author{
Lúcio Felippe de Mello Neto
}

Orientador: Prof. Dr. Adenilso da Silva Simão

Dissertação apresentada ao Instituto de Ciências Matemáticas e de Computação - ICMC/USP, como parte dos requisitos para obtenção do título de Mestre em Ciências Ciências de Computação e Matemática Computacional.

USP - São Carlos

Março/2008 

Aos meus pais, Lúcio e Marília. 



\section{Agradecimentos}

- A Deus, por me proporcionar uma oportunidade única e me confortar em todos os momentos da vida.

- Aos meus queridos pais, Lúcio e Marília, por me incentivarem e acreditarem em mim em todos os momentos. Gostaria de agradecer os bons princípios que vocês me ensinaram e dizer que sem vocês eu não seria capaz de percorrer essa importante etapa da minha vida. Eu amo vocês.

- Ao meu irmão e melhor amigo, André, pela amizade e pela ajuda que sempre recebo.

- À Gabriela, pelo amor, compreensão e amizade. É muito importante ter a pessoa que amo sempre ao meu lado.

- Aos meus avós, Álvaro e Jorgina, Lúcio e Dirce, pelas lições de vida que aprendo a cada dia.

- A todos os meus familiares, pelo incentivo recebido. Agradeço as orações por mim e pela Gabriela, pois nos fortaleceram muito diante das dificuldades encontradas.

- Ao meu orientador Prof. Dr. Adenilso da Silva Simão, pela confiança demonstrada e pela orientação deste trabalho. Agradeço os ensinamentos que aprendi com um grande amigo.

- Aos amigos do LABES, de São Carlos e de Marília, pelo apoio e grande amizade: Abe, Alessandra, André Endo, André Freire, André Domingues, Camila, Carlão, Dalcimar, Danilo, Edson, Eduardo, Erika, Falcão, Felipe, Gambi, Ícaro, Ivan, Jarbas, Jaú, Kika, Marcão, Marcela, Marcelo Eller, Marcelo Morais, Marília, Marllos, Matrix, Maycon, Merley, Nardo, Nelson, Otávio, Paula, Paula Herculano, Pedra, Resina, Taty, Tott, Vanessa, Vânia, Valdecir, Vasco, Wladimir e Yamandú.

- Aos professores do mestrado e da graduação, em especial, à Fátima, Maria Istela, Dino, Maldonado, Guilherme, Masiero e Rosely Sanches pela ajuda, confiança e amizade.

- Aos funcionários do ICMC, pelo constante auxílio.

- A todas as pessoas que contribuíram de alguma forma para a realização deste trabalho.

- À CAPES, pelo apoio financeiro. 

TESTE baseado em modelos visa a possibilitar a derivação de conjuntos de casos de teste a partir de especificações formais, tais como Máquinas de Estados Finitos. Os conjuntos de teste podem ser obtidos tanto pelos métodos clássicos de geração quanto por alguma abordagem ad hoc. Procura-se obter um conjunto de teste que consiga detectar todos os possíveis defeitos de uma implementação e possua tamanho reduzido para que a sua aplicação seja factível. Por questões de ordem prática, pode não ser possível a aplicação de todo o conjunto de teste gerado. Desse modo, um subconjunto de casos de teste deve ser selecionado, ou seja, uma minimização do conjunto de teste deve ser realizada. No entanto, é fundamental que a minimização reduza o custo de aplicação dos testes, mas mantenha a efetividade em revelar defeitos. Neste trabalho, propõe-se um algoritmo de minimização de conjuntos de teste para Máquinas de Estados Finitos. O algoritmo baseia-se em condições de suficiência para que a completude em relação à detecção de defeitos seja mantida. O algoritmo foi utilizado em dois diferentes contextos. Utilizou-se o algoritmo com conjuntos de teste gerados de forma aleatória para verificar a minimização obtida. $\mathrm{O}$ algoritmo também foi utilizado para reduzir o esforço em se obter um conjunto completo em relação à detecção de defeitos. 

7 HE Model-based testing aims at generating test suites from formal specifications, such as Finite State Machines. Test suites can be obtained either from classical test derivation methods or from some ad-hoc approach. It is desirable to produce a test suite which detects all possible faults of an implementation and has small size, so that its application can be feasible. For practical reasons, the application of the generated test suite may not be possible. Therefore, a subset of test cases should be selected, i.e., a test suite minimization should be performed. However, it is important that the minimization reduces the test application cost, but keeps the effectiveness in revealing faults. In this work, an algorithm is proposed for the minimization of test suites generated from Finite State Machines. The algorithm is based on sufficient conditions, so that test suite completeness can be maintained. The algorithm was used in two different contexts. It was used with randomly generated test suites to verify the minimization obtained. The algorithm was also used to reduce the effort of obtaining a test suite with full fault coverage. 

$\begin{array}{ll}\text { Resumo } & \mathbf{v}\end{array}$

$\begin{array}{lll}\text { Abstract } & \text { vii }\end{array}$

1 Introdução $\quad 1$

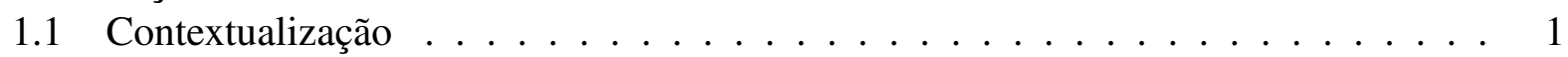

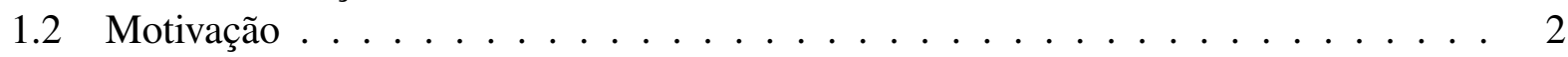

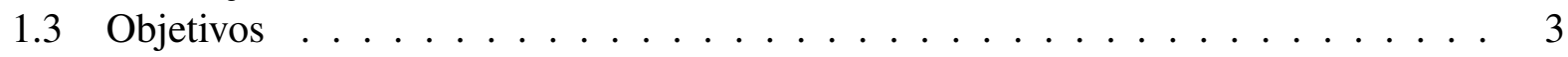

1.4 Organização . . . . . . . . . . . . . . . . . . . . 4

2 Teste de Software 5

2.1 Considerações Iniciais $\ldots \ldots \ldots \ldots \ldots$

2.2 Teste de Software . . . . . . . . . . . . . . . . . . . 5

2.2.1 Técnicas de Teste . . . . . . . . . . . . . . . . . . . . . . 8

2.3 Geração de Casos de Teste . . . . . . . . . . . . . . . . . . . . 13

2.4 Minimização de Conjuntos de Teste . . . . . . . . . . . . . . . . . . . . 15

2.5 Ferramentas de Apoio ao Teste de Programas . . . . . . . . . . . . . . . 16

2.6 Considerações Finais . . . . . . . . . . . . . . . . . . . 17

3 Teste Baseado em Modelos $\quad 19$

3.1 Considerações Iniciais . . . . . . . . . . . . . . . . . . . . . . . . . . . . . . . . . . . . . . .

3.2 Teste Baseado em Modelos . . . . . . . . . . . . . . . . . . . . . . . 19

3.3 Máquinas de Estados Finitos . . . . . . . . . . . . . . . . . . . . 21

3.4 Teste Baseado em Máquinas de Estados Finitos . . . . . . . . . . . . . . . . 25

3.5 Métodos de Geração de Casos de Teste . . . . . . . . . . . . . . . . . . . . . . 26

3.5.1 Cobertura de Estados e Transições . . . . . . . . . . . . . . . . 26

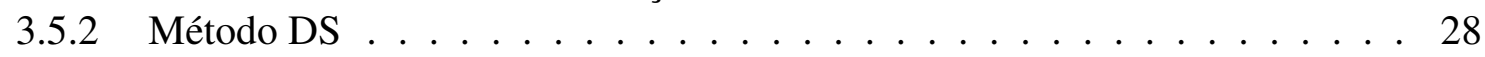

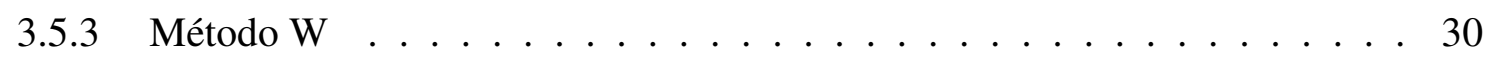

3.5 .4 Método Wp . . . . . . . . . . . . . . . . 31

3.5 .5 Método HSI . . . . . . . . . . . . . . . . . . . . . . . . . . . . . . . . . . . . 32

3.5 .6 Método State Counting . . . . . . . . . . . . . . . . . 33

3.5 .7 Método HIS . . . . . . . . . . . . . . . . . 33

3.5 .8 Método UIO . . . . . . . . . . . . . . . . . . . . 34

3.5 .9 Método UIOv . . . . . . . . . . . . . . . . . . . 35

3.5 .10 Método $\mathrm{H} \ldots \ldots \ldots \ldots \ldots \ldots$ 
3.6 Comparação entre os Métodos de Geração . . . . . . . . . . . . . . . . . . . . . . 36

3.7 Comparação Empírica entre os Métodos de Geração . . . . . . . . . . . . . . . . 37

3.8 Completude de Conjuntos de Casos de Teste . . . . . . . . . . . . . . . . . . . . 38

3.9 Ferramentas de Apoio ao Teste de Modelos . . . . . . . . . . . . . . . . . . . 40

3.9 .1 Ferramenta $T A G \ldots \ldots \ldots \ldots$. . . . . . . . . . . . 40

3.9 .2 Ferramenta Plavis/FSM . . . . . . . . . . . . . . . 41

3.9 .3 Ferramenta MGASet . . . . . . . . . . . . . . . . 41

3.9 .4 Ferramenta Proteum/FSM . . . . . . . . . . . . . . . . . 42

3.9 .5 Ferramenta ConData . . . . . . . . . . . . . . . . 42

3.9 .6 Ambiente ATIFS . . . . . . . . . . . . . . . . . . . . . . . . . . . . . . . 43

3.10 Considerações Finais . . . . . . . . . . . . . . . . . . 43

4 Algoritmo de Minimização $\quad 45$

4.1 Considerações Iniciais . . . . . . . . . . . . . . . . . . . . . 45

4.2 Condições de Suficiência . . . . . . . . . . . . . . . . . . . . . . . . . . . . . . . . . . . . 46

4.3 Algoritmo de Minimização . . . . . . . . . . . . . . . . . . . . . . . . 47

4.3.1 Seleção do State Cover . . . . . . . . . . . . . . . . . . . . . . . 49

4.3.2 Verificação dos Estados . . . . . . . . . . . . . . . . . 50

4.3 .3 Verificação das Transições . . . . . . . . . . . . . . . . 52

4.4 Exemplo de Minimização . . . . . . . . . . . . . . . . . . . . . . . . . 54

4.5 Redução ao Problema do Clique . . . . . . . . . . . . . . . . . . . . 55

4.6 Limitações do Algoritmo . . . . . . . . . . . . . . . . . . . . . . 56

4.7 Aspectos de Implementação . . . . . . . . . . . . . . . . . . . . . . 57

4.8 Complexidade . . . . . . . . . . . . . . . . . . . . . . 59

4.9 Considerações Finais . . . . . . . . . . . . . . . . . . . . 60

5 Experimentos $\quad \mathbf{6 1}$

5.1 Considerações Iniciais . . . . . . . . . . . . . . . . . . . . 61

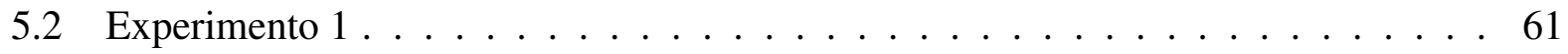

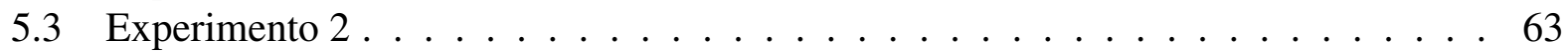

$5.3 .1 \quad$ Número de Estados . . . . . . . . . . . . . . . . . . . . . . 64

5.3 .2 Número de Saídas . . . . . . . . . . . . . . . . . . . 65

5.3 .3 Número de Entradas . . . . . . . . . . . . . . . . . . . . . . . . . . . . . . 65

5.3 .4 Tamanho de $T_{a d-h o c} \ldots \ldots \ldots \ldots 6 \ldots$

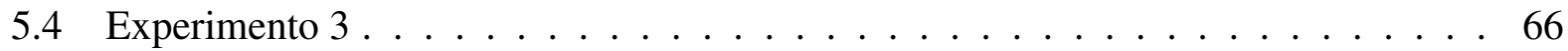

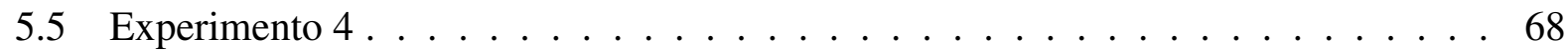

5.6 Considerações Finais . . . . . . . . . . . . . . . . . 72

6 Conclusões $\quad \mathbf{7 3}$

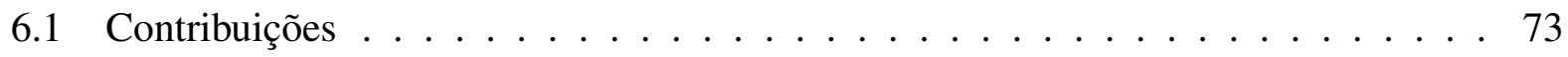

6.2 Limitações . . . . . . . . . . . . . . . . . . . . . . . . . 74

6.3 Trabalhos Futuros . . . . . . . . . . . . . . . . 75

6.4 Publicações . . . . . . . . . . . . . . . . . . . . 75

$\begin{array}{lll}\text { A Detalhes do Código } & 85\end{array}$

A.1 Estrutura de Dados . . . . . . . . . . . . . . . . . . . . 85

A.2 Formatação dos Arquivos . . . . . . . . . . . . . . 86 


\section{Lista de Figuras}

2.1 Grafo de Fluxo de Controle do programa Identifier.c. . . . . . . . . . . . . . . . . . . . . . . .

2.2 Programa Identifier.c (Maldonado et al., 2004) . . . . . . . . . . . . . . . . . . . 11

2.3 Grafo Def-Uso do programa Identifier.c. . . . . . . . . . . . . . . . . . . . . . 12

2.4 Exemplo de ordenação de casos de teste (Adaptado de Offutt et al. (1995)). . . . . 15

3.1 MEF para um extrator de comentários (Chow, 1978) . . . . . . . . . . . . . 21

3.2 Exemplo de MEF extraído de Dorofeeva et al. (2005a). . . . . . . . . . . . . . . 27

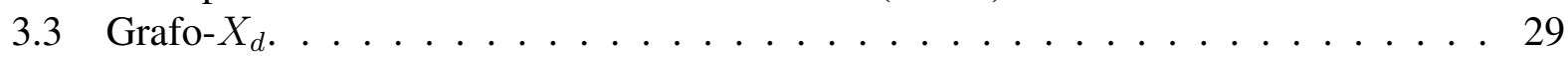

3.4 Grafo- $\beta$ e Grafo- $\beta$ reduzido. . . . . . . . . . . . . . . . . . . . . 29

4.1 Defeito de Inicialização. . . . . . . . . . . . . . . . . . . . . 50

4.2 Representação de pref $(T)$ com o grafo 4-partido. . . . . . . . . . . . . . 56

4.3 Representação do conjunto de teste por meio de uma árvore. . . . . . . . . . . . 57

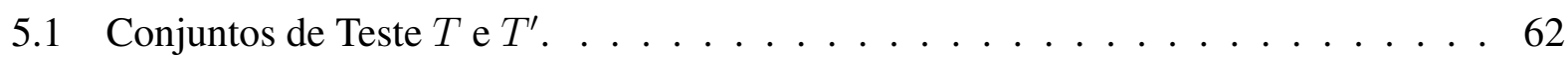

5.2 Conjuntos de Teste. . . . . . . . . . . . . . . . . 63

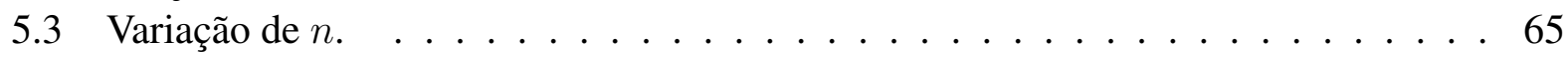

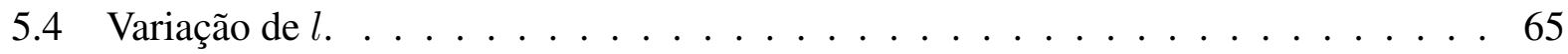

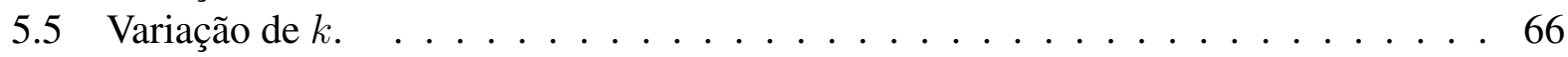

5.6 Variação de $w\left(T_{a d-h o c}\right) . \ldots \ldots \ldots \ldots \ldots \ldots$. . . . . . . . . . . . . . . . . . . . . . . . . . . . . 68

5.7 Representações da MEF. . . . . . . . . . . . . . . . . . . . . 68

A.1 Campos do nó da árvore. . . . . . . . . . . . . . . . . . 86

A.2 Representação da MEF no arquivo de entrada. . . . . . . . . . . . . . . . . . . 86

A.3 Representações dos conjuntos de teste $T$ e $T^{\prime} \ldots \ldots \ldots$. . . . . . . . . . 87 



\section{Lista de Tabelas}

3.1 Tabela representativa da MEF do extrator de comentários. . . . . . . . . . . . 22

3.2 Comparação entre os métodos de geração. . . . . . . . . . . . . . . . . . 37

5.1 Sumário dos resultados obtidos. . . . . . . . . . . . . . . . . . 62

5.2 Exemplos de MEFs. . . . . . . . . . . . . . . . . . . . 70

5.3 Sumário dos resultados obtidos. . . . . . . . . . . . . . . 71 


\subsection{Contextualização}

Atualmente, os sistemas de computadores são intensamente utilizados nas atividades da sociedade. Como resultado dessa utilização, encontra-se uma crescente demanda por produtos de software. Considerando também a grande competitividade existente nos dias atuais, torna-se essencial a busca por produtos de software de boa qualidade. Com a utilização de processos, técnicas e ferramentas, um dos objetivos da Engenharia de Software é buscar o aumento da qualidade desses produtos de software.

Segundo Pressman (2005), existem diversas categorias de produto de software, tais como software básico, sistemas de informação, sistemas científicos, sistemas embutidos, sistemas pessoais, sistemas de inteligência artificial e sistemas reativos. Um sistema reativo caracteriza-se por manter uma interação permanente com seu ambiente externo, seja esse um usuário, um dispositivo de entrada, uma outra parte do sistema, ou mesmo um outro sistema (Furbach, 1993). Seu comportamento é baseado na relação entre eventos de entrada e de saída que ocorrem discretamente no tempo. Como exemplos desses sistemas, podem-se citar o controle de tráfego aéreo, o controle metroviário e o controle de monitoramento hospitalar (Leveson e Stolzy, 1987; Liu e McDermid, 1996). Deve-se ressaltar que, mesmo com o uso de métodos, técnicas e ferramentas, defeitos podem ser introduzidos no produto durante o processo de desenvolvimento de software (Maldonado et al., 2004). Dessa forma, para que o produto de software, e, em especial, um sistema reativo, atinja um grau aceitável de qualidade, é necessário que atividades de garantia de qualidade sejam aplicadas durante todo o processo de desenvolvimento de software. 
Dentre as várias causas para o desenvolvimento de baixa qualidade estão as negligências cometidas durante a definição, projeto e codificação, que ocasionam a introdução de defeitos no produto de software. A utilização de métodos mais precisos de desenvolvimento assegura que uma quantidade menor de defeitos seja incluída, pois contribui para a redução de inconsistências e ambigüidades (Barroca e McDermid, 1992). Com o objetivo de facilitar a especificação do aspecto comportamental de sistemas reativos, várias técnicas formais de especificação foram propostas. Essas técnicas tentam conciliar o poder de modelagem com a capacidade de análise de propriedades do sistema. Dentre as diversas técnicas utilizadas para a especificação de sistemas reativos, as Máquinas de Estados Finitos (MEFs) (Gill, 1962) se destacam pela simplicidade e poder de representação.

A especificação do sistema serve como um guia de desenvolvimento para que, a partir dela, implementações possam ser construídas e, posteriormente, serem avaliadas quanto a sua corretude. Para realizar tal avaliação, as MEFs também são utilizadas para a geração de conjuntos de casos de teste que possibilitam testar se a implementação está em conformidade com sua respectiva especificação.

Nesse contexto, vários métodos foram propostos para a geração de um conjunto de casos de teste que possa revelar os possíveis erros existentes em uma implementação. Os métodos para a geração de casos de teste em MEF vêm sendo propostos há décadas, como por exemplo, os métodos DS (Gönenc, 1970), W (Chow, 1978), UIO (Sabnani e Dahbura, 1988), UIOv (Vuong et al., 1989), Wp (Fujiwara et al., 1991), HIS (Petrenko et al., 1993) e o HSI (Luo et al., 1995). Mais recentemente, destacam-se também os métodos $\mathrm{H}$ (Dorofeeva et al., 2005b) e o State Counting (Petrenko e Yevtushenko, 2005). Para que cada método seja aplicado, a MEF deve possuir certas propriedades. Por exemplo, os métodos W e Wp são aplicados somente às MEFs completas enquanto os métodos $\mathrm{H}$ e State Counting podem ser aplicados às MEFs parciais. Os métodos também se diferenciam em relação ao custo de execução do conjunto de casos de teste gerado. Por exemplo, enquanto o método $\mathrm{W}$ gera um número elevado de casos de teste que garantem a cobertura completa de defeitos para MEFs, o método UIO resulta um número menor de casos de teste, mas que não garantem a cobertura completa de defeitos.

A aplicação dos métodos torna-se improdutiva quando realizada manualmente e, por isso, existe a necessidade da criação de ferramentas de apoio para a utilização de tais métodos. Essas ferramentas, tais como a ConData (Martins et al., 1999), a Proteum/FSM (Fabbri et al., 1999), a MGASet (Candolo et al., 2001) e a PLAVIS/FSM (Simão et al., 2005), proporcionam a aplicação dos diferentes métodos propostos e, conseqüentemente, auxiliam a etapa de teste.

\subsection{Motivação}

Um problema identificado na tentativa de utilizar os métodos em aplicações reais é a grande quantidade de sequiências de testes geradas que inviabilizam os testes devido ao tempo despen- 
dido na aplicação de todos os casos de testes. Ainda pode haver situações em que um conjunto de teste de alta cardinalidade seja obtido de alguma outra forma. Por exemplo, um conjunto de casos de teste pode ter sido criado com base em outros modelos disponíveis, tais como a especificação textual ou diagramas de análise. Desse modo, questões pragmáticas levam a selecionar uma porcentagem dos casos de teste, ou seja, minimizar o conjunto de teste. Contudo, para poder ser realizada de forma adequada, a seleção deve ser feita a partir de critérios bem definidos. Pode-se utilizar como parâmetro o interesse em uma parte particular da MEF, selecionando-se, assim, os casos de teste que passam por essa parte. Ao mesmo tempo em que diminui o custo da aplicação do teste, a seleção de um subconjunto de casos de teste pode implicar em uma diminuição da efetividade da atividade. Desse modo, para que não haja prejuízos quanto à eficiência dos testes, torna-se importante realizar a minimização de forma a garantir que o conjunto resultante possua a mesma capacidade na detecção de defeitos. Em outras palavras, se um conjunto de teste consegue detectar todos os defeitos de uma implementação (dito ser completo) é importante que o conjunto minimizado também possua tal característica, ou seja, também seja completo.

Outro aspecto interessante seria quanto à redução do esforço para se completar um conjunto de teste, ou seja, tornar esse conjunto capaz de detectar todos os possíveis defeitos. Para atingir tal objetivo, a adição de outros casos de teste é necessária. Nesse cenário, seria interessante que essa adição fosse minimizada, ou seja, que poucas seqüências fossem escolhidas para que o conjunto se tornasse completo.

\subsection{Objetivos}

O objetivo deste trabalho foi a investigação de uma estratégia para a redução do custo da aplicação de casos de teste gerados a partir de MEFs. Procurou-se uma forma de minimizar um conjunto de teste, mas garantindo a mesma efetividade na detecção de defeitos. Neste trabalho foi desenvolvido um algoritmo para a minimização de conjuntos de teste para MEFs. A minimização foi baseada em condições de suficiência propostas por Dorofeeva et al. (2005b) e por Simão e Petrenko (2007) de forma a manter a efetividade dos testes. Desse modo, o algoritmo de minimização obtém um conjunto minimizado e ao mesmo tempo completo. Foram conduzidos experimentos para verificar a minimização obtida em conjuntos de teste e para verificar a redução do esforço de se completar conjuntos de teste. Os resultados apontam uma redução significativa do tamanho dos conjuntos de teste que foram obtidos de forma aleatória. Com relação ao esforço utilizado para se completar um conjunto de teste, os resultados apontam que o algoritmo de minimização pode reduzi-lo em até $50 \%$. 


\subsection{Organização}

Este trabalho está organizado da seguinte forma. No Capítulo 2 são apresentadas as definições, conceitos, técnicas e ferramentas relacionadas ao teste de software. No Capítulo 3 discutem-se as motivações para o teste baseado em modelos. Apresentam-se também os principais conceitos sobre MEFs e métodos de geração de casos de teste a partir de MEFs, destacando-se as diferenças entre eles. Em seguida, no Capítulo 4, é apresentado o algoritmo de minimização proposto neste trabalho. No Capítulo 5 são apresentados os experimentos realizados com o algoritmo de minimização. Por fim, no Capítulo 6, as conclusões são apresentadas. 


\section{Teste de Software}

\subsection{Considerações Iniciais}

Neste capítulo são abordados os conceitos e definições fundamentais relacionadas ao teste de software. Na Seção 2.2 é discutida a importância da atividade de teste e os conceitos fundamentais referentes ao teste de software são apresentados. Também é apresentada uma visão geral sobre as técnicas funcional, estrutural, baseada em erros e baseada em estados. Nas Seções 2.3 e 2.4 apresentam-se trabalhos relacionados à geração automática de casos de teste e à minimização de conjuntos de teste, respectivamente. Em seguida, na Seção 2.5, ferramentas de apoio ao teste de software são apresentadas.

\subsection{Teste de Software}

Durante o desenvolvimento de software, mesmo com a utilização de ferramentas, métodos e técnicas, defeitos ainda podem ser inseridos no software. Dessa forma, torna-se importante a existência de atividades de apoio que procurem minimizar a ocorrência desses erros. Essas atividades devem ser introduzidas durante todo o processo de desenvolvimento de software, sendo agregadas sob o nome de Garantia de Qualidade de Software (GQS).

Dentre as atividades de GQS, encontram-se as atividades de Verificação, Validação e Teste (VV\&T). Segundo Pressman (2005), verificação consiste em atividades que garantem que o software implementa corretamente uma função específica e validação refere-se às atividades que garantem que o software construído está de acordo com os requisitos do cliente. O teste é um conjunto 
de atividades que tem como objetivo encontrar os erros de um programa por meio de sua execução (Myers, 2004). O teste é uma atividade importante, pois permite que erros sejam identificados e corrigidos antes que o software seja entregue ao usuário final. De acordo com Pressman (2005), não é incomum que a atividade de teste corresponda entre $30 \%$ e $40 \%$ de todo o esforço gasto em um projeto durante o desenvolvimento do software.

A atividade de teste consiste basicamente nas etapas de: planejamento do teste, no qual são formulados quais os testes que serão realizados, ou seja, um plano de teste é elaborado; projeto dos casos de teste, que consiste na elaboração de um conjunto de casos de teste que atenda os critérios estabelecidos; еxecução do teste, em que o programa é executado com os casos de teste anteriormente criados, e, por último, a avaliação dos resultados, que consiste em avaliar as saídas produzidas pelo teste para que ações posteriores possam ser tomadas. Os testes podem ser realizados em três fases (Beizer, 1990; Pressman, 2005):

Teste de Unidade: uma unidade pode ser vista como a menor parte (módulo) testável de um software. Nessa fase, o teste é realizado na unidade do software. Cada módulo do software é testado separadamente com o objetivo de identificar erros de lógica e de implementação. Por existir dependências entre os módulos do software, torna-se necessária a criação de pseudocontroladores (drivers) e/ou pseudo-controlados (stubs). Os pseudo-controladores têm a função de controlar o teste do módulo, ativando-o e fornecendo os dados de teste definidos pelo testador. Os pseudo-controlados têm a função de simular os módulos que são chamados pelo módulo sob teste.

Teste de Integração: a partir das unidades já testadas, o teste de integração visa a testar as interfaces entre as unidades, ou seja, tem como objetivo identificar os erros que possam surgir na etapa de integração das unidades do software. É uma etapa importante, pois os erros ainda podem existir mesmo se as unidades foram testadas independentemente. Por exemplo, dois módulos acoplados podem não produzir a função principal desejada.

Teste de Sistema: com os testes de unidade e integração já realizados, torna-se necessário o teste por completo do sistema baseado em computador para assegurar que a função global desejada seja obtida. Nessa fase, o objetivo é garantir a funcionalidade correta da combinação do software com os demais elementos do sistema (hardware e banco de dados, por exemplo).

Neste trabalho a "atividade de teste" será considerada como uma atividade de análise dinâmica, em contraste a outras formas de se validar um produto sem a sua execução como, por exemplo, as verificações formais, tais como o model checking. Desse modo, o programa deve ser executado com os casos de teste e os resultados são analisados posteriormente (Weyuker, 1986).

No contexto deste trabalho, é importante definir a terminologia utilizada para os termos "defeito", "erro" e "falha". O padrão IEEE 610.12-1990 (IEEE, 1990) diferencia os termos: defeito (fault): passo, processo ou definição de dados incorretos; erro (error): diferença entre o valor 
obtido e o valor esperado, ou seja, qualquer estado interno que diverge do estado esperado; e falha (failure): produção de uma saída incorreta com relação à especificação. Os termos "erro" e "defeito" serão utilizados como sinônimos para indicar uma causa. O termo "falha" é utilizado para indicar uma manifestação externa de um erro, ou seja, uma conseqüência.

Pela observação do resultado obtido a partir da execução de um programa com um caso de teste, é possível verificar se houve falhas e, conseqüentemente, se o programa possui um defeito. Desse modo, a atividade de teste tem como objetivo revelar o defeito, enquanto que a atividade de depuração é responsável por rastrear e encontrar tal defeito.

Para os testes serem realizados, casos de teste devem ser projetados. Os casos de teste são os elementos do domínio de entrada $D$ de um programa $P$. Seja $S$ a especificação do programa $P$ e $x \in D$ um elemento do domínio de entrada. $S(x)$ representa o resultado da especificação $S$ com a entrada $x$. Um caso de teste é um par ordenado $(d, S(d))$, tal que $d$ é um elemento do domínio de entrada $D$ e $S(d)$ é a saída esperada de acordo com a especificação, utilizando o elemento $d$ como entrada. Para verificar se a saída produzida por uma implementação está em conformidade com a saída esperada (especificação), um oráculo deve existir. Segundo Howden (1978), um oráculo pode ser uma tabela de valores, um algoritmo ou simplesmente o conhecimento do programador em reconhecer a saída correta de um programa.

O cenário ideal para verificar se o programa está de acordo com a sua especificação, seria aquele em que todos os elementos do domínio de entrada $D$ de um programa $P$ fossem utilizados na atividade de teste. Contudo, isso geralmente é impraticável, pois o domínio de entrada pode ser extremamente grande, ou mesmo infinito (Rapps e Weyuker, 1985). Dessa forma, torna-se importante e necessário realizar a seleção de um subconjunto finito dos casos de teste.

Para se obter subconjuntos dos casos de teste, critérios de teste são definidos. Os critérios de teste estabelecem requisitos de teste a serem cumpridos e são diretrizes que auxiliam o testador a estabelecer um subconjunto (relativamente pequeno) $T$ do domínio de entrada $D$. Um critério de teste é um método utilizado tanto para a avaliação de um conjunto de casos de teste quanto para a construção dos mesmos (Frankl e Weyuker, 2000). Nota-se a importância da definição dos critérios de teste para realizar uma seleção de casos de teste que aumentem as chances em revelar defeitos para estabelecer-se um bom nível de confiança na correção do programa.

Os critérios de teste podem ser divididos basicamente em quatro técnicas: funcional, estrutural, baseada em erros e baseada em estados. De acordo com Simão (2004), alguns critérios não se enquadram adequadamente em nenhum dos quatro grupos citados, como é o caso dos critérios de teste exaustivo e de teste aleatório. O teste exaustivo consiste na execução do programa com todo o domínio de entrada, ou seja, o conjunto dos casos de teste $T$ é o próprio domínio de entrada $D$ $(T=D)$. Geralmente, o teste exaustivo é impraticável, pois, mesmo para programas pequenos, o domínio de entrada pode ser infinito. O teste exaustivo deve ser considerado, quando possível, se o custo de sua execução for menor que o custo resultante da ocorrência de uma falha. Já o teste aleatório consiste na seleção aleatória de um conjunto $T(T \subseteq D)$. O teste aleatório é realizado de forma sistemática considerando-se as características do domínio e a probabilidade de cada entrada. 


\subsubsection{Técnicas de Teste}

Como citado anteriormente, os critérios podem ser agrupados em quatro técnicas: funcional, estrutural, baseada em erros e baseada em estados. A diferença existente entre essas técnicas refere-se à origem da informação utilizada na construção e na avaliação dos conjuntos de casos de teste (Maldonado, 1991). Essas técnicas se complementam e devem ser utilizadas em conjunto, pois provavelmente revelam classes diferentes de erros (Pressman, 2005).

\section{Teste Funcional}

O teste funcional, também conhecido como teste caixa-preta, consiste no teste de um programa considerando-o como uma caixa em que apenas os dados de entrada e as saídas produzidas podem ser visualizados. Os casos de teste são derivados a partir da especificação do software com o intuito de que as suas funcionalidades sejam verificadas, sem considerar os aspectos de implementação. Para identificar as funcionalidades que o programa deve realizar, casos de teste são criados.

A especificação do software é muito importante, pois é essencialmente o documento em que o teste funcional se baseia para a geração dos casos de teste. Desse modo, é importante que a especificação seja consistente quanto aos requisitos do usuário final. Caso contrário, os testes serão improdutivos. Alguns exemplos de critérios da técnica de teste funcional são apresentados a seguir.

Particionamento em Classe de Equivalência: o critério particionamento em classe de equivalência divide o domínio de entrada de um programa em um número finito de classes de dados válidas (entradas válidas para o programa) e inválidas (demais entradas). A partir dessa divisão, os casos de teste são derivados com a suposição de que um teste realizado com um caso de teste de uma classe seja equivalente ao teste realizado com qualquer outro caso de teste da mesma classe, ou seja, um elemento de uma classe revela os mesmos erros que qualquer outro elemento dessa mesma classe revelaria. Desse modo, um número menor de casos de teste é selecionado da seguinte forma: seleciona-se um caso de teste distinto para cada classe inválida e um conjunto mínimo de casos de teste representativos das classes válidas.

Análise do valor limite: o critério de análise do valor limite consiste em uma extensão ao particionamento em classe de equivalência, pois os elementos que se encontram nos "limites" das classes são selecionados. Em vez de selecionar os elementos do interior da classe, os elementos que se concentram nas "fronteiras" das classes são escolhidos, pois os erros tendem a ocorrer nesses pontos (Pressman, 2005). As saídas também são particionadas em classes e casos de teste são selecionados para resultar em valores que estão nos limites dessas classes.

Grafo de causa-efeito: o critério grafo de causa-efeito considera as condições dos dados de entrada. As condições de entradas (causas) e as ações (efeitos) são identificadas para a cons- 
trução de um grafo. Uma tabela de decisão é montada, a partir do grafo, para a posterior derivação dos casos de teste.

\section{Teste Estrutural}

O teste estrutural, também conhecido como teste caixa-branca, utiliza a estrutura interna do programa para a derivação dos casos de teste. Desse modo, as características de implementação devem ser conhecidas. Devido à natureza dos erros existentes em um programa, o teste estrutural é visto como complementar ao teste funcional. Geralmente, os critérios de teste estrutural utilizam uma representação de programa conhecida como grafo de fluxo de controle (ou grafo de programa). Nesse grafo, o fluxo de controle lógico do programa é ilustrado com a utilização de uma notação simples, composta de arcos e nós (Pressman, 2005).

O grafo de fluxo de controle é construído de forma que seus nós representem os blocos dos programas e seus arcos representem os possíveis fluxos de controle entre esses blocos (Zhu et al., 1997). Um bloco é um conjunto de comandos de um programa que sempre são executados de forma seqüencial, ou seja, quando o primeiro comando do bloco é executado, todos os comandos restantes (do mesmo bloco) são também executados. Os arcos, que representam os possíveis desvios de controle, conectam os nós. Assim, a ligação entre os blocos ocorre no início ou no fim de um bloco. Na Figura 2.1 é ilustrado um grafo de fluxo de controle gerado a partir do código da função main do programa Identifier.c (Figura 2.2). O programa Identifier.c, extraído de (Maldonado et al., 2004), realiza a validação de identificadores. Um identificador válido deve começar com uma letra e conter apenas letras ou dígitos. Além disso, deve ter no mínimo um caractere e no máximo seis caracteres de comprimento.

O nó correpondente ao bloco que possui o primeiro comando do programa é denominado de nó inicial e o nó correspondente ao bloco que possui o comando final do programa é denominado nó final. Um caminho corresponde a uma sequiência finita de nós $\left(n_{1}, n_{2}, \ldots, n_{k}\right)$ onde $k \geq 2$, tal que exista um arco de $n_{i}$ para $n_{i+1}$ para $i=1,2, \ldots, k-1$. Um caminho é livre de laço quando todos os nós que o compõem são distintos. Um caminho é completo quando começa a partir do nó inicial e vai até o nó final do grafo. Um caminho não executável é um caminho no qual não existe nenhum elemento do domínio de entrada que o cubra. Com a construção do grafo de fluxo de controle pode-se escolher os caminhos que serão executados a partir dos critérios de teste estrutural.

Na Figura 2.1, o nó inicial corresponde ao nó de número 1 e o nó final corresponde ao nó de número 11. O bloco referente ao nó de número 8 possui apenas a expressão if (valid_id \&\& (length $>=1) \quad \& \& \quad($ length $<=6))$ da Figura 2.2. O caminho $(1,2,3,4,8,9,11)$ é um exemplo de caminho livre de laço e completo. O caminho $(6,7,4,5,7,4,8,9)$ é um caminho não executável, pois a variável valid_id possuirá valor 0 (zero) e, dessa forma, o nó 10 é o nó atingido após a passagem pelo nó 8 . 


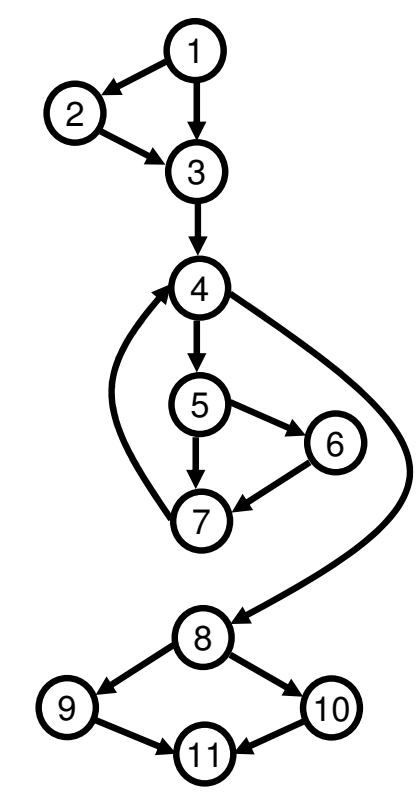

Figura 2.1: Grafo de Fluxo de Controle do programa Identifier.c.

Os critérios de teste estrutural são agrupados em duas categorias: critérios baseados em fluxo de controle e critérios baseados em fluxo de dados.

Critérios Baseados em Fluxo de Controle Os critérios de teste baseados em fluxo de controle utilizam os aspectos do controle da execução do programa (pelo grafo do programa) para derivar os casos de teste. Os critérios mais conhecidos são:

Critério Todos-Nós: exige que cada nó do grafo do programa seja executado ao menos uma vez.

Critério Todos-Arcos: exige que cada arco seja exercitado (percorrido) ao menos uma vez.

Critério Todos-Caminhos: exige que cada possível caminho do grafo seja exercitado. Geralmente é impraticável, pois o grafo pode conter laços, fazendo com que a quantidade de caminhos existente seja infinita.

Critérios Baseados em Fluxo de Dados Nos critérios de teste baseados em fluxo de dados, os dados também são considerados. Dessa forma, consideram-se as definições e os usos das variáveis durante a execução do programa. Para isso, adiciona-se ao grafo de fluxo de controle informações referentes aos dados do programa. Esse grafo é chamado de grafo Def-Uso (Rapps e Weyuker, 1982). Uma definição de variável acontece quando atribui-se um valor a uma variável. Um uso ocorre quando o seu valor é referenciado em uma computação (uso computacional) ou em uma condição de desvio (uso predicativo). Na Figura 2.3 é ilustrado um grafo Def-Uso do programa Identifier.c (Figura 2.2). Por exemplo, os nós 1 e 2 possuem uma definição da variável 


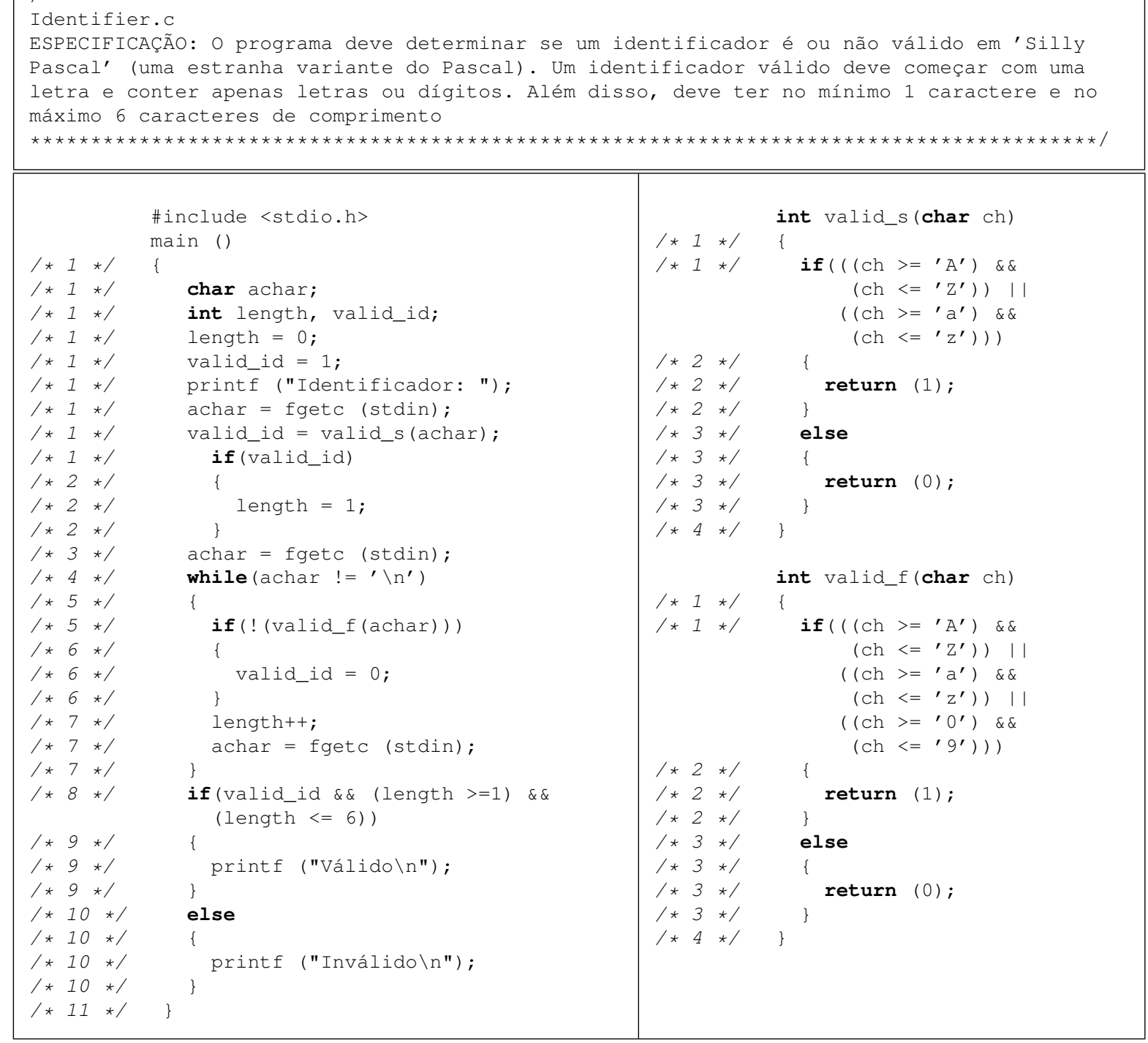

Figura 2.2: Programa Identifier.c (Maldonado et al., 2004).

length. O nó 7 possui uma definição e um uso computacional da variável length, devido à expressão length++.

Dentre os critérios baseados em fluxo de dados pode-se citar:

Critério Todas-Definições: exige que cada definição de variável seja executada ao menos uma vez, ou por um uso computacional, ou por um uso predicativo.

Critério Todos-Usos: exige que todas as associações entre uma definição de variável e seus usos sejam executadas (ao menos uma vez) por um caminho em que não haja uma redefinição da variável (caminho livre de definição).

Critério Todos-Potenciais-Usos: exige que todas as associações entre uma definição de variável e um nó ou arco possível de ser alcançado sejam executadas (ao menos uma vez) por um caminho em que não haja uma redefinição da variável (caminho livre de definição). 


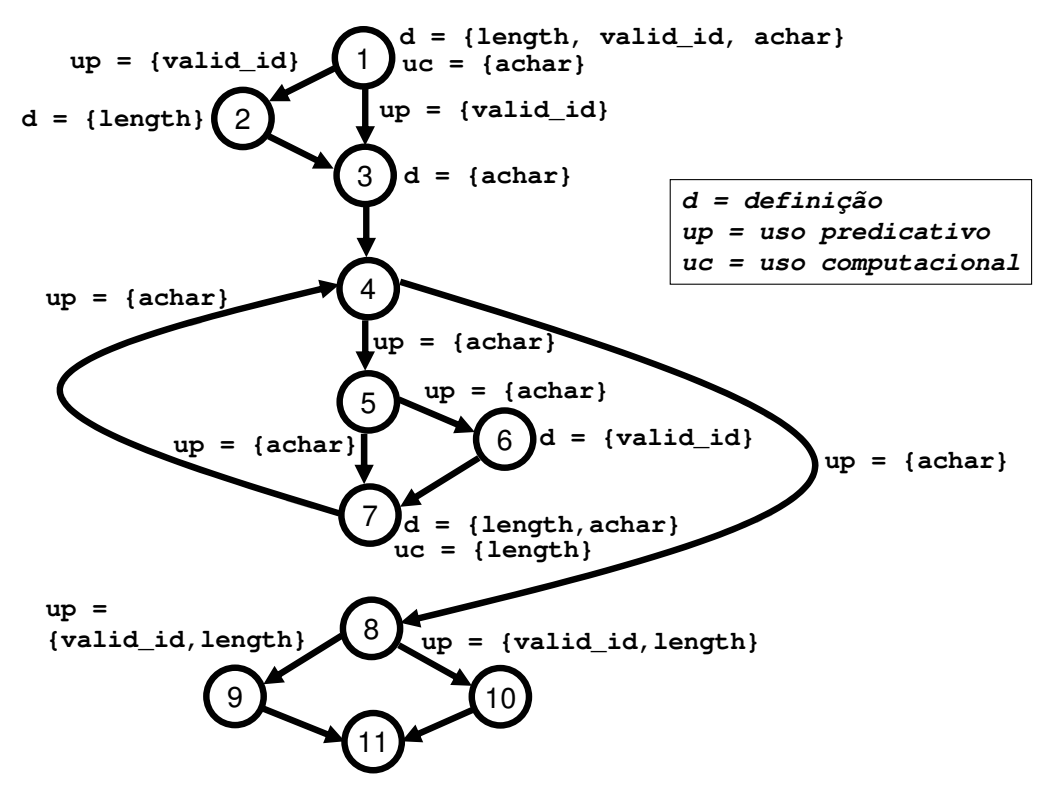

Figura 2.3: Grafo Def-Uso do programa Identifier.c.

\section{Teste Baseado em Erros}

O teste baseado em erros consiste na utilização de informações sobre os erros que podem existir em um programa para a derivação dos casos de teste. Essas informações geralmente variam devido às características da linguagem de programação, método ou técnica utilizada ao longo do desenvolvimento do software. A seguir, alguns critérios baseados em erros são apresentados.

Teste Algébrico de Defeitos O teste algébrico de defeitos, apresentado por Morell (1990), consiste em verificar quais programas não podem estar corretos a partir de um caso de teste já executado. Dessa forma, após a execução de um caso de teste, verificam-se quais programas alternativos poderiam estar corretos em relação ao programa original.

Semeadura de Erros A Semeadura de Erros (Error Seeding) foi proposta originalmente para estimar o número de erros remanescentes em um software. Por esse critério, realiza-se a introdução de uma quantidade conhecida de erros artificiais no software, sob teste, de forma aleatória e sem o conhecimento do testador. Em seguida, o software é testado e os erros artificiais e naturais revelados são contabilizados separadamente. Uma indicação dos erros naturais ainda existentes no programa é estaticamente prevista com probabilidade máxima de ser $f / r$, onde $f$ é a quantidade de erros naturais encontrados no teste e $r$ é a taxa de erros artificiais encontrados em relação ao total de erros artificiais introduzidos. Segundo Zhu et al. (1997), um dos problemas da semeadura de erros é que, geralmente, os erros artificiais são mais fáceis de serem encontrados em relação aos erros naturais e portanto, a validade estatística do método é questionável. 
Análise de Mutantes No teste de um programa $P$, o critério Análise de Mutantes (Mutation Analysis) consiste na geração de programas semelhantes (mutantes) a partir de $P$. Um erro é introduzido em cada programa mutante e os casos de teste são gerados para serem executados com $P$ e com os seus mutantes. Os resultados da execução dos programas mutantes são comparados com os resultados obtidos pelo programa $P$. O objetivo é encontrar um conjunto de casos de teste que seja capaz de revelar os defeitos, ou seja, as diferenças entre o programa $P$ e seus mutantes.

\section{Teste Baseado em Estados}

No teste baseado em estados, uma representação baseada em máquina de estados é utilizada para modelar o aspecto comportamental do sistema ou unidade que será testada. Uma máquina de estados é um modelo que representa o comportamento do sistema na forma de estados que ele possui durante a sua existência e as possíveis transições entre esses estados. A partir desse modelo, métodos de geração de seqüências de teste (descritos na Seção 3.5) podem ser utilizados para verificar se o comportamento do sistema está de acordo com o comportamento do modelo. No contexto de orientação a objetos, o teste baseado em estados é utilizado devido à própria característica dos objetos que possuem estados e comportamento. A classe é modelada como uma máquina de estados e as chamadas aos métodos resultam em transições de estados. O modelo define as transições permitidas e os casos de teste são derivados para exercitar cada transição. Segundo Binder (1999), o teste baseado em estados é adequado para o teste de sistemas orientados a objeto, pois uma máquina de estados pode fornecer uma forma compacta e previsível do comportamento da classe. As máquinas de estados podem modelar o sistema em diferentes níveis, tais como: classe, subsistema e sistema, o que permite a realização do teste nesses diferentes níveis. O teste baseado em estados não detecta todos os tipos de erros sendo importante que outros critérios sejam incorporados, tais como o critério de fluxo de dados e controle, para a obtenção de um teste de melhor qualidade (Binder, 1999).

No Capítulo 3 será apresentado o teste baseado em modelos, no qual se insere o teste baseado em estados.

\subsection{Geração de Casos de Teste}

Durante a atividade de teste, os casos de teste são utilizados para revelar os erros de um programa. Desse modo, a geração dos casos de teste é uma etapa importante e essencial para a própria realização da atividade de teste e tem como objetivo identificar um conjunto de dados de entrada de um programa que satisfaça um determinado critério de teste (Korel, 1990). É importante que essa etapa seja automatizada de forma a auxiliar o testador e agilizar a atividade de teste. No entanto, existem limitações inerentes à própria atividade de teste que dificultam a geração de casos de teste (Harrold, 2000). Por exemplo, não é possível decidir se dois programas são equivalentes ou se um 
determinado caminho de um programa é executável. Trabalhos relacionados à geração automática de casos de teste procuram, por meio de heurísticas, contornar essas limitações.

Um método dinâmico de geração de dados de teste é proposto por Korel (1990). Esse método é baseado na execução do programa sob teste, análise dinâmica de fluxo de dados e métodos de função de minimização. O fluxo de execução do programa é monitorado durante sua execução com alguns dados de entrada.

No trabalho de DeMillo e Offutt (1991), é apresentada uma técnica baseada na análise de mutantes que utiliza restrições para gerar casos de teste que são projetados especificamente para matar os mutantes do programa. Um conjunto de restrições é gerado para cada mutante e um caso de teste é selecionado se satisfizer esse conjunto.

No trabalho de Bueno e Jino (2001), a geração de casos de teste é feita com a utilização de algoritmos genéticos para identificar uma entrada que execute um caminho do programa. Por meio de uma função de fitness, ocorre a combinação, eliminação ou favorecimento de elementos de entrada para que exista maior probabilidade de execução de um determinado caminho.

No trabalho de Simão (2004), a geração de casos de teste é realizada com base na análise de mutantes. Foi proposto um algoritmo para a geração automática de casos de teste e para a identificação automática de mutantes equivalentes no contexto das Redes de Petri. Os mutantes são executados com um conjunto de teste. É verificado se os mutantes vivos são equivalentes ao produto original. Os mutantes equivalentes são descartados. Os mutantes não equivalentes são analisados e novos casos de teste são gerados para matar tais mutantes. Esses casos de teste devem ser adicionados ao conjunto de teste. Segundo Simão (2004), houve uma redução significativa do número de mutantes a serem analisados manualmente, reduzindo a necessidade de interação do testador.

O método proposto no trabalho de Fraser e Wotawa (2006) utiliza o model-checking para automatizar a geração e análise dos casos de teste baseado em mutação. A partir do modelo comportamental do sistema e da especificação dos requisitos, mutantes são utilizados para a criação dos casos de teste com o objetivo de checar os possíveis erros da implementação que violam a especificação. Mutações geradas a partir do modelo introduzem um comportamento errôneo. Se esse comportamento é inconsistente com o comportamento definido pela especificação, ele pode ser detectado pela execução de um model-checker com o modelo mutante e a especificação. Nessa fase, casos de teste são gerados. A mutação gerada a partir da especificação permite que algumas de suas partes sejam alteradas ou removidas, fazendo com que o seu comportamento não seja cumprido pelo modelo, o que permite a geração de casos de teste. Casos de teste gerados a partir de mutações do modelo checam os possíveis erros da implementação que não estão de acordo com a especificação. Já os casos de teste gerados a partir de mutações da especificação mostram se o comportamento correto tem sido implementado. 


\subsection{Minimização de Conjuntos de Teste}

Casos de teste são utilizados para revelar os erros de um programa. Um conjunto de casos de teste deve ser aplicado em um programa sob teste para verificar a conformidade entre implementação e especificação. A aplicação de todos os casos de teste de um conjunto pode ser inviável devido a sua alta cardinalidade. Dessa forma, torna-se importante a investigação de critérios para minimizar o conjunto de teste e, conseqüentemente, viabilizar a etapa de teste. É importante salientar que a minimização do conjunto de teste deve ser realizada sem que a efetividade na detecção de defeitos seja afetada. Desse modo, a minimização não afeta a qualidade dos testes. A seguir, apresentam-se trabalhos que procuram minimizar conjuntos de casos de teste.

No trabalho de Offutt et al. (1995) são propostas estratégias para a seleção de um menor número de casos de teste pela reordenação dos conjuntos de teste no contexto de teste de mutação. Foi observado que para os conjuntos de teste baseados em mutação a ordem de aplicação dos casos de teste teve impacto no tamanho do conjunto de teste obtido. Por exemplo, considere a Figura 2.4. Se os casos de teste são aplicados na ordem dada $<1,2,3>$, então os três casos de teste são necessários para cobrir os quatro trechos de código. Porém, se os casos de teste são aplicados na ordem $<3,2,1>$, então apenas os casos de teste 3 e 2 são necessários para cobrir os quatro trechos de código. Os autores utilizaram algumas heurísticas para a ordenação dos conjuntos de teste.

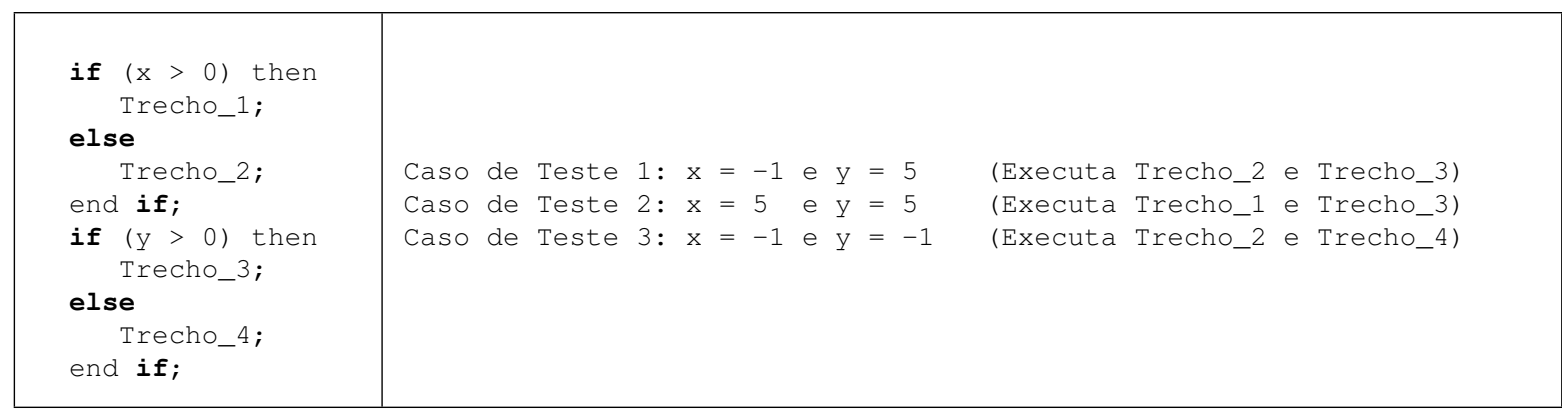

Figura 2.4: Exemplo de ordenação de casos de teste (Adaptado de Offutt et al. (1995)).

No trabalho de Yevtushenko et al. (1998), os autores propuseram um método de minimização de conjuntos de teste para MEFs em relação ao "teste de contexto". No teste de contexto apenas uma parte do sistema precisa ser testada. Assim, a especificação do sistema é representada pela combinação de duas MEFs. Enquanto uma MEF, chamada de componente, representa a parte que necessita ser testada, a outra MEF, chamada de contexto, representa a parte que está correta. Os autores relatam que os métodos clássicos de geração de casos de teste (Seção 3.5), quando aplicados nessa combinação de MEFs, produzem um conjunto com vários casos de teste redundantes. Isso ocorre, pois os métodos de geração assumem o sistema sob teste como uma "caixa preta" e geram casos de teste para testar tanto o componente quanto o contexto (desnecessariamente). Dessa forma, os autores definiram um método para retirar os casos de teste que checam apenas as transições que não afetam o componente. Assim, considerando que o contexto seja livre de defei- 
tos, a minimização do conjunto de teste é realizada sem que a efetividade na detecção de defeitos seja afetada. Uma extensão da minimização de conjuntos de teste para MEFs é proposta no trabalho de Yevtushenko et al. (1999). Os autores estenderam o método de minimização para MEFs não-determinísticas.

\subsection{Ferramentas de Apoio ao Teste de Programas}

A utilização de ferramentas de apoio torna-se essencial para que a atividade de teste seja automatizada. Nessa atividade, critérios devem ser aplicados e a aplicação realizada de forma manual torna-se propensa a erros e limitada a produtos simples (Horgan e Mathur, 1992). Nesse contexto, a criação e utilização de ferramentas de teste tornam-se importantes para viabilizar a atividade de teste e aumentar sua produtividade. As ferramentas de teste permitem a aplicação de técnicas e critérios de teste, o apoio a estudos empíricos e a transferência de tecnologia para a indústria. No entanto, há algumas dificuldades na utilização concorrente de mais de uma ferramenta de apoio devido às diferenças existentes entre elas (Horgan e Mathur, 1992). Por exemplo, uma dificuldade está na diferença existente no formato do arquivo dos casos de teste, sendo que um mesmo conjunto de casos de teste deve ser codificado de diferentes formas para funcionar em diferentes ferramentas.

Diversas ferramentas de teste têm sido elaboradas. Dentre as ferramentas existentes podem-se citar: a Proteum (Delamaro, 1993) e a Mothra (DeMillo, 1991) que fornecem apoio ao teste de mutação; a PokeTool (Chaim, 1991; Maldonado et al., 1989) e a Asset (Frankl e Weyuker, 1985) para apoio ao teste estrutural; a JaBUTi (Vincenzi et al., 2003; Vincenzi, 2004) que apoia o teste estrutural de programas e componentes Java; e a SPACES (Barbosa et al., 2004) que apoia o teste funcional de componentes. A seguir são apresentadas algumas ferramentas relacionadas ao teste de programas.

A ferramenta Proteum (Delamaro, 1993) foi desenvolvida no ICMC/USP e apóia o teste de mutação para programas escritos na linguagem C. Pela aplicação do critério Análise de Mutantes, a ferramenta oferece recursos tanto para avaliar a adequação de um conjunto de casos de teste quanto para a sua seleção. Esses recursos permitem que as seguintes operações sejam realizadas: definição de casos de teste, execução do programa em teste, seleção dos operadores de mutação (utilizados para gerar os mutantes), geração dos mutantes, execução dos mutantes com os casos de teste definidos, análise dos mutantes vivos e cálculo do escore de mutação.

A ferramenta PokeTool (Potential Uses Criteria Tool for Program Testing) (Chaim, 1991) criada no DCA/FEEC/UNICAMP com a colaboração do ICMC/USP, apóia a aplicação dos critérios Potenciais-Usos bem como a aplicação de critérios estruturais como Todos-Nós e Todos-Arcos. Essa ferramenta apóia o teste de programas escritos na linguagem $\mathrm{C}$ e, posteriormente, foi incrementada para atender programas escritos em COBOL (Leitão, 1992) e FORTRAN (Fonseca, 1993). 
A ferramenta Asset (A System to Select and Evaluate Tests) foi desenvolvida por Frankl e Weyuker (1985) na New York University. Ela é uma ferramenta que permite a aplicação dos critérios de teste baseados em fluxo de dados para programas escritos na linguagem Pascal.

A ferramenta Mothra (DeMillo, 1991), desenvolvida na Purdue University e no Georgia Institute of Technology apóia o teste de programas escritos na linguagem FORTRAN-77. Ela fornece apoio ao critério Análise de Mutantes para o teste de programas permitindo ao usuário criar e alterar os casos de teste, monitorar o andamento do teste, localizar e remover os erros e extrair dados estatísticos.

No contexto de orientação a objetos, a ferramenta JaBUTi (Java Bytecode Understanding and Testing) (Vincenzi et al., 2003; Vincenzi, 2004) criada no ICMC/USP, apóia o teste de programas e componentes escritos em Java. Tem como objetivo ser um ambiente completo para o teste de programas Java. A ferramenta permite a aplicação de quatro critérios de fluxo de dados e quatro critérios de fluxo de controle. Uma das vantagens dessa ferramenta consiste na realização do teste a partir do bytecode Java, ou seja, do arquivo .class do programa. Dessa forma, o código-fonte não é necessário para a condução do teste, sendo que componentes de terceiros podem ser testados sem a necessidade de ter o código-fonte em mãos. A ferramenta é completamente implementada em Java e possibilita a interação por meio de scripts ou pela interface gráfica.

A ferramenta SPACES (Barbosa et al., 2004) foi desenvolvida para apoiar o teste funcional de componentes, realizando a geração, execução e análise dos resultados do teste. Ela possui cinco módulos: Seletor de Casos de Teste, que permite a seleção dos casos de teste a serem executados; Gerador de Oráculos, que consiste na geração de oráculos para cada caso de teste; Seletor de Dados de Teste, que determina os valores de entrada para os casos de teste; Gerador de Código de Teste, que consiste na criação de classes de teste JUnit; e Empacotador que agrupa todas as classes de teste geradas formando um outro componente que torna-se responsável pela execução e análise dos casos de teste.

\subsection{Considerações Finais}

Neste capítulo foram apresentados os conceitos, as técnicas e ferramentas sobre o teste de software e uma visão geral sobre sua importância no processo de desenvolvimento de software.

Foi observado que, apesar de diversos métodos que auxiliam o processo de desenvolvimento do software, erros ainda podem existir no software final. Desse modo, a atividade de teste é de fundamental importância para auxiliar no aumento da qualidade do software. Verificou-se a importância dos critérios de teste para a seleção de um subconjunto de casos de teste, pois, de certa forma, auxiliam o testador permitindo que a atividade de teste seja factível.

A atividade de teste pode ser apoiada por ferramentas de teste para que seja realizada com maior agilidade. Foram apresentadas algumas ferramentas tanto para o teste de programas quanto para o teste de especificações. No contexto de automatização da atividade de teste, foram apresentados 
alguns trabalhos sobre a geração de casos de teste. A minimização de conjuntos de casos de teste também foi abordada. Observou-se que a minimização deve ser conduzida de forma a manter a efetividade do conjunto de casos de teste em relação à detecção de defeitos.

O teste baseado em modelos é assunto do capítulo a seguir. Maior ênfase será dada em relação às características referente ao teste baseado em MEFs, contexto no qual este trabalho se insere. 


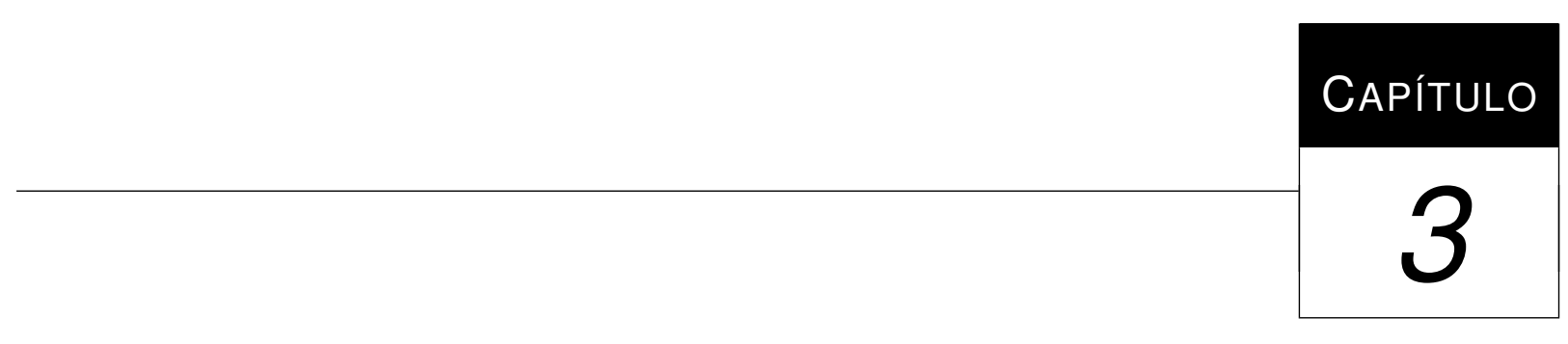

\section{Teste Baseado em Modelos}

\subsection{Considerações Iniciais}

Neste capítulo são abordados os conceitos, definições e métodos de geração de casos de teste relacionados ao teste baseado em modelos. Inicialmente, na Seção 3.2 é discutida a importância da modelagem no contexto do teste baseado em modelos. Apresenta-se também a importância da utilização dos métodos formais para a especificação do aspecto comportamental de um sistema, bem como algumas técnicas de especificação de sistemas. Em seguida, por estar diretamente relacionada com este trabalho, a técnica de Máquina de Estados Finitos é apresentada de forma mais detalhada e formal na Seção 3.3. Na Seção 3.4 são apresentadas as características relacionadas ao teste baseado em Máquinas de Estados Finitos. Na Seção 3.5, os métodos para a geração de casos de teste para Máquinas de Estados Finitos são descritos. São apresentadas as características de cada método para a geração de casos de teste. Na Seção 3.6 é realizada uma comparação entre os métodos de geração. Na Seção 3.7, uma comparação empírica entre alguns métodos é ilustrada e, na Seção 3.8, a completude de conjuntos de casos de teste é abordada. Por fim, na Seção 3.9 são apresentadas as ferramentas de apoio relacionadas ao teste de modelos.

\subsection{Teste Baseado em Modelos}

O teste de software é uma etapa importante do processo de desenvolvimento de software que visa a encontrar os possíveis erros de uma implementação obtida a partir de uma especificação, seja ela formal ou não. Durante a realização dos testes, um grande obstáculo é determinar exatamente qual é o objetivo do teste. Em geral, especificações não rigorosas deixam grande margem a 
opiniões e especulações. A forma da especificação pode variar de um grafo de fluxos de chamadas inter-módulos a um guia de usuário. Uma especificação clara é importante para definir o escopo do trabalho de desenvolvimento e, de forma especial, o de teste. Se a única definição precisa do que o sistema deve fazer é o próprio sistema, os testes podem ser improdutivos.

Desse modo, a correta modelagem do sistema torna-se importante, permitindo que o conhecimento do sistema seja reutilizado durante diversas fases de desenvolvimento. No teste baseado em modelos, o modelo permite que casos de teste sejam derivados para serem utilizados no teste de uma implementação. A correta modelagem de um sistema torna-se mais crítica quando esse sistema opera em situações de risco à vida ou ao patrimônio, que pode ser o caso dos Sistemas Reativos.

Os Sistemas Reativos são sistemas que possuem a característica de interação contínua com o ambiente, em resposta a eventos externos. Geralmente, esses sistemas controlam atividades críticas, sendo fundamental que a atividade de teste seja realizada de forma adequada para assegurar o comportamento esperado do sistema. O comportamento de um Sistema Reativo é um conjunto de sequiências permitidas de eventos de entrada e saída, condições e ações, bem como algumas informações adicionais (restrições de tempo, por exemplo). Existem diversas técnicas que fornecem apoio para a especificação do comportamento de Sistemas Reativos. O comportamento de um sistema, por exemplo, pode ser modelado por meio da linguagem natural durante a etapa de especificação de requisitos. No entanto, a documentação resultante tende a ser ambígua e inconsistente, devido à ambigüidade existente na linguagem natural (Wing, 1990).

Tratando-se de Sistemas Reativos, é essencial uma maior precisão e rigor na especificação do sistema. Nesse cenário, a utilização de métodos formais para a especificação do comportamento de sistemas torna-se importante, pois auxilia na redução de possíveis erros (Barroca e McDermid, 1992). Segundo Wing (1990), os métodos formais são utilizados para a especificação do aspecto comportamental do sistema, entretanto, podem ser utilizados em qualquer estágio do desenvolvimento.

Há diversas técnicas para a especificação de sistemas que são utilizadas para agregar maior rigor ao teste baseado em modelos, tais como Máquinas de Estados Finitos (MEFs), MEFs estendidas, Statecharts e Redes de Petri. O modelo mais simples são as MEFs. Uma MEF é composta por estados e transições entre os estados. Suas configurações e transições são representadas explicitamente. A MEF estendida adiciona às MEFs tradicionais conceitos como variáveis de contexto e transições parametrizadas. Uma configuração particular do sistema não é mais explicitamente representada no modelo. Em vez disso, uma configuração será composta pelo estado atual da MEF e os valores das variáveis de contexto. Os Statecharts, criados por Harel (1987), constituem uma extensão das MEFs com a adição de características de decomposição, ortogonalidade e broadcasting . Desse modo, a especificação pode ser construída de forma modularizada, há uma independência dos subestados e a concorrência pode ser modelada. As Redes de Petri (Peterson, 1977) são modelos formais do fluxo da informação e foram inicialmente desenvolvidas para a modelagem de sistemas com interação de componentes concorrentes e paralelos (Peterson, 1977). As Redes de 
Petri são representadas como um grafo que modela as propriedades estáticas do sistema. Além das propriedades estáticas, a Rede de Petri possui propriedades dinâmicas que são representadas pela simulação do grafo.

Em seguida, por estar diretamente relacionada com este trabalho, a técnica de MEF é apresentada mais detalhadamente.

\subsection{Máquinas de Estados Finitos}

Uma Máquina de Estados Finitos (MEF) (Gill, 1962) é uma máquina hipotética composta por estados e transições. Cada transição liga um estado $a$ a um estado $b$ ( $a$ e $b$ podem ser o mesmo estado). A cada instante, uma máquina pode estar em apenas um de seus estados. Em resposta a um evento de entrada, a máquina gera um evento de saída e muda de estado. Tanto o evento de saída gerado quanto o novo estado são definidos unicamente em função do estado atual e do evento de entrada (Davis, 1988). Uma MEF pode ser representada tanto por um diagrama de transição de estados quanto por uma tabela de transição. Em um diagrama de transição de estados, os estados são representados por círculos e as transições são representadas por arcos direcionados entre estados. Na Figura 3.1 tem-se a representação de uma MEF com quatro estados para um extrator de comentários, extraída de Chow (1978). Cada arco é rotulado com a entrada que gera a transição e a saída que é produzida, usando o formato entrada:saída.

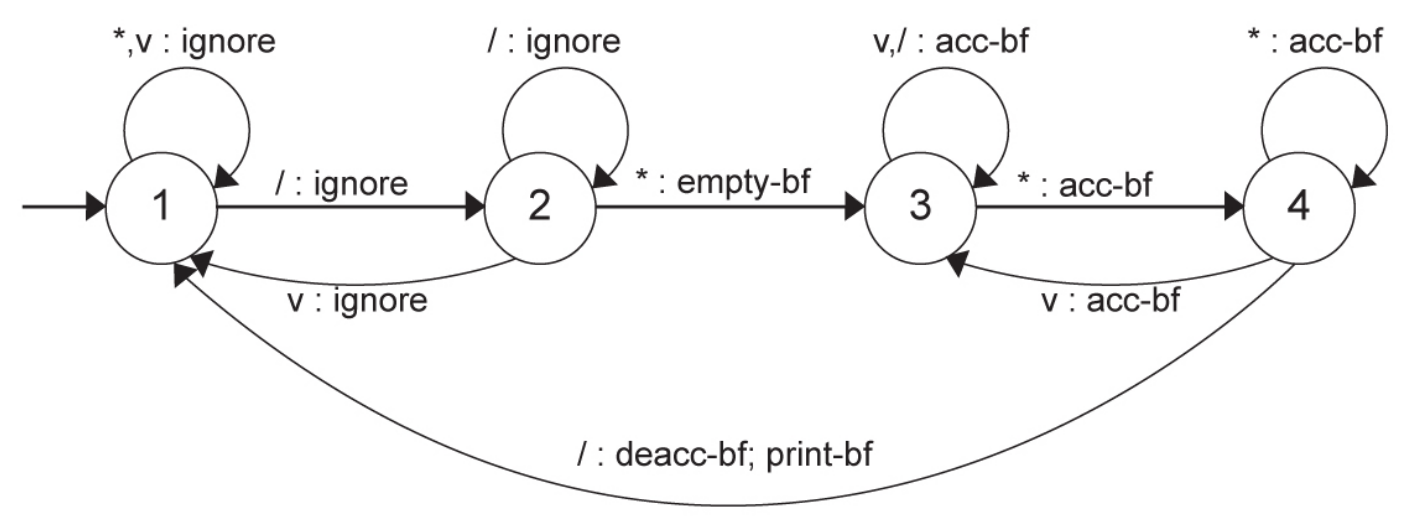

Figura 3.1: MEF para um extrator de comentários (Chow, 1978).

Em uma tabela de transição, os estados são representados por linhas e as entradas, por colunas (Davis, 1988). Por exemplo, a tabela de transição da MEF da Figura 3.1 é apresentada na Tabela 3.1.

De acordo com Petrenko e Yevtushenko (2005), uma MEF $A$ pode ser representada formalmente por uma tupla $\left(S, s_{0}, X, Y, D_{M}, \delta, \lambda\right)$, onde:

- $S$ é um conjunto finito de estados, incluindo o estado inicial $s_{0}$; 
Tabela 3.1: Tabela representativa da MEF do extrator de comentários.

\begin{tabular}{|c|c|c|c|c|c|c|}
\hline & \multicolumn{3}{|c|}{ Saída } & \multicolumn{3}{|c|}{ Próx. Estado } \\
\hline $\begin{array}{ll}\text { Estado } & \text { Entrada }\end{array}$ & $*$ & / & $\mathrm{v}$ & $*$ & I & $\mathrm{V}$ \\
\hline 1 & ignore & ignore & ignore & 1 & 2 & 1 \\
\hline 2 & empty-bf & ignore & ignore & 3 & 2 & 1 \\
\hline 3 & acc-bf & acc-bf & acc-bf & 4 & 3 & 3 \\
\hline 4 & acc-bf & deacc-bf & acc-bf & 4 & 1 & 3 \\
\hline
\end{tabular}

- $X$ é um conjunto finito de entradas;

- $Y$ é um conjunto finito de saídas;

- $D_{M} \subseteq S \times X$ é um domínio da especificação;

- $\delta$ é uma função de transição, $\delta: D_{M} \rightarrow S$, e

- $\lambda$ é uma função de saída, $\lambda: D_{M} \rightarrow Y$;

Uma MEF completamente especificada (ou completa) é aquela em que existem transições definidas para todos os símbolos de entrada em cada estado da MEF. Caso contrário, a MEF é parcialmente especificada (ou parcial). Formalmente, uma MEF é completa se $D_{M}=S \times X$.

Uma MEF é fortemente conexa se para cada par de estados $s_{i}, s_{j} \in S$ existe uma sequiência que leva a MEF $M$ do estado $s_{i}$ ao estado $s_{j}$. Uma MEF é dita ser inicialmente conexa quando todos os estados são alcançáveis a partir do estado inicial $s_{0}$. De uma forma geral, somente as MEFs inicialmente conexas são consideradas nos estudos realizados, pois, de acordo com Yannakakis e Lee (1995), qualquer estado inatingível a partir do estado inicial não afeta o comportamento da MEF.

Uma MEF é determinística se em cada estado, dada uma entrada, há somente uma única transição definida para um próximo estado caso contrário, a MEF é não-determinística. De acordo com a definição de MEF utilizada neste trabalho, apenas as MEFs determinísticas serão consideradas.

Como em Fujiwara et al. (1991), a notação $s_{i}-x / y \rightarrow s_{j}$ será utilizada para indicar que a MEF $M$ no estado $s_{i}$ produz $y$ como saída e realiza uma transição para o estado $s_{j}$ quando a entrada $x$ é aplicada. A notação $s_{i}-x \rightarrow s_{j}$ será utilizada quando a entrada $x$ é aplicada ao estado $s_{i}$ sem se importar com a respectiva saída. Os estados $s_{i}$ e $s_{j}$ são chamados de estado inicial e estado final de uma transição, respectivamente.

Sejam $M=\left(S, s_{0}, X, Y, D_{M}, \delta_{M}, \lambda_{M}\right)$ e $I=\left(T, t_{0}, X, Y, D_{T}, \Delta_{I}, \Lambda_{I}\right)$ que representam uma especificação e uma implementação, respectivamente. Uma sequiência de entrada $\alpha=$ $x_{1} x_{2} \ldots x_{k} \in X^{*}$ é chamada de seqüência de entrada definida (defined input sequence) para o estado $s_{i} \in S$ se existem $k$ estados $s_{i_{1}}, s_{i_{2}}, \ldots, s_{i_{k}} \in S$ tal que haja uma seqüência de transições 
$s_{i}-x_{1} \rightarrow s_{i_{1}} \cdots \rightarrow s_{i_{(k-1)}}-x_{k} \rightarrow s_{i_{k}}$ na MEF $M$. A notação $\Omega_{M}\left(s_{i}\right)$ significa o conjunto de todas as seqüências de entrada definidas no estado $s_{i}$ da MEF $M$. A notação $\Omega_{M}$ representa o conjunto de todas as seqüências de entrada definidas no estado inicial $s_{0}$ da MEF $M$. A seqüência vazia é denotada pelo símbolo $\epsilon$.

A notação $\alpha \beta$ representa a concatenação da seqüência $\alpha$ com a seqüência $\beta$. Dados os conjuntos $A$ e $B$, a notação $A B$ representa a concatenação do conjunto $A$ com o conjunto $B$, tal que $A B=\{\alpha \beta \mid \alpha \in A, \beta \in B\}$.

Uma seqüência $\alpha$ é prefixo de uma seqüência $\beta$, denotado por $\alpha \leq \beta$, se $\beta=\alpha \omega$, para algum $\omega$. A sequiência $\alpha$ é um prefixo próprio de $\beta$, denotado por $\alpha<\beta$, se $\beta=\alpha \omega$, para algum $\omega \neq \epsilon$.

As funções de transição e saída estendem-se para a sequiência de entrada definida. Assim, dada uma seqüência de entrada $\alpha x \in \Omega_{M}\left(s_{i}\right)$ então $\delta\left(s_{i}, \alpha x\right)=\delta\left(\delta\left(s_{i}, \alpha\right), x\right), \lambda\left(s_{i}, \alpha x\right)=$ $\lambda\left(s_{i}, \alpha\right) \lambda\left(\delta\left(s_{i}, \alpha\right), x\right), \delta\left(s_{i}, \epsilon\right)=s_{i}$ e $\lambda\left(s_{i}, \epsilon\right)=\epsilon$.

Um caso de teste de uma MEF $M$ é uma seqüência de entrada definida $x \in \Omega_{M}$. Um conjunto de casos de teste $T$ (ou conjunto de teste) para uma MEF $M$ é um conjunto finito de casos de teste de $M$, tal que não existam dois casos de teste $\alpha, \beta \in T$ com $\alpha<\beta$. Neste trabalho, os termos seqüência e caso de teste são usados como sinônimos.

Para um conjunto de teste $T$, a notação pre $f(T)$ representa todos os prefixos dos casos de teste contidos em $T$, ou seja, $\operatorname{pref}(T)=\{\alpha \mid \beta \in T, \alpha \leq \beta\}$. Seja $w(\alpha)$ o comprimento da seqüência $\alpha$, ou seja, $w(\alpha)=|\alpha|$. A notação $w(A)$ representa o tamanho de um conjunto $A$ calculado pela soma dos comprimentos das seqüências contidas em $A$ que não são prefixos próprios de outras seqüências.

Dois estados, $s_{j}$ de $M$ e $t_{i}$ de $I$ são compatíveis se para todo $\alpha \in \Omega_{M}\left(s_{j}\right) \cap \Omega_{I}\left(t_{i}\right)$, tem-se que $\lambda_{M}\left(s_{j}, \alpha\right)=\Lambda_{I}\left(t_{i}, \alpha\right)$. Caso contrário, os estados são distinguíveis. Formalmente, os estados $s_{j}$ e $t_{i}$ são distinguíveis se existe uma seqüência de entrada $\gamma \in \Omega_{M}\left(s_{j}\right) \cap \Omega_{I}\left(t_{i}\right)$, chamada de sequiência de separação (separating sequence), tal que $\lambda_{M}\left(s_{j}, \gamma\right) \neq \Lambda_{I}\left(t_{i}, \gamma\right)$.

Dois estados $s_{i}, s_{j} \in S$ são equivalentes em relação ao conjunto $V \subseteq \Omega_{M}\left(s_{i}\right)$, representado por $s_{i} \cong_{V} s_{j}$, se $\lambda_{M}\left(s_{i}, \alpha\right)=\lambda_{M}\left(s_{j}, \alpha\right)$ para todo $\alpha \in V$. O estado $s_{i}$ é quasi-equivalente ao estado $s_{j}$, se $\Omega_{M}\left(s_{i}\right) \supseteq \Omega_{M}\left(s_{j}\right)$ e $\lambda_{M}\left(s_{i}, \alpha\right)=\lambda_{M}\left(s_{j}, \alpha\right)$ para todo $\alpha \in \Omega_{M}\left(s_{j}\right)$. Em outras palavras, um estado $s_{i}$ é quasi-equivalente a um estado $s_{j}$ se para toda entrada definida em $s_{j}, s_{i}$ produzir a mesma saída.

Uma MEF parcial é reduzida se seus estados, tomados par-a-par, são distinguíveis. Uma MEF completa é minimal se não possui par de estados equivalentes. Neste trabalho os termos reduzida e minimal são utilizados como sinônimos.

Dados os estados $s_{i}, s_{j} \in S$ e uma seqüência $\alpha \in \Omega_{M}\left(s_{i}\right)$ tal que $\delta_{M}\left(s_{i}, \alpha\right)=s_{j}$ diz-se que $\alpha$ é uma seqüência de transferência (transfer sequence) de $s_{i}$ para $s_{j}$. Um conjunto state cover $Q$ de uma MEF $M$ com $n$ estados é definido como um conjunto com $n$ sequiências de transferência, incluindo a seqüência vazia $\epsilon$, que leva $M$ a partir de seu estado inicial $s_{0}$ para cada um dos estados. 
Um conjunto transition cover $P$ é um conjunto de sequiências de entrada em que para cada estado $s \in S$ e para cada entrada $\alpha \in X$, existe uma seqüência de entrada $x \in P$ partindo do estado inicial $s_{0}$ e terminando com a transição que aplica $\alpha$ ao estado $s$. O conjunto $P$ faz com que a máquina execute cada transição e que, em seguida, pare.

Uma sequiência de distinção (distinguishing sequence) é uma seqüência de entrada $d$ em que a sequiência de saída produzida pela MEF $M$, em resposta à entrada $d$, identifica o estado da máquina $M$, ou seja, para todo $s_{i}, s_{j} \in S, i \neq j, \lambda_{M}\left(s_{i}, d\right) \neq \lambda_{M}\left(s_{j}, d\right)$.

Uma sequiência UIO (unique input/output sequence) de um estado $s_{j}$ é uma sequiência de entrada/saída única para esse estado. Em outras palavras, com a aplicação da sequiência UIO pode-se distinguir o estado $s_{j}$ de qualquer outro estado, pois a saída produzida é específica (única) do estado $s_{j}$. Desse modo, a seqüência UIO pode determinar em qual estado a máquina se encontrava antes de sua aplicação.

Um conjunto de caracterização (characterization set), freqüentemente chamado de conjunto $W$, é um conjunto de seqüências de entrada tal que, para dois estados distintos quaisquer $s_{j}$ e $s_{i}$, existe $\beta \in W$ tal que $\lambda_{M}\left(s_{j}, \beta\right) \neq \lambda_{M}\left(s_{i}, \beta\right)$. Em outras palavras, o conjunto $W$ é um conjunto de sequiências de entrada que possui uma seqüência que diferencia todo par de estados existentes em $M$. O conjunto de caracterização sempre existe para MEFs reduzidas.

Um conjunto $W_{j} \subseteq \Omega_{M}\left(s_{j}\right)$ de sequiências de entrada definidas é chamado de identificador de estado (state identifier) ou conjunto de separação (separating set) do estado $s_{j}$ se para qualquer outro estado $s_{i}$ existe $\alpha \in W_{j} \cap \Omega_{M}\left(s_{i}\right)$ tal que $\lambda_{M}\left(s_{j}, \alpha\right) \neq \lambda_{M}\left(s_{i}, \alpha\right)$. Em outras palavras, o conjunto $W_{j}$ é um identificador do estado $s_{j}$ se possui uma seqüência de entrada $\alpha$ que o diferencia de todos os demais estados.

Uma família de separação (separating family) ou identificadores harmonizados (harmonized identifiers) é um conjunto de identificadores de estado $W_{j}, s_{j} \in S$, que satisfaz a seguinte condição:

- Para dois estados quaisquer $s_{j}, s_{i} \in S, i \neq j$, existe $\beta \in W_{j}$ e $\gamma \in W_{i}$ que têm um prefixo comum $\alpha$ tal que $\alpha \in \Omega_{M}\left(s_{j}\right) \cap \Omega_{M}\left(s_{i}\right)$ e $\lambda_{M}\left(s_{j}, \alpha\right) \neq \lambda_{M}\left(s_{i}, \alpha\right)$.

A operação reset (representada como " $r$ " no início das seqüências de entrada) é uma operação que "reinicia" corretamente a MEF, ou seja, leva a implementação ao seu estado inicial. Uma mensagem de status é uma entrada que produz como saída um valor que indica em qual estado a MEF se encontra e a MEF não muda de estado (Broy et al., 2005).

Um checking experiment da MEF $M$ é um conjunto de seqüências de entrada que diferencia a classe de MEFs, equivalentes à $M$, de todas as outras MEFs (Kohavi e Kohavi, 1968). Na etapa de teste de uma MEF, as seqüências de entrada são produzidas e aplicadas à implementação com o propósito de verificar-se a conformidade com sua especificação. A aplicação sucessiva de cada sequiência de entrada do conjunto de teste $T$ (assumindo a existência do símbolo " $r$ " no início de cada seqüência) é equivalente à aplicação de apenas uma única seqüência, formada pela 
concatenação de todas as sequiências do conjunto de teste. Se essa única seqüência forma um checking experiment então essa seqüência é uma checking sequence.

Seja $M$ uma especificação e $\psi_{m}(M)$ o conjunto de todas as implementações $I=\left(T, t_{0}, X, Y\right.$, $\left.D_{I}, \Delta, \Lambda\right)$ com até $m$ estados tal que $\Omega_{I} \supseteq \Omega_{M}$ e $m \geq n$, onde $n$ é o número de estados de $M$. Um conjunto de teste $T S$ é m-completo para a especificação $M$ se para todo $I \in \psi_{m}(M)$ tal que $I \nsim M$, existe uma sequiência $\alpha \in T S$ que distingue $I$ de $M$. Para $m=n$, o conjunto é dito ser $n$-completo. Neste trabalho, o caso particular $m=n$ é considerado.

A implementação $I$ está em conformidade com a especificação $M$ se e somente se $t_{0} \cong_{\Omega_{M}\left(s_{0}\right)}$ $s_{0}$, sendo $t_{0}$ e $s_{0}$ estados iniciais de $I$ e $M$, respectivamente. Isso significa que, para cada seqüência de entrada onde um comportamento de $M$ seja definido, $I$ comporta-se de maneira idêntica.

\subsection{Teste Baseado em Máquinas de Estados Finitos}

O teste baseado em MEF consiste na geração de um conjunto de casos de teste que consiga encontrar o máximo de defeitos possível em uma implementação. Com isso, é possível verificar se a implementação da MEF está ou não de acordo com sua especificação.

Como visto anteriormente, em diferentes aplicações, tais como protocolos de comunicação, sistemas de telecomunicações e outros Sistemas Reativos, a especificação pode ser modelada como uma MEF. Dessa forma, o teste baseado em MEF considera que tanto a especificação quanto a implementação sejam modeladas por uma MEF. Assim, a implementação contém um defeito no caso em que possuir um comportamento diferente em relação à especificação. Os defeitos podem ser dos seguintes tipos:

- Defeito de Inicialização: quando o estado inicial não é o correto.

- Defeito de Transferência (transfer faults): quando o estado atingido por uma transição não é o correto.

- Defeito de Saída (output faults): quando a saída gerada por uma transição não é a correta.

- Estados Faltantes (missing states): quando os estados da implementação precisam ser aumentados para torná-la equivalente à especificação.

- Estados Extras (extra states): quando os estados da implementação precisam ser reduzidos para torná-la equivalente à especificação.

Para o teste baseado em MEF estima-se o número $m$ de estados da implementação. Quanto mais perto esse número chegar em relação ao número real de estados da implementação, melhor o resultado do método de geração de casos de teste.

Os métodos de geração consideram que a implementação é modelada por uma MEF com no máximo $m$ estados (tal que $m$ seja igual ou maior que $n$, número de estados da especificação) e, 
a partir dessa informação, a implementação estará de acordo com sua especificação se não possuir defeitos de transferência nem defeitos de saída.

Diversos métodos de derivação de casos de teste têm sido propostos para testar-se a conformidade de protocolos de comunicação (Chow, 1978; Fujiwara et al., 1991; Petrenko et al., 1993; Vuong et al., 1989). Esses métodos objetivam verificar se uma implementação está correta em relação à especificação. De acordo com Fujiwara et al. (1991), um método de geração de casos de teste deve gerar um conjunto de casos de teste que possua as seguintes características:

a) ser relativamente pequeno para que se tenha baixo custo de execução durante o teste da implementação.

b) conseguir cobrir o máximo de defeitos possíveis que uma implementação possa ter.

Dentre os métodos existentes, alguns necessitam que a MEF possua certas propriedades, tais como completamente especificada, minimal, fortemente conexa e determinística.

A seguir são apresentados alguns métodos de geração de casos de teste para MEFs.

\subsection{Métodos de Geração de Casos de Teste}

Embora os métodos possuam um objetivo comum (de verificar se uma implementação está correta com sua especificação), eles diferem com relação ao custo da geração das seqüências de teste, tamanho do conjunto de teste e capacidade de detecção de defeitos (efetividade). Da mesma forma que as sequiências geradas precisam detectar o máximo de defeitos existentes em uma implementação, elas devem ser relativamente pequenas para que seja possível sua aplicação na prática.

Nesta seção, são apresentados alguns métodos de geração de casos de teste, buscando ilustrar as diferenças apresentadas em relação ao conjunto de propriedades requeridas. Uma MEF, ilustrada na Figura 3.2, será utilizada como exemplo para a geração dos casos de teste. Essa MEF possui quatro estados $\left\{S_{1}, S_{2}, S_{3}, S_{4}\right\}$, sendo $S_{1}$ o estado inicial, as entradas $X=\{x, y\}$ e as saídas $Y=\{0,1\}$. A MEF também admite o conjunto de seqüências $\{x, y, y y\}$ como o conjunto $W$, o conjunto state cover $Q=\{\epsilon, y, x, y y\}$, os identificadores de estado $W_{1}=\{y y\}, W_{2}=\{y\}$, $W_{3}=\{x\}$ e $W_{4}=\{x, y y\}$ e as famílias de separação $H_{1}=\{x, y y\}, H_{2}=\{x, y\}, H_{3}=\{x\}$ e $H_{4}=\{x, y y\}$.

\subsubsection{Cobertura de Estados e Transições}

Em Holzmann (1991), um algoritmo é proposto para o teste de conformidade. Dada uma implementação $I$ e uma especificação $M$, o algoritmo leva em consideração as seguintes suposições:

- $M$ é reduzida; 


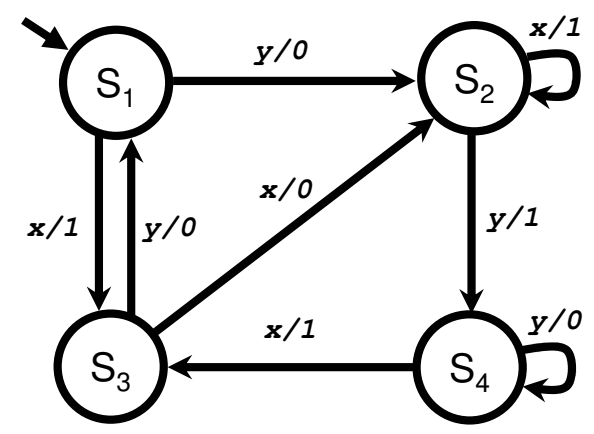

Figura 3.2: Exemplo de MEF extraído de Dorofeeva et al. (2005a).

- $M$ é completamente especificada;

- $M$ é fortemente conexa;

- I não se altera durante o teste;

- I está em seu estado inicial antes do teste;

- $I$ e $M$ possuem o mesmo número de estados;

- Existem as mensagens de status, reset e set.

O algoritmo de teste de conformidade funciona com a aplicação das mensagens status, reset e set para todo estado $s \in S$, sendo $x \in X$ da seguinte forma. Aplique uma mensagem de reset para trazer $I$ ao seu estado inicial. Aplique uma mensagem set $(s)$ para levar $I$ ao estado $s$. Aplique a entrada $x$. Verifique se a saída produzida está em conformidade com a especificação $M$, ou seja, se é igual a $\lambda_{M}(s, x)$. Aplique a mensagem de status e verifique se o estado final está em conformidade com a especificação $M$, ou seja, se é igual a $\delta_{M}(s, x)$.

A checking sequence produzida pelo algoritmo é uma concatenação das sequiências reset, set $(s), x$ e status repetida para cada estado $s$ do conjunto de estados $S$ e para cada símbolo de entrada $x$ do conjunto de símbolos de entrada $X$. Esse algoritmo é capaz de revelar qualquer defeito de saída e de transferência. No entanto, o algoritmo baseia-se na mensagem set, que por sua vez, pode não existir.

Para evitar o uso de mensagens set, uma seqüência transition tour (TT) pode ser construída. Essa seqüência percorre a máquina visitando cada estado e cada transição ao menos uma vez sem que ela precise ser reiniciada após a execução de cada teste. Pela aplicação do método TT, juntamente com uma mensagem de status (inserida após cada entrada da sequiência TT), uma checking sequence é obtida. Essa seqüência de entrada consegue descobrir os defeitos de transferência e de saída. No entanto o método TT, proposto originalmente por Naito e Tsunoyama (1981), não utiliza 
a mensagem de status e obtém somente uma cobertura das transições. Dessa forma, o método TT não garante a detecção de defeitos de transferência.

Para a MEF da Figura 3.2, o conjunto de casos de teste, gerado pelo método TT, é composto pelas seqüências que realizam a cobertura das transições. O conjunto de teste obtido poderia ser $T S_{T T}=\{$ ryxyyxy, rxxxyxy $\}$ de tamanho 14 .

\subsubsection{Método DS}

O método DS, proposto por Gönenc (1970), baseia-se na seqüência de distinção, ou seja, para a sua utilização é necessário que a MEF possua essa sequiência. No entanto, segundo Gill (1962), tal seqüência pode não existir mesmo para MEFs minimais.

É importante selecionar a menor seqüência de distinção para que, conseqüentemente, se obtenha um conjunto menor de casos de teste. Seja $X_{d}$ a seqüência de distinção escolhida. O método resulta na geração de uma checking sequence pela composição de duas sub-seqüências:

Seqüências- $\alpha$ : Verificam todos os estados da MEF.

Seqüências- $\beta$ : Verificam todas as transições.

Primeiramente, o método consiste na geração das seqüências- $\alpha$. Para isso, um grafo (grafo- $X_{d}$ ) é construído de modo que cada estado da MEF seja representado por um nó. Para cada nó, existe uma aresta que o liga a um outro nó representando a aplicação de $X_{d}$. As seqüências- $\alpha$ são geradas percorrendo-se o grafo sem repetir as arestas.

Em seguida, as seqüências- $\beta$ são produzidas de forma semelhante às seqüências- $\alpha$. Um outro grafo é produzido (grafo- $\beta$ ), no entanto, as arestas representam seqüências da forma $x_{i} . X_{d}$. As sequiências- $\beta$ são geradas obtendo-se uma cobertura das arestas do grafo- $\beta$.

Considerando a MEF da Figura 3.2 com a seqüência de distinção $X_{d}=y y y$, o método DS é ilustrado a seguir. Para a geração das seqüências- $\alpha$ o grafo- $X_{d}$, ilustrado na Figura 3.3, é construído. Para cada nó, as transições referentes à aplicação de $X_{d}$ são representadas.

No início, um estado que não é destino de nenhuma aresta (estado origem) é escolhido arbitrariamente. Por exemplo, o estado $S_{1}$ é escolhido e marcado como "reconhecido". Aplica-se a sequiência $X_{d}$ atingindo o estado $S_{4}$ que também é marcado como "reconhecido". Aplica-se $X_{d}$ atingindo o estado $S_{4}$ novamente. Assim, um novo estado origem deve ser selecionado, mas antes disso, aplica-se novamente $X_{d}$ para verificar se o estado atingido foi realmente o estado $S_{4}$. A partir de $S_{4}$ aplica-se $x$ que leva a MEF ao novo estado origem $S_{3}$. Estando no estado $S_{3}$, repete-se o procedimento anterior. A sequiência- $\alpha$ obtida é: \{ yyy yyy yyy $x$ yy yyy $x x$ yy y yy $\}$.

Em seguida, para a construção das seqüências- $\beta$, o grafo- $\beta$ (Figura 3.4(a)) é criado. Considerando que as sequiências- $\alpha$ já foram aplicadas e, dessa forma, todos os estados já foram verificados, duas reduções podem ser realizadas no grafo- $\beta$. A primeira refere-se à última transição da aplicação de $X_{d}$. Por exemplo, aplicando-se $X_{d}$ ao estado $S_{1}$ a MEF passa pelos estados $S_{2}, S_{4}$ e 


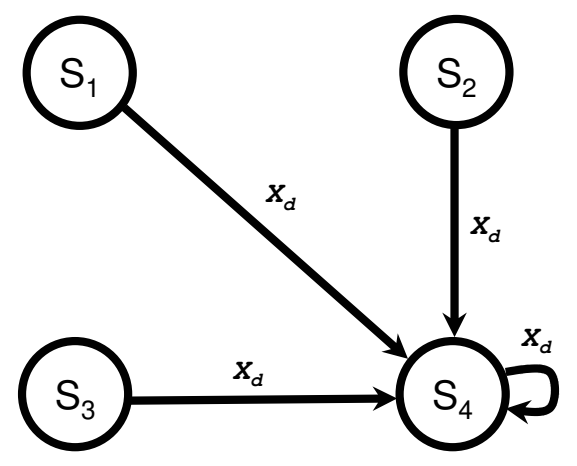

Figura 3.3: Grafo- $X_{d}$.

$S_{4}$. O último passo pode ser descartado, pois essa verificação já foi realizada na construção das sequiências- $\alpha$. Desse modo, a transição de $S_{4}$ com a entrada $y$ pode ser retirada do grafo- $\beta$. De maneira semelhante, a transição de $S_{2}$ com a entrada $y$ pode ser retirada do grafo- $\beta$.

A segunda redução refere-se à última transição da seqüência incluída para ligar os estados de origem. A seqüência $x$ ligou o estado $S_{4}$ ao estado $S_{3}$, então a transição de $S_{4}$ com a entrada $x$ pode ser retirada do grafo- $\beta$. Do mesmo modo, a seqüência $x x$ ligou o estado $S_{4}$ ao estado $S_{2}$, passando pelo estado $S_{3}$. Dessa forma, a transição de $S_{3}$ com a entrada $x$ também pode ser retirada do grafo- $\beta$. O grafo- $\beta$ reduzido é ilustrado na Figura 3.4(b).

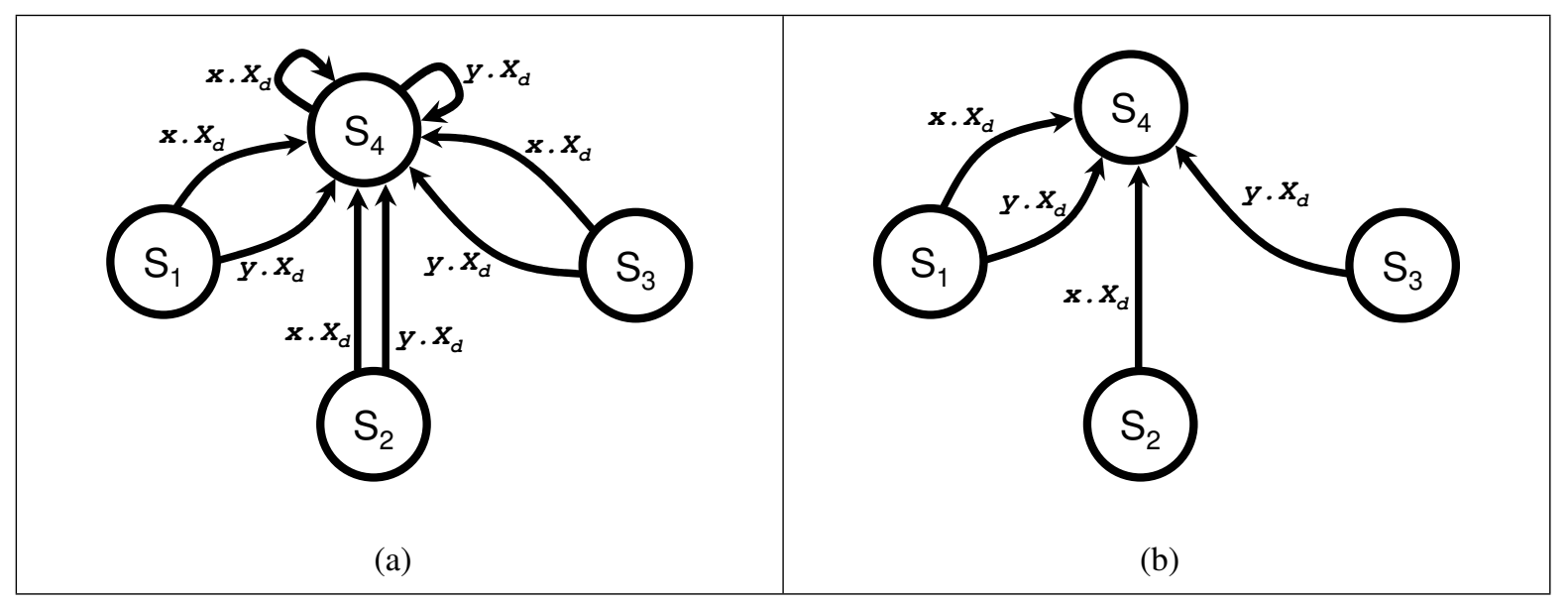

Figura 3.4: Grafo- $\beta$ e Grafo- $\beta$ reduzido.

Percorre-se o grafo- $\beta$ reduzido para a obtenção da seqüência- $\beta$. A seqüência- $\beta$ obtida é: $\{$ xyyy xy yyyy $x x$ xyyy $x$ yyy $\}$.

O conjunto de casos de teste resultante da aplicação do método DS é: $T S_{D S}=\{$ yyyyyyyyyx

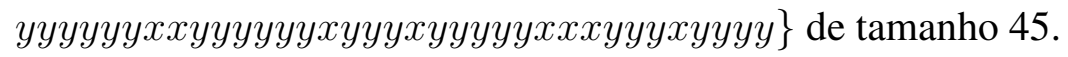

É importante salientar que trabalhos vêm sendo desenvolvidos em relação à redução de checking sequences. No trabalho de Ural et al. (1997), um método para a construção de checking sequences é proposto e, da mesma forma que o método DS, é aplicável somente para MEFs que 
possuam uma seqüência de distinção. No trabalho de Hierons e Ural (2002), uma melhoria é proposta ao método criado em Ural et al. (1997) para a construção de checking sequences de tamanho mínimo. A partir dessa melhoria, houve uma redução no tamanho das checking sequences geradas a partir de MEFs determinísticas, minimais e completamente especificadas. A checking sequence é produzida com base nos conjuntos $A$ (conjunto de sequiências) e $E_{c}$ (conjunto de transições). No trabalho de Hierons e Ural (2006) investiga-se a escolha desses conjuntos. Os autores demonstram como o conjunto $A$ deve ser escolhido para minimizar a soma dos tamanhos das seqüências e como essa etapa deve ser adaptada para a geração de um conjunto $E_{c}$ ótimo. Os resultados obtidos apontam uma redução de $25 \%$ a $40 \%$ das checking sequences.

No trabalho de Simão e Petrenko (2008), um método para a geração de checking sequences é proposto. O método é aplicável em MEFs completas ou parciais e que podem possuir a operação reset. Os resultados obtidos apontam que, em média, houve uma redução de $45 \%$ do tamanho das checking sequences obtidas no trabalho de Hierons e Ural (2006) e uma redução de $20 \%$ em relação ao trabalho de Chen et al. (2005).

\subsubsection{Método W}

Um dos métodos mais conhecidos para a geração de seqüências de teste é o Método W ( $A u$ tomata Theoretic) proposto por Chow, em 1978. O método W não é aplicado a MEFs parciais, considerando apenas MEFs fortemente conexas, completamente especificadas, minimais e determinísticas. Esse método consiste em gerar dois conjuntos de seqüências e concatená-las de forma a obter uma seqüência de entrada para teste de determinada MEF. Esses dois conjuntos são:

$P:$ Conjunto de seqüências que percorre cada transição ao menos uma vez.

$T$ : Conjunto de seqüências capaz de identificar qual é o estado da máquina.

O conjunto $T$ é gerado a partir de um conjunto de caracterização (conjunto $W$ ). Em seguida, é estimado o número $m$ de estados da máquina a ser testada. Tem-se $T=\bigcup_{i=0}^{m-n}\left(X^{i} W\right)$, onde $X^{0}=\{\epsilon\}$ e $X^{i}=X X^{i-1}$. Ao fim, as sequiências de teste são geradas pela concatenação de $P$ com $T$. As sequiências desse conjunto são executadas uma a uma na máquina, gerando as saídas que são analisadas posteriormente.

Em suma, o método $\mathrm{W}$ consiste em três passos principais:

1. Estima-se um número máximo $(m)$ de estados que a implementação possa conter.

2. Geração das sequiências de teste que garantem que cada transição foi implementada corretamente.

3. Verificação das respostas geradas pelas seqüências de teste produzidas na segunda etapa. 
Se a implementação da MEF (a máquina em teste) gerar saídas corretas a partir das sequiências de entrada geradas pelo método $\mathrm{W}$, essa máquina está correta, pois o método é confiável para testar estruturas de controle modeladas por uma MEF (Chow, 1978). Contudo, o método W produz muitas seqüências de entrada para serem testadas, o que pode promover um alto custo para a realização da etapa de teste.

A aplicação do método W na MEF da Figura 3.2 é ilustrada a seguir. Considerando $m=n$ tem-se o conjunto $T=W=\{x, y, y y\}$. Considera-se o conjunto transition cover $P=\{\epsilon, x, y$, $x x, x y, y y, y x, y y y, y y x\}$. Pela concatenação de $P \operatorname{com} T$ obtém-se as sequiências $\{x, y, y y, x x$, $x y, x y y, y x, y y, y y y, x x x, x x y, x x y y, x y x, x y y, x y y y, y y x, y y y, y y y y, y x x, y x y, y x y y, y y y x$, yyyy, yyyyy, yyxx, yyxy, yyxyy\}.

Com a retirada das sequiências que são prefixos de outras, a aplicação do método $\mathrm{W}$ na MEF da Figura 3.2 resulta no conjunto $T S_{W}=\{r x x x$, rxxyy, rxy $x$, rxyyy, ryx $x$, ryxyy, ryy $x$, ryyxyy, ryyyx, ryyyyy de tamanho 49.

\subsubsection{Método Wp}

Fujiwara et al. (1991) propuseram o método Wp (partial $W$ ) que é um aprimoramento do método $W$. A principal vantagem do método $\mathrm{Wp}$ em relação ao $\mathrm{W}$ é que ele utiliza um subconjunto do conjunto $W$ para a criação das seqüências de teste, e, assim, obtém-se uma quantidade reduzida de casos de teste para serem utilizados.

O método $\mathrm{Wp}$, semelhante ao $W$, também opera em MEFs completas. Esse método possui o mesmo poder do método $\mathrm{W}$ na detecção de defeitos, mas produz um menor conjunto de seqüências de entradas (Fujiwara et al., 1991).

O método basicamente consiste em duas fases:

Fase 1: É verificado se todos os estados definidos na especificação também são encontrados na implementação.

Fase 2: Todas as transições definidas na especificação e que não foram testadas na Fase 1 são verificadas.

Um conjunto $P$ que cobre todas as transições da MEF é determinado e identifica-se um subconjunto $Q$ que cobre todos os estados da MEF. Para cada estado $S_{i} \in S$ da especificação determina-se um conjunto de identificação $W_{i}$, que distingue o estado $S_{i}$ de todos os demais. A união de todos os conjuntos $W_{i}$ resulta no conjunto $W$ e diferentes casos de testes podem ser gerados dependendo da escolha dos conjuntos $P, Q$ e $W_{i}$.

Na primeira fase, os casos de teste resultam da concatenação dos conjuntos $Q$ e $W$. Se o teste obtiver sucesso significa que o número de estados da implementação é igual ao número de estados da especificação. 
$\mathrm{Na}$ segunda fase, os casos de teste são gerados a partir da concatenação das seqüências do conjunto $P$, menos as seqüências do conjunto $Q$, com o conjunto $W_{i}$ correspondente ao estado atingido após a execução de cada seqüência, ou seja, $R=P-Q$ e $R \otimes W=\bigcup_{p \in R}\{p\} W_{i}$. A operação $R \otimes W$ resulta em um conjunto formado pela união da concatenação das seqüências do conjunto $R$ com o conjunto de identificação $W_{i}$, ou seja, $R \otimes W=\left\{\alpha W_{i} \mid \alpha \in R, \delta\left(s_{0}, \alpha\right)=s_{i}\right\}$. Dessa forma, obtém-se um conjunto de casos de teste menor em relação ao conjunto gerado pelo método $W$, pois a concatenação ocorre com um subconjunto $W_{i}$ ao invés de ocorrer com o conjunto $W$.

Para a MEF da Figura 3.2, a aplicação do método Wp é ilustrado a seguir. Na primeira fase, considerando o conjunto state cover $Q$, as seqüências são geradas pela concatenação de $Q$ com $W$. Dessa forma, como resultado da primeira fase tem-se as seqüências $\{x, y, y y, y x, y y, y y y, x x, x y$, $x y y$, yyx, yyy, yyyy\}.

Na segunda fase, considerando o conjunto transition cover $P=\{\epsilon, x, y, x x, x y, y y, y x$, yyy, $y y x\}$, as sequiências são geradas pela concatenação do conjunto $P$, menos o conjunto $Q$, com o conjunto $W_{i}$ de cada estado $S_{i}$ atingido. Tem-se $R=P-Q=\{x x, x y$, yyy, yyx, yx $\}$. Realizando a operação $R \otimes W$ obtém-se as seqüências da forma: $\left\{x x W_{2}, x y W_{1}, y y y W_{4}\right.$, yyx $W_{3}$, $\left.y x W_{2}\right\}$. Realizando as substituições necessárias, as seqüências obtidas são: $\{x x y, x y y y, y y y x$, yyyyy, yyxx, yxy\}.

Com a retirada das sequiências que são prefixos de outras, a aplicação do método Wp na MEF da Figura 3.2 produz o conjunto $T S_{W p}=\{r x x y$, rxyyy, ryxy, ryyxx, ryyyx, ryyyyy $\}$ de tamanho 29.

\subsubsection{Método HSI}

Existem diferentes métodos para geração de casos de teste em MEF completas, mas na maioria das situações práticas as MEFs não são completas (Petrenko e Yevtushenko, 2005). Por isso, existe a necessidade de métodos para atender as MEFs parciais. Uma solução para esse problema seria completar artificialmente a MEF, adicionando arcos nulos nos estados não totalmente especificados. Com isso, entretanto, tem-se o problema de um grande número de casos de teste e os arcos artificiais poderiam interferir no cálculo dos casos de teste, gerando, na maioria dos casos, um conjunto de teste inviável.

Nesse contexto encontra-se o método HSI (Harmonized State Identification) (Luo et al., 1995) que resolve o problema das MEFs parciais e ainda o problema das MEFs não-determinísticas. Esse método é um dos mais versáteis, pois pode ser aplicado à maioria dos tipos de MEFs.

O Método HSI é similar ao método W, entretanto, diferencia-se em relação ao critério de seleção do conjunto de caracterização, selecionando um subconjunto deste, chamado de conjunto HSI. Por ser menor que o conjunto $W$, o conjunto de seqüências de teste final também será menor, o que otimiza o processo de teste final. Com essa diferenciação na seleção do conjunto de caracterização, 
o método HSI tem a capacidade de gerar casos de testes que antes não eram possíveis com outros métodos. Contudo, o método não garante que todos os possíveis defeitos sejam encontrados.

Considerando a MEF da Figura 3.2, o método HSI gera o conjunto $T S_{H S I}=\{r x x x, r x x y$, rxyx, rxyy, ryxx, ryxy, ryyxx, ryyyx, ryyyy\} de tamanho 39.

\subsubsection{Método State Counting}

O método State Counting (SC), proposto por Petrenko e Yevtushenko (2005), atinge os mesmos objetivos do método $W$ em relação à efetividade, ou seja, o método garante a cobertura completa de defeitos existentes na implementação de uma MEF.

De um modo geral, o método State Counting utiliza um algoritmo que expande as sequiências de teste a partir de um estado da MEF até que seja atingida uma condição que permita verificar que todas os defeitos já foram identificados. Por exemplo, se um estado é visitado mais do que $m$ vezes, sendo $m$ o número de estados da MEF, pode-se parar de expandir a sequiência, uma vez que, desse ponto em diante, o comportamento começará a se repetir. Os autores provam que, utilizando-se as relações de quasi-equivalência entre estados e sequiências capazes de distinguir pares de estado, pode-se determinar a parada da expansão da seqüência sem que seja necessário atingir o limite de $m$ visitas a um estado.

O método State Counting pode ser utilizado com MEFs parciais e gera um conjunto de casos de teste que pode ser usado para identificar todos os possíveis defeitos, sendo, dessa forma, mais eficiente que o método HSI e mais amplamente aplicável que os métodos W e Wp. Contudo, verifica-se que, em geral, o número de casos de teste gerados é elevado. Esse método gera um conjunto de casos de teste completo a partir de MEF parciais e não reduzidas.

Considerando a MEF da Figura 3.2, o método State Counting gera o conjunto $T S_{S C}=\{r x x x$, rxxy, rxyx, rxyyy, ryxx, ryxy, ryyxx, ryyyx, ryyyyy\} de tamanho 41.

\subsubsection{Método HIS}

O método HIS (Petrenko et al., 1993), semelhante ao método Wp, também é uma modificação do método $W$. Esse método garante a cobertura completa de defeitos existentes sendo aplicável em qualquer especificação reduzida, seja ela completa ou parcial. Esse método utiliza o conceito de família de separação (separating family) ou identificadores harmonizados (harmonized identifiers).

Com o objetivo de testar a conformidade de uma implementação $I$ em relação à especificação $M$, o método consiste basicamente em duas fases:

1) Identificação de estados: Ocorre a verificação para saber se cada estado especificado em $M$ existe em $I$. A partir do conjunto state cover $\left(Q=\left\{\alpha_{1}, \alpha_{2}, \ldots, \alpha_{n}\right\}\right)$ e da família de separação $\left(F=\left\{H_{1}, \ldots, H_{n}\right\}\right)$, sendo $n$ o número de estados de $I$, as seqüências são geradas. Essa fase compreende as seqüências $r \alpha_{j} H_{j}$ para cada estado $s_{j}$. 
2) Teste de transições: Garante que para cada transição definida de $M$ exista uma transição correspondente em $I$. Para cada seqüência $\alpha_{j} \in Q$ que leva a MEF para um estado $s_{j}$ e para cada $x$ do conjunto de símbolos de entrada que leva a MEF do estado $s_{j}$ para o estado $s_{k}$, essa fase compreende o conjunto de seqüências $r \alpha_{j} x H_{k}$, sendo que $H_{k} \in F$ é um identificador do estado $s_{k}$.

Se a MEF resultar em respostas corretas para as seqüências produzidas em ambas as fases, pode-se considerar que ela está em conformidade com sua especificação.

Para a MEF da Figura 3.2, a aplicação do método HIS é ilustrado a seguir, considerando o conjunto state cover $Q$ e as famílias de separação $H_{1}, H_{2}, H_{3}, H_{4}$.

Na primeira fase (Identificação de Estados) as seqüências geradas são da forma: $\left\{\epsilon H_{1}, y H_{2}\right.$, $\left.x H_{3}, y y H_{4}\right\}$ resultando nas seqüências $\{x, y y, y x, y y, x x, y y x, y y y y$.

Na segunda fase (Teste de Transições) as seqüências geradas são da forma: $\epsilon x H_{3}, \epsilon y H_{2}, y x H_{2}$, $y y H_{4}, x x H_{2}, x y H_{1}, y y x H_{3}, y y y H_{4}$. Realizando as substituições necessárias, essa fase gera as sequiências: $\{x x, x y, y x, y y, y x x, y x y, y y x, y y y y, x x x, x x y, x y x, x y y y, y y x x, y y y x, y y y y\}$.

Com a retirada das seqüências que são prefixos de outras, o método HIS gera o conjunto $T S_{H I S}=\{r x x x, r x x y, r x y x, r x y y y, r y x x, r y x y, \operatorname{ryyxx}, \operatorname{ryyyx}$, ryyyyy $\}$ de tamanho 41.

\subsubsection{Método UIO}

O método UIO, proposto originalmente por Sabnani e Dahbura (1988), é baseado em seqüências UIO e utiliza apenas a fase de teste das transições. Originalmente, foi afirmado que os casos de teste gerados pelo método eram completos. No entanto, o trabalho de Vuong et al. (1989) mostrou, com um contra-exemplo, que o método UIO não garante uma cobertura completa de defeitos.

As seqüências UIO (unique input/output sequence) foram introduzidas por Hsieh (1971). Algoritmos para verificar sua existência, em uma MEF, mais tarde foram propostos (Sabnani e Dahbura, 1988; Lee e Yannakakis, 1994; Naik, 1997).

Se para cada estado de uma MEF há uma seqüência UIO, pode-se utilizá-las para identificar cada estado, atuando como uma mensagem de status, exceto pela alteração do estado corrente da máquina (Broy et al., 2005).

O método UIO consiste em duas fases:

$\mathbf{1}^{\text {a }}$ Fase: Verifica cada estado da MEF com sua respectiva seqüência UIO. Essa fase consiste na concatenação de $Q$ com a respectiva seqüência UIO de cada estado atingido.

$2^{a}$ Fase: Verifica se cada transição da MEF, produz a saída desejada. Nessas transições, cada estado atingido também é verificado pela aplicação de sua respectiva seqüência UIO.

Para a MEF da Figura 3.2 consideram-se as seqüências UIO $\{y y, y, x, y y y\}$ para os estados $S_{1}, S_{2}, S_{3}$ e $S_{4}$, respectivamente. Para simplificar, a notação $U I O\left(S_{i}\right)$ representa a sequiência UIO 
do estado $S_{i}$. Considera-se o conjunto state cover $Q=\left\{\alpha_{1}, \alpha_{2}, \alpha_{3}, \alpha_{4}\right\}$ tal que $\alpha_{1}=\epsilon, \alpha_{2}=$ $y, \alpha_{3}=x, \alpha_{4}=y y$.

Na primeira fase as seqüências geradas são: $\alpha_{1} U I O(1), \alpha_{2} U I O(2), \alpha_{3} U I O(3), \alpha_{4} U I O(4)$. Realizando as devidas substituições, essa fase resulta nas seqüências $\{y y, y y, x x, y y y y y\}$.

Na segunda fase as sequiências são geradas pela concatenação: $\alpha_{i} z U I O\left(S_{j}\right)$ para todo $z \in$ $X$ sendo que $\alpha_{i}$ leva a MEF do estado inicial ao estado $S_{i}$. Essa fase resulta nas seqüências $\{x x, y y$, yxy, yyyyy, xxy, xyyy, yyxx, yyyyyy $\}$.

Com a retirada das sequiências que são prefixos de outras, o método UIO gera o conjunto de teste $T S_{U I O}=\{r y x y$, rxxy, rxyyy, ryyxx, ryyyyyy $\}$ de tamanho 25.

\subsubsection{Método UIOv}

O método UIOv (Vuong et al., 1989) é uma versão modificada do método UIO sendo também aplicável às MEFs completas. Esse método consiste em três fases:

$1^{\text {a }}$ Fase: Para cada estado $S_{i}$ da MEF uma seqüência de entrada é aplicada para alcançar tal estado. O conjunto state cover $Q$ é utilizado para que cada estado seja alcançado. Em seguida, é aplicada a respectiva seqüência UIO de cada estado. O conjunto de casos de teste resultante dessa fase consiste na concatenação de $Q$ com a respectiva sequiência UIO de cada estado atingido.

$\mathbf{2}^{\mathbf{a}}$ Fase: Deve-se visitar cada estado $S_{i}$ da MEF com a utilização do conjunto $Q$ e aplicar as sequiências UIO dos outros estados ao estado $S_{i}$. Desse modo, há a verificação para saber se não existe uma mesma sequiência UIO definida para outro estado da MEF. Retiram-se as seqüências UIO que são prefixos da seqüência UIO (utilizada na $1^{\text {a }}$ fase) do estado $S_{i}$.

$3^{\text {a }}$ Fase: Ocorre a verificação se cada transição da MEF, ainda não testada nas fases anteriores, produz a saída desejada. Nessas transições, cada estado atingido também é verificado pela aplicação de sua respectiva seqüência UIO.

O método UIOv pode ser considerado como um caso especial do método $\mathrm{Wp}$, quando o conjunto W é a união de todas as sequiências UIO. O método UIOv ainda foi melhorado no trabalho de Chen et al. (1995).

Para a MEF da Figura 3.2 consideram-se as seqüências UIO $\{y y, y, x, y y y\}$ para os estados $S_{1}, S_{2}, S_{3}$ e $S_{4}$, respectivamente.

De modo semelhante ao método UIO, as seqüências geradas na primeira fase são: $\{y y, y y, x x$, yyyyy $\}$. Na terceira fase (segunda fase do método UIO), as sequiências geradas são: $\{x x, y y, y x y$, yyyyy, xxy, xyyy, yyxx, yyyyyy\}.

A diferença do método UIOv em relação ao método UIO consiste na existência de uma outra fase ( $2^{\text {a }}$ fase do método UIOv). Nessa fase, estando em um estado $S_{i}$, as seqüências 
UIO de outros estados são aplicadas ao estado $S_{i}$. Essa fase gera as sequiências da forma Q. $\neg U I O$, tal que $\neg U I O$ são as seqüências UIO de outros estados. As seqüências geradas são: $\{x$, yyy, yyy, yx, yyyy, xyy, xy, xyyy, yyx $\}$.

Com a retirada das sequiências que são prefixos de outras, o método UIOv gera o conjunto de teste $T S_{U I O v}=\{$ ryxy, rxxy, rxyyy, ryyxx, ryyyyyy $\}$ de tamanho 25. Nota-se que os conjuntos de teste dos métodos UIO e UIOv foram idênticos para esse exemplo. A partir dessa informação, pode-se concluir que, para o exemplo ilustrado na Figura 3.2, o método UIO gera um conjunto de teste completo.

\subsubsection{Método H}

O método H (Dorofeeva et al., 2005b) é uma melhoria do método HIS. A idéia é não definir, a priori, os identificadores de estados. Os identificadores de estados são construídos com base nos casos de teste já derivados com o intuito de distinguir-se os estados finais das transições. No trabalho de Dorofeeva et al. (2005b) o método H, proposto originalmente para MEFs completas e determinísticas, é estendido para MEFs determinísticas parciais.

Os autores também estenderam o método $\mathrm{H}$ para máquinas parciais não-determinísticas. $\mathrm{O}$ método $\mathrm{H}$, bem como o HIS, gera um conjunto de teste completo, sendo aplicável em qualquer especificação reduzida completa ou parcial. No entanto, o tamanho do conjunto dos casos de teste gerado depende da ordem na qual as transições são checadas. Os autores afirmam que um procedimento para determinar a ordem de escolha das transições está sendo incorporado ao método para a obtenção de seqüências menores.

Considerando a MEF da Figura 3.2, para identificar os estados, o método H utiliza as família de separação $H_{1}, H_{2}, H_{3}, H_{4}$ gerando as seqüências $\{y x, x x, y y x, y y y y\}$. Para verificar as transições, os identificadores de estados são gerados. Por exemplo, seja a transição do estado $S_{3}$ para o estado $S_{2}$ com a entrada $x$. Ao invés de se utilizar a seqüência $x x H_{2}$ como no método HIS, utiliza-se a seqüência $x x y$.

Para a MEF da Figura 3.2, a aplicação do método H produz o conjunto $T S_{H}=\{r x x y$, rxyyy, ryxy, ryyxx, ryyyyyy de tamanho 25.

\subsection{Comparação entre os Métodos de Geração}

Para que o testador escolha um método de geração com o objetivo de aplicá-lo em alguma especificação baseada em MEF, é necessário que algumas características sejam observadas. Essas características referem-se à exigência de cada método para que a MEF possua certas propriedades, ao tamanho das seqüências geradas e à aplicabilidade de cada um.

Na Tabela 3.2 é fornecida uma comparação entre os métodos apresentados nesta seção. Todos os métodos são aplicados às MEFs determinísticas, fortemente conexas, completas e minimais. 
Dessa forma, na Tabela 3.2 são apresentadas outras características das MEFs em que alguns métodos ainda podem ser aplicados.

Tabela 3.2: Comparação entre os métodos de geração.

\begin{tabular}{|c||c|c|c|c|c|c|c|c|c|c|}
\hline & TT & DS & W & Wp & HSI & SC & HIS & UIO & UIOv & H \\
\hline \hline Não-minimal/Não-reduzida & $\checkmark$ & & & & & $\checkmark$ & & & & \\
\hline Parcial & $\checkmark$ & & & & $\checkmark$ & $\checkmark$ & $\checkmark$ & & & $\checkmark$ \\
\hline Não-determinística & & & & & $\checkmark$ & & & & & $\checkmark$ \\
\hline Cobertura Completa & & $\checkmark$ & $\checkmark$ & $\checkmark$ & & $\checkmark$ & $\checkmark$ & & $\checkmark$ & $\checkmark$ \\
\hline
\end{tabular}

Dentre os métodos apresentados, o método State Counting é o único que pode ser aplicado às MEFs não-reduzidas e que obtém um conjunto de casos de teste completo. De acordo com Petrenko e Yevtushenko (2005), tem-se trabalhado para realizar a generalização desse método para que seja aplicado às MEFs não-determinísticas.

Para a aplicação do método $\mathrm{W}$, o conjunto de caracterização (conjunto $\mathrm{W}$ ) deve existir, sendo que ele sempre existe em MEFs minimais. Os métodos DS e UIO, para serem aplicados, ficam restritos à existência da seqüência de distinção e de seqüências UIO, respectivamente.

\subsection{Comparação Empírica entre os Métodos de Geração}

É importante a comparação dos métodos de geração de casos de teste existentes, pois possibilita que sejam observadas suas principais diferenças em relação ao custo de geração, tamanho do conjunto de teste que cada um produz e efetividade.

No trabalho de Dorofeeva et al. (2005a), experimentos foram realizados com o intuito de comparar alguns métodos de geração de casos de teste para MEFs. Os métodos W, Wp, UIO, UIOv, DS, H e HIS foram comparados quanto ao tamanho e tempo de geração dos conjuntos de casos de teste. As especificações das MEFs utilizadas foram geradas randomicamente. Tais especificações são reduzidas e completamente especificadas. Os resultados obtidos com a realização dos experimentos apontam que:

- O método UIO gerou os conjuntos de casos de teste de menor tamanho, entretanto a maioria desses conjuntos fornecia uma cobertura incompleta.

- Os métodos H e DS geraram conjuntos de teste de tamanhos comparáveis, mas o método DS nem sempre foi aplicável.

- Os métodos HIS e Wp também geraram conjuntos de teste de tamanhos comparáveis. Os tamanhos dos casos de teste foram menores que os gerados pelo método W (como era esperado). 
- O método UIOv não se saiu melhor em relação ao método Wp e HIS. Isso era esperado, pois o UIOv é um caso particular do Wp.

Em um outro experimento (do mesmo trabalho) realizado com MEFs pequenas, os autores relatam que $41 \%$ dos casos de teste gerados pelo método UIO (quando aplicável) eram incompletos. Os experimentos foram realizados considerando o número de estados de uma implementação igual ao número de estados da especificação $(m=n)$. Nesse trabalho, o método State Counting não foi observado.

No trabalho de Herculano (2007) os conjuntos de teste foram comparados em outro contexto. Foi realizada uma comparação entre conjuntos de teste gerados pelos métodos clássicos de geração e conjuntos de teste derivados a partir de critérios estruturais. Foram utilizados os métodos $W$, State-Counting e UIO para as MEFs e o critério de análise de mutantes para MEFs e Redes de Petri Coloridas. Dois estudos de caso foram conduzidos. Segundo Herculano (2007), o conjunto $W$ gerou um conjunto de teste maior em relação aos demais. No entanto, a autora destacou que os métodos de geração não detectaram alguns elementos requeridos que não faziam parte do comportamento normal do protocolo. Assim, a implementação do sistema possuía mais informação em relação a sua especificação. Desse modo, destaca-se a importância da modelagem do sistema que, mesmo sendo criada de forma criteriosa, permite que erros ainda possam existir.

\subsection{Completude de Conjuntos de Casos de Teste}

Para um conjunto de casos de teste gerado (de alguma forma) a partir de uma MEF, uma questão importante refere-se em como avaliar a efetividade (ou qualidade) do mesmo, ou seja, avaliar sua cobertura em relação a defeitos. Para avaliar se um conjunto de casos de teste fornece uma cobertura completa a defeitos, Yao et al. (1994) propuseram um procedimento. Esse procedimento pode ser aplicado em conjuntos gerados a partir de MEFs parciais ou completas. A idéia do procedimento consiste em: para um inteiro $m$ (número máximo de estados da implementação) verificar se o conjunto de teste é $m$-completo em relação à especificação. O conjunto de teste é $m$-completo se para qualquer implementação $I$ (com um número máximo de estados $m$ ), $I$ vai passar pelo teste, se e somente se, $I$ cobrir a especificação $M$. Em linhas gerais, as três etapas são descritas:

1. Conversão de um conjunto de teste em uma máquina de árvore (tree machine). Uma máquina de árvore é uma MEF cuja representação gráfica é uma árvore em que o nó raiz da árvore representa o estado inicial da máquina. Cada caminho da máquina representa um caso de teste do conjunto.

2. Realização de uma chamada a um procedimento de minimização de estados para minimizar a máquina de árvore, considerando o inteiro $m$ e a especificação como referência. 
3. Se a forma reduzida da máquina de árvore (encontrada no passo 2) não estiver em conformidade com a especificação e possuir no máximo $m$ estados, então o conjunto de teste não é $m$-completo, caso contrário, o conjunto de teste é $m$-completo.

A verificação da completude de um conjunto de teste também pode ser realizada pela tentativa exaustiva, onde todas as possíveis implementações de MEFs são verificadas com o conjunto de teste. Tanto a técnica exaustiva quanto a técnica de minimização da máquina de árvore não apresentam um bom desempenho à medida que os estados aumentam (Simão e Petrenko, 2007).

Além dessas técnicas, a verificação da completude pode ser realizada por algumas condições, chamadas de condições de suficiência (Petrenko et al., 1996; Dorofeeva et al., 2005b; Simão e Petrenko, 2007). Segundo Petrenko et al. (1996), um conjunto de teste é completo se ele contém um subconjunto de seqüências que satisfaz as condições de suficiência. Se o conjunto de teste satisfaz tais condições, o conjunto é dito ser $m$-completo. Por outro lado, se o conjunto de teste não as satisfazem então não se pode afirmar sobre a completude do conjunto de teste.

Além das condições de suficiência, Petrenko et al. (1996) também formularam algumas condições necessárias para que o conjunto de teste seja $m$-completo. Seja $A P(T S)$ todos os prefixos dos casos de teste pertencentes ao conjunto de teste $T S$. Duas condições necessárias são descritas a seguir:

1a) Condição Necessária: Se, para algum $m \geq n, T S$ é $m$-completo em relação à especificação, então $A P(T S)$ deve conter um conjunto state cover. Em outras palavras, o conjunto de teste $m$-completo deve conter seqüências que percorrem todos os estados da especificação.

$2^{\mathbf{a}}$ ) Condição Necessária: Se, para algum $m \geq n$, TS é $m$-completo em relação à especificação, então $A P(T S)$ deve conter um conjunto transition cover. Em outras palavras, o conjunto de teste $m$-completo deve conter seqüências que percorrem todas as transições da especificação.

Neste trabalho é considerado o caso particular $m=n$. Nesse contexto, Petrenko et al. (1996) formularam algumas condições de suficiência para a $n$-completude de conjuntos de teste, considerando MEFs reduzidas. Tais condições são sumarizadas a seguir:

Condição Suficiente: $O$ conjunto $T S$ é $n$-completo em relação à especificação reduzida se:

- $A P(T S)$ contém o conjunto state cover $Q$ e um conjunto transition cover $P$; e

- Para cada par de seqüências $\alpha, \beta \in Q$ tal que $\delta\left(s_{0}, \alpha\right) \neq \delta\left(s_{0}, \beta\right)$, devem existir duas sequiências $\alpha \gamma, \beta \gamma \in A P(T S)$ tal que $\lambda\left(\delta\left(s_{0}, \alpha\right), \gamma\right) \neq \lambda\left(\delta\left(s_{0}, \beta\right), \gamma\right)$; e

- Para cada $\alpha \in P \backslash Q$ e cada $\beta \in Q$ tal que $\delta\left(s_{0}, \alpha\right) \neq \delta\left(s_{0}, \beta\right)$, devem existir duas seqüências $\alpha \gamma, \beta \gamma \in A P(T S)$ tal que $\lambda\left(\delta\left(s_{0}, \alpha\right), \gamma\right) \neq \lambda\left(\delta\left(s_{0}, \beta\right), \gamma\right)$. 
No trabalho de Dorofeeva et al. (2005b), condições de suficiência mais abrangentes para $m=n$ são propostas. Essas condições são apresentadas na Seção 4.2, pois se relacionam diretamente com este trabalho. No trabalho de Simão e Petrenko (2007), uma melhoria das condições de suficiência é proposta. Essa melhoria também é apresentada na Seção 4.2.

Segundo Petrenko et al. (1996), as técnicas de análise de cobertura de defeitos podem ser utilizadas para a criação incremental do conjunto de casos de teste. Se um conjunto de teste não é completo, uma MEF não-equivalente à especificação deve ser gerada para que novos casos de teste sejam derivados. Os novos casos de teste que diferenciem a MEF gerada de sua especificação devem ser adicionados ao conjunto de teste. Esse processo é repetido até que o conjunto seja $m$-completo.

A adição de novos casos de teste, com o intuito de se completar um conjunto de teste, pode resultar em um aumento exagerado do tamanho desse conjunto. Nesse contexto, torna-se importante que a completude seja obtida, mas que a adição seja realizada de forma minimizada.

\subsection{Ferramentas de Apoio ao Teste de Modelos}

No contexto de teste baseado em modelos, a automatização também é um aspecto importante, pois possibilita que o testador obtenha maior produtividade durante a atividade de teste. Assim, torna-se necessária a criação de ferramentas que apóiam o teste de especificações. Dentre as ferramentas que se relacionam ao teste basedo em modelos, encontram-se a MGASet (Candolo et al., 2001), ConData (Martins et al., 1999), TAG (Tan et al., 1996), Proteum/FSM (Fabbri et al., 1999), Plavis/FSM (Simão et al., 2005) e ATIFS (Martins et al., 2003). Essas ferramentas são apresentadas resumidamente a seguir.

\subsubsection{Ferramenta TAG}

A ferramenta TAG (Test Automatic Generation) (Tan et al., 1996) apóia a atividade de teste realizando a geração de casos de teste. A ferramenta utiliza o método HSI (descrito na Seção 3.5) que pode ser aplicado em MEFs parciais e possui dois modos de derivação de testes:

- Derivação de teste completa: Quando o conjunto de teste deve testar todas as transições especificadas na MEF fornecida.

- Derivação de teste seletivo: Quando o caso de teste deve testar uma única transição.

Inicialmente o usuário deve fornecer um arquivo que descreve os estados, as transições, as saídas e as entradas da MEF para que o conjunto de casos de teste seja gerado utilizando-se o método HSI. A ferramenta requer que a MEF seja determinística e inicialmente conectada podendo ser parcial ou completa. Se a MEF possuir estados que não são distinguíveis, a derivação dos casos de teste ainda é possível, entretanto esse conjunto gerado não garante a cobertura completa de defeitos. 


\subsubsection{Ferramenta Plavis/FSM}

O projeto PLAVIS (Plataforma para Validação e Integração de Software em Sistemas Espaciais) (PLAVIS, 2005) foi desenvolvido em conjunto por Universidades e Institutos de Pesquisa brasileiros, além da colaboração de Centros de Pesquisas franceses. Tem como objetivo estabelecer um trabalho de cooperação entre universidades e institutos de pesquisa que possuem o domínio da tecnologia em pesquisas para melhorar as técnicas de VV\&T (Verificação, Validação e Teste). Esse projeto habilita experimentos com estudos de casos reais fornecidos pelo INPE (Instituto Nacional de Pesquisas Espaciais). A plataforma PLAVIS consiste em um conjunto de técnicas, métodos e ferramentas que apóiam as atividades de VV\&T para software de sistemas espaciais. Há uma versão da PLAVIS que se concentra no teste em MEF denominada PLAVIS/FSM (Simão et al., 2005). A PLAVIS/FSM é uma plataforma integrada para apoiar a validação de sistemas baseados em MEFs. Ela promove a integração de três ferramentas que apóiam o teste: Proteum/FSM (Fabbri et al., 1999), ConData (Martins et al., 1999) e MGASet (Candolo et al., 2001). Os métodos de geração de casos de teste UIO, HSI e State Counting também foram implementados e podem ser utilizados para a geração de seqüências de teste.

\subsubsection{Ferramenta MGASet}

A ferramenta MGASet (Candolo et al., 2001) tem como objetivo apoiar o teste e a validação de especificações baseadas em MEFs. Utiliza o método W (descrito na Seção 3.5) para a geração de sequiências de teste e é composta por quatro módulos:

- Módulo de Controle de Geração (MCG): Tem como objetivo mostrar ao usuário as atividades de teste e validação que estão disponíveis na ferramenta. Esse módulo realiza o gerenciamento das atividades por meio do controle de execução dos três módulos restantes.

- Módulo de Verificação de Propriedades (MVP): Verifica as propriedades da MEF. As propriedades verificadas da MEF são: minimalidade, determinismo, máquina de Mealy, especificação completa e conectividade forte.

- Módulo de Geração de Sequiências Básicas (MGSB): Realiza a geração de seqüências fundamentais necessárias para a realização do teste. A seqüência de sincronização, sequiências distinguíveis, sequiências únicas de entrada e saída são geradas. O conjunto de caracterização também é gerado.

- Módulo de Seqüências de Teste (MST): O objetivo desse módulo é gerar as sequiências finais de teste, ou seja, as seqüências geradas pelo método $\mathrm{W}$. 


\subsubsection{Ferramenta Proteum/FSM}

A ferramenta Proteum/FSM (Program Testing Using Mutants/Finite Sate Machines) (Fabbri et al., 1999) apóia a aplicação do teste de mutantes para validar especificações de Sistemas Reativos baseadas em MEFs. A ferramenta possui oito módulos, que são: Editar Especificação da MEF, Abrir Teste, Manipular Casos de Teste, Gerar Seqüências de Teste, Gerar Mutantes, Executar Mutantes, Marcar Mutante Equivalente e Emitir Relatórios.

Em relação aos casos de teste, a ferramenta possibilita ao testador a capacidade de: adicioná-los de modo interativo ou em batch; visualizá-los ou excluí-los; gerar um conjunto de casos de teste a partir de métodos de geração e importar os casos de teste de outras ferramentas. A simulação da MEF é iniciada após os casos de teste serem adicionados. O testador deve observar o resultado da simulação e confirmar a inclusão do caso de teste, caso seja obtido o resultado esperado. Uma vez que os casos de teste são confirmados, os mutantes são gerados e executados. Cada caso de teste é aplicado apenas uma vez em um mutante e os resultados obtidos são comparados com os resultados obtidos na simulação da MEF original. Por fim, o testador verifica se os mutantes que continuaram "vivos" são equivalentes, caso contrário, novos casos de teste devem ser criados. Relatórios sobre o teste realizado podem ser emitidos.

\subsubsection{Ferramenta ConData}

A ferramenta ConData (Martins et al., 1999) é utilizada na geração de casos de teste para protocolos de comunicação que estejam especificados como MEFs ou Máquinas de Estados Finitos Estendidas (MEFE). Uma MEFE combina o modelo de MEF com a adição de variáveis representando os dados. Dessa forma, a geração dos casos de teste é realizada considerando a parte de controle e a parte de dados. Para a parte de controle, os casos de teste são gerados baseados em subcaminhos que começam e terminam no estado inicial. Para a parte de dados, são realizados o teste de sintaxe para produzir formatos de entrada válidos e o particionamento em classes de equivalência para produzir dados válidos para os parâmetros de entrada.

Para a geração dos casos de teste, utilizando a ferramenta ConData, três passos são necessários:

1. O protocolo de comunicação é especificado na forma de uma MEFE. O testador deve fornecer uma MEFE que seja inicialmente conexa, mas que pode ser não-determinística, parcialmente ou completamente especificada.

2. A especificação é transformada em uma especificação de teste. Essa função é realizada pelo tradutor da ferramenta.

3. A especificação de teste é utilizada para a geração dos casos de teste.

A ferramenta ConData é uma das ferramentas que compõem o ATIFS (Ambiente de Testes baseado por Injeção de Falhas por Software) (Martins et al., 2003). 


\subsubsection{Ambiente ATIFS}

O ATIFS (Ambiente de Testes baseado por Injeção de Falhas por Software) (Martins et al., 2003) é um ambiente de teste que integra diversas ferramentas para o teste de sistemas reativos. Esse ambiente permite a geração dos casos de teste, a execução dos casos de teste e a análise dos resultados. O ATIFS é desenvolvido em conjunto entre a UNICAMP e o INPE com o objetivo de melhorar a qualidade dos softwares espaciais utilizados pelo INPE. As ferramentas que compõem o ATIFS são:

- AnaLEP: Analisa a especificação escrita em LEP (Linguagem de Especificação de Protocolo).

- VerProp: Verifica as propriedades da especificação.

- ConData: Gera os casos de teste.

- SeDados: Auxilia a ConData na geração dos casos de teste. A SeDados seleciona dados de entrada com o intuito de atender todas as condições existentes nas transições das MEFEs.

- GerScript: Transforma os casos de teste em um formato executável.

- FSoFIST: Suporta a execução dos casos de teste.

- Antrex: Implementa um oráculo para verificar se as saídas obtidas são as saídas desejadas.

\subsection{Considerações Finais}

Neste capítulo foram abordados os principais aspectos relacionados ao teste baseado em modelos. Devido ao escopo deste trabalho, as características e definições relacionadas ao teste baseado em Máquina de Estados Finitos foram apresentadas de forma mais detalhada.

Verificou-se a importância da utilização de modelos formais para a representação do aspecto comportamental de um sistema, em particular de um Sistema Reativo. No que se refere a técnicas de especificação de Sistemas Reativos, foi dada ênfase à técnica de Máquinas de Estados Finitos. Trabalhos recentes relacionados aos métodos de geração também estão sendo propostos, o que mostra o atual interesse dos pesquisadores nessa área. De forma geral, também foram apresentadas algumas ferramentas que apóiam o teste de modelos.

Um aspecto interessante que pode ser observado em relação aos métodos de geração, refere-se ao conjunto de casos de teste gerado. Alguns métodos geram um conjunto completo e ao mesmo tempo grande para ser aplicado. Essa relação de tamanho e efetividade dos conjuntos de teste é uma questão relevante. Dessa forma, torna-se necessária a investigação de estratégias para a redução do tamanho dos conjuntos de casos de teste procurando-se, de certa forma, manter sua efetividade. Nesse contexto, é assunto do capítulo a seguir o algoritmo de minimização de conjuntos de teste proposto neste trabalho. 



\section{Algoritmo de Minimização}

\subsection{Considerações Iniciais}

Apesar dos vários métodos disponíveis, pode haver situações em que um conjunto de teste seja obtido de alguma outra forma. Por exemplo, um conjunto de casos de teste pode ter sido criado com base em outros modelos disponíveis, tais como a especificação textual ou diagramas de análise. Além disso, conjuntos previamente utilizados para o teste de outras versões do sistema (tais como no teste de regressão) ou de outros sistemas semelhantes podem ser empregados. No entanto, a tarefa de se aplicar esse conjunto de teste torna-se muito onerosa quando há uma quantidade elevada de casos de teste a serem aplicados. Com o intuito de viabilizar a aplicação dos testes, uma minimização do conjunto de teste pode ser realizada.

Diversos critérios de cobertura podem ser utilizados para guiar a minimização, tais como a cobertura de elementos da MEF (por exemplo, estados e transições), buscando reduzir o conjunto de forma a manter casos de teste necessários para garantir que tais elementos foram exercitados ao menos um número pré-definido de vezes. No entanto, a satisfação de tais critérios não garante que todos os defeitos sejam revelados, tal como ocorre com os conjuntos de teste gerados por alguns métodos clássicos. Para que não haja prejuízos quanto à eficiência dos testes, torna-se importante realizar a minimização de forma a garantir a propriedade de que o conjunto resultante possua a mesma capacidade na detecção de defeitos.

São conhecidas algumas condições, chamadas de condições de suficiência, que garantem que, uma vez satisfeitas essas condições, o conjunto possua tal propriedade, tais como as propostas por Petrenko et al. (1996); Dorofeeva et al. (2005b); Simão e Petrenko (2007). 
Neste capítulo, um algoritmo para a minimização de conjuntos de teste para MEFs é apresentado. O algoritmo de minimização proposto neste trabalho baseia-se nas condições de suficiência formuladas em Dorofeeva et al. (2005b) e Simão e Petrenko (2007) para o caso particular $m=n$. Desse modo, a efetividade do conjunto de teste é mantida. O algoritmo utiliza uma estratégia baseada no algoritmo guloso (Cormen et al., 2001) para determinar quais casos de teste devem ser selecionados.

Este capítulo está dividido da seguinte forma. Na Seção 4.2 apresentam-se as condições de suficiência em que o algoritmo se baseia. Na Seção 4.3 ilustra-se o algoritmo de minimização proposto neste trabalho. São apresentados os passos e as características do algoritmo. Na Seção 4.4 um exemplo de minimização é apresentado. Na Seção 4.5 ilustra-se a redução do problema de se encontrar um conjunto state cover ao problema de se encontrar um clique em um grafo. Por fim, as limitações e os aspectos relacionados à implementação do algoritmo são apresentados nas Seções 4.6 e 4.7, respectivamente.

\subsection{Condições de Suficiência}

Petrenko et al. (1996) formularam algumas condições de suficiência relacionadas à completude de conjuntos de casos de teste (Seção 3.8). Dorofeeva et al. (2005b) propuseram condições de suficiência mais fracas, ou seja, em alguns casos, essas condições de suficiência podem determinar se um conjunto de teste é $m$-completo, enquanto que as condições definidas no trabalho de Petrenko et al. (1996) não determinariam.

Condições particulares são apresentadas para $m=n$, ou seja, quando a implementação e a especificação possuem o mesmo número de estados. As condições propostas por Dorofeeva et al. (2005b) para a $n$-completude de conjuntos de teste são sumarizadas no Teorema 1.

Teorema 1. (Dorofeeva et al., 2005b). Dada uma especificação determinística e reduzida M com n estados e um conjunto state cover $Q$, seja TS um conjunto finito de casos de teste que contém o conjunto $Q X \cap \Omega_{M}\left(s_{0}\right)$. O conjunto TS é n-completo se satisfaz as seguintes condições:

Cond1 Para cada par de estados distintos de $M$ que seja alcançável pelas seqüências $\alpha, \beta \in Q$, $T S$ possui as seqüências $\alpha \gamma$ e $\beta \gamma$ onde $\gamma$ é uma seqüência de separação para os estados $\delta\left(s_{0}, \alpha\right)$ e $\delta\left(s_{0}, \beta\right)$.

Cond2 Para cada transição definida $(s, x) \in D_{M}$, TS possui uma seqüência $\alpha x$ tal que $\delta\left(s_{0}, \alpha\right)=$ $s$, com as seguintes propriedades:

- Para cada estado alcançável por uma seqüência $\beta \in Q$, tal que $\delta\left(s_{0}, \beta\right) \neq s$, TS possui as seqüências $\alpha \gamma$ e $\beta \gamma$ onde $\gamma$ é uma seqüência de separação para os estados $s$ e $\delta\left(s_{0}, \beta\right)$. 
- Para cada estado alcançável por uma seqüência $\beta \in Q$, tal que $\delta\left(s_{0}, \beta\right) \neq \delta(s, x), T S$ possui as seqüências $\alpha x \gamma$ e $\beta \gamma$ onde $\gamma$ é uma seqüência de separação para os estados $\delta(s, x)$ e $\delta\left(s_{0}, \beta\right)$.

Com base nas condições de suficiência do Teorema 1, foi proposto um algoritmo para realizar a minimização de um conjunto de teste garantindo sua completude. No trabalho de Simão e Petrenko (2007), diversas formas de melhoria das condições de suficiência do Teorema 1 são propostas. No algoritmo de minimização foi usada a seguinte melhoria. Suponha que Cond2 é satisfeita para uma determinada transição $(s, x) \in D_{M}$. Suponha também que $\alpha \in Q$, tal que $\delta\left(s_{0}, \alpha\right)=s$. Então, na verificação subseqüente de Cond2, não apenas a seqüência $\alpha \in Q$, mas também a sequiência $\alpha x$ pode ser utilizada (Simão e Petrenko, 2007). Em outras palavras, após satisfazer Cond2, o conjunto state cover pode ser "estendido". Da mesma forma que Simão e Petrenko (2007), o conjunto estendido state cover será chamado de conjunto confirmado (representado como conjunto $K$ ). A melhoria utilizada no algoritmo é apresentada no Lema 1, mas com a utilização das notações definidas neste trabalho.

Lema 1 (Simão e Petrenko, 2007). Seja $K$ um conjunto confirmado e $\alpha \in$ pre $f(T)$. Se existem seqüências $\beta, \chi \in K$, tal que $\delta\left(s_{0}, \beta\right)=\delta\left(s_{0}, \chi\right)$ e uma seqüência $\omega$, tal que $\beta \omega \in K$ e $\chi \omega=\alpha$, então o conjunto $K \cup\{\alpha\}$ também é um conjunto confirmado.

\subsection{Algoritmo de Minimização}

O algoritmo possui duas entradas: uma $\operatorname{MEF} M=\left(S, s_{0}, X, Y, D_{A}, \delta, \lambda\right)$ e um conjunto de teste $T$. O conjunto de teste $T$ pode ser $n$-completo ou não. Se o conjunto de teste $T$ não for $n$-completo a minimização não ocorre, pois o conjunto $T$ não irá satisfazer as condições de suficiência. Se o conjunto de teste é $n$-completo tem-se duas possibilidades:

- A minimização não é realizada, pois o conjunto de teste $T$ não satisfaz as condições de suficiência.

- A minimização ocorre e um conjunto de teste $n$-completo $T^{\prime} \subseteq T$ é obtido.

Observa-se que, quando a minimização não ocorre, não se pode afirmar que o conjunto $T$ não é $n$-completo. $\mathrm{O}$ algoritmo possui três passos:

Passo 1: Um conjunto state cover $Q$ é selecionado de forma que $Q$ possa ser utilizado no Passo 2 para satisfazer Cond1. O algoritmo identifica um conjunto $Q \subseteq$ pre $f(T)$, tal que para cada par de seqüências $\alpha, \beta \in Q$ onde $\delta\left(s_{0}, \alpha\right) \neq \delta\left(s_{0}, \beta\right)$, há seqüências $\alpha \gamma, \beta \gamma \in \operatorname{pref}(T)$, tal que $\lambda\left(\delta\left(s_{0}, \alpha\right), \gamma\right) \neq \lambda\left(\delta\left(s_{0}, \beta\right), \gamma\right)$. Inicialmente $T^{\prime}=Q$. 
Passo 2: A adição de seqüências ao conjunto $T^{\prime}$ é realizada com o intuito de satisfazer Cond1. Para cada par de sequiências $\alpha, \beta \in Q$, onde $\delta\left(s_{0}, \alpha\right) \neq \delta\left(s_{0}, \beta\right)$, uma seqüiência de separação $\gamma$ é encontrada, tal que $\alpha \gamma, \beta \gamma \in \operatorname{pref}(T)$ e $\lambda\left(\delta\left(s_{0}, \alpha\right), \gamma\right) \neq \lambda\left(\delta\left(s_{0}, \beta\right), \gamma\right)$. As seqüências $\alpha \gamma, \beta \gamma$ são adicionadas ao conjunto $T^{\prime}$.

Passo 3: A adição de seqüências ao conjunto $T^{\prime}$ é realizada com o intuito de satisfazer Cond2. Seja $K$ o conjunto confirmado, inicialmente igual à $Q$. Para cada transição $(s, x) \in D_{M}$, as seqüências $\alpha, \beta \in K$, tal que $\delta\left(s_{0}, \alpha\right)=s$ e $\delta\left(s_{0}, \beta\right) \neq s$, e uma seqüência de separação $\gamma$, tal que $\lambda\left(\delta\left(s_{0}, \alpha x\right), \gamma\right) \neq \lambda\left(\delta\left(s_{0}, \beta\right), \gamma\right)$, são encontradas em pref $(T)$. As seqüências $\alpha x \gamma, \beta \gamma$ são adicionadas ao conjunto $T^{\prime}$. Desse modo, o conjunto confirmado $K$ é estendido.

A seguir, é demonstrado que os passos do algoritmo satisfazem as condições de suficiência. Para isso, torna-se necessário o estabelecimento de alguns lemas auxiliares.

\section{Lema 2 O Passo 1 sempre seleciona um conjunto state cover $Q$ que atende Cond1.}

Prova. No Passo 1, todas as seqüências $\alpha \in \operatorname{pref}(T)$ são consideradas para a composição do conjunto $Q$. Seja $n$ o número de estados da MEF. O conjunto $Q$ inicia-se com a seqüência vazia $\epsilon$. Para cada sequiência $\alpha \in \operatorname{pref}(T), \beta \in Q$ tal que $\delta\left(s_{0}, \alpha\right) \neq \delta\left(s_{0}, \beta\right)$ o algoritmo verifica se existem sequiências $\alpha \gamma, \beta \gamma \in \operatorname{pref}(T)$, tal que $\lambda\left(\delta\left(s_{0}, \alpha\right), \gamma\right) \neq \lambda\left(\delta\left(s_{0}, \beta\right), \gamma\right)$. Se existem tais sequiências, adiciona-se $\alpha$ ao conjunto $Q$. Esse procedimento é repetido até que $Q$ seja composto por $n$ sequiências de transferência. Se o conjunto state cover contiver $n$ sequiências de transferência significa que existe uma seqüência de separação $\gamma$ para todo par de seqüências contidas em $Q$ e, conseqüentemente, o conjunto $Q$ atenderá Cond1. Se não existe nenhum conjunto $Q \subseteq$ pref $(T)$ que atenda Cond1, o algoritmo termina.

\section{Lema 3 O Passo 2 sempre atende Cond1.}

Prova. Pelo Lema 2, após o Passo 1 sempre existe (no mínimo) uma seqüência $\gamma$ onde $\alpha \gamma, \beta \gamma \in \operatorname{pre} f(T)$, tal que $\lambda\left(\delta\left(s_{0}, \alpha\right), \gamma\right) \neq \lambda\left(\delta\left(s_{0}, \beta\right), \gamma\right)$ para todo $\operatorname{par} \alpha, \beta \in Q$ onde $\delta\left(s_{0}, \alpha\right) \neq$ $\delta\left(s_{0}, \beta\right)$. Desse modo, no Passo 2 sempre existirão seqüências $\alpha \gamma, \beta \gamma \in \operatorname{pref}(T)$ para serem adicionadas ao conjunto $T^{\prime}$ e que, conseqüentemente, atendem Cond1.

\section{Lema 4 O Passo 3 atende Cond2.}

Prova. No Passo 3, para cada transição $(s, x) \in D_{M}$, as seqüências $\alpha, \beta \in K$, tal que $\delta\left(s_{0}, \alpha\right)=s$ e $\delta\left(s_{0}, \beta\right) \neq s$, e uma seqüência de separação $\gamma$, tal que $\lambda\left(\delta\left(s_{0}, \alpha x\right), \gamma\right) \neq \lambda\left(\delta\left(s_{0}, \beta\right), \gamma\right)$ são encontradas em $\operatorname{pre} f(T)$. As seqüências $\alpha x \gamma, \beta \gamma$ são adicionadas ao conjunto $T^{\prime}$. Dessa forma, a segunda parte de Cond2 é atendida. Quando ocorre a seleção das seqüências $\alpha, \beta \in K$, tal que $\delta\left(s_{0}, \alpha\right)=s$ e $\delta\left(s_{0}, \beta\right) \neq s$, a primeira parte de Cond2 é atendida, pois se as sequiências $\alpha$ e $\beta$ estão contidas em $K$, significa que uma sequiência de separação $\gamma$, tal que $\lambda\left(\delta\left(s_{0}, \alpha\right), \gamma\right) \neq$ 
$\lambda\left(\delta\left(s_{0}, \beta\right), \gamma\right)$ já foi encontrada em pre $f(T)$. Desse modo, o conjunto $T^{\prime}$ obtido após o Passo 3 satisfaz Cond2. Se não é possível encontrar nenhuma seqüência $\gamma$ para atender Cond2, o algoritmo termina sem realizar a minimização.

Teorema 2 Os passos do algoritmo satisfazem as condições de suficiência.

Prova. Pelos Lemas 2 e 3, verifica-se que Cond1 é satisfeita pelos Passos 1 e 2 do algoritmo. Pelo Lema 4, Cond2 é satisfeita pelo Passo 3 do algoritmo. Dessa forma, o conjunto final $T^{\prime}$ produzido pelo algoritmo satisfaz as condições de suficiência Cond1 e Cond2.

Nas próximas seções serão descritos os passos do algoritmo.

\subsubsection{Seleção do State Cover}

No Passo 1, um conjunto state cover $Q \in \operatorname{pref}(T)$ deve ser selecionado. No entanto, o conjunto pre $f(T)$ pode conter diversos subconjuntos de casos de teste candidatos a state cover. No algoritmo de minimização, a seleção do conjunto $Q$ é realizada da seguinte forma. As seqüências de transferência para cada estado de $M$ são encontradas. Para o estado inicial $s_{0}$, a sequiência vazia $\epsilon$ é escolhida para que não ocorra um defeito de inicialização, como discutido a seguir. Para os demais estados, as menores seqüências de transferência são escolhidas de forma a atender Cond1. $\mathrm{O}$ algoritmo verifica se para cada par de seqüências $\alpha, \beta \in Q$, onde $\delta\left(s_{0}, \alpha\right) \neq \delta\left(s_{0}, \beta\right)$, há seqüências $\alpha \gamma, \beta \gamma \in \operatorname{pref}(T)$, tal que $\lambda\left(\delta\left(s_{0}, \alpha\right), \gamma\right) \neq \lambda\left(\delta\left(s_{0}, \beta\right), \gamma\right)$. As seqüências $\alpha \gamma, \beta \gamma$ são adicionadas ao conjunto $T^{\prime}$.

O problema para se encontrar um conjunto state cover em pref $(T)$ pode ser reduzido ao problema de se encontrar um clique em um grafo (Cormen et al., 2001), que por sua vez é um problema NP-completo (Garey e Johnson, 1979). Desse modo, soluções aproximadas devem ser utilizadas para se encontrar um conjunto state cover $Q$. A redução ao problema do clique é feita a partir de um grafo que representa o conjunto pref $(T)$. Cada vértice do grafo representa uma sequiência $\alpha \in \operatorname{pref}(T)$ e cada aresta representa a existência de uma seqüência de separação $\gamma$ entre as sequiências conectadas. A redução ao problema do clique será ilustrada na Seção 4.5.

\section{Seleção da seqüência vazia}

No algoritmo de minimização a seqüência vazia $\epsilon$ sempre é selecionada para compor o conjunto state cover. Essa seleção tem como objetivo garantir que a seqüência vazia $\epsilon$ esteja confirmada (isto é, $\epsilon \in K$ ) ao final do algoritmo e que o conjunto final $T^{\prime}$ seja $n$-completo. Se a seqüência vazia $\epsilon$ não estiver confirmada ao final do algoritmo, então essa seqüência não foi distinguida das sequiências que atingem os demais estados da MEF o que pode resultar em um defeito de inicialização. Em outras palavras, pode existir uma implementação que "responda" corretamente 
ao conjunto de teste produzido, mas que possua um estado inicial diferente ao da especificação. Desse modo, o conjunto de teste produzido pelo algoritmo não garantiria a completude dos testes.

Por exemplo, considere a MEF da Figura 4.1(a) e o conjunto de teste $n$-completo $T=\{r a b b b$, raabab, raabb, rbb\} de tamanho 19.

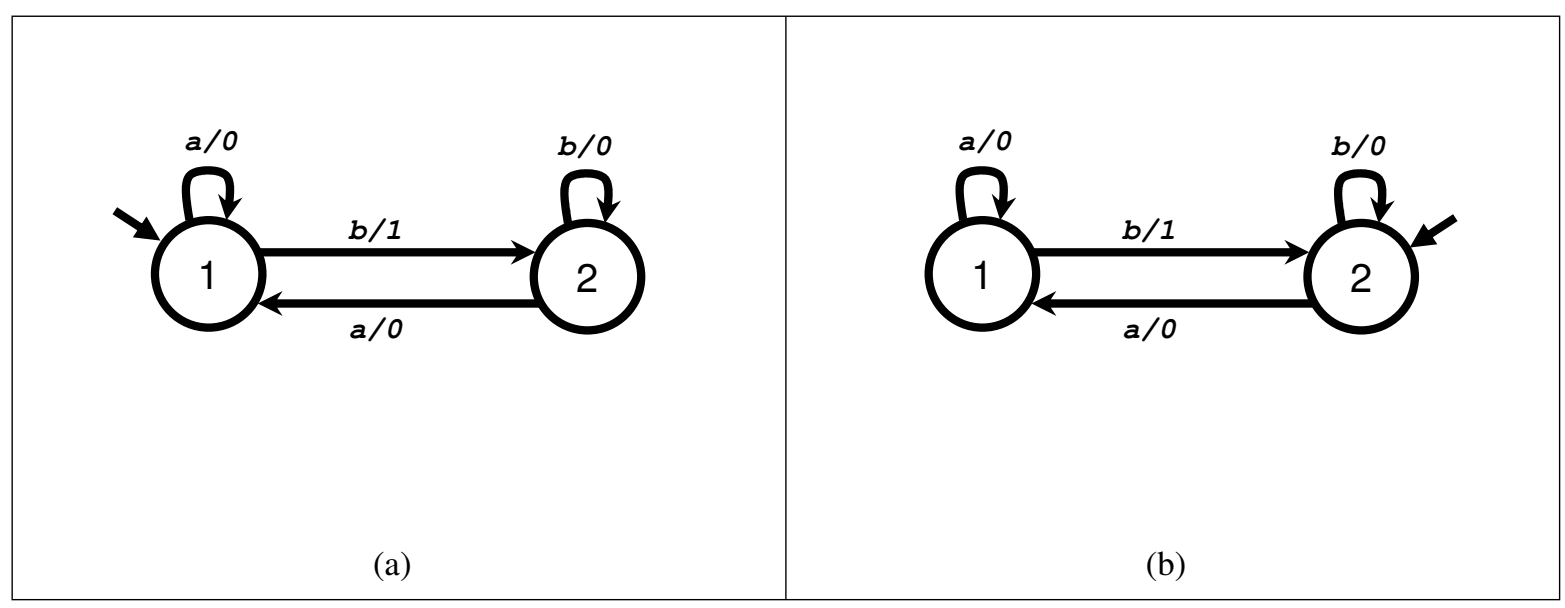

Figura 4.1: Defeito de Inicialização.

Suponha que, no Passo 1, o conjunto state cover $Q=\{r a$, raab $\}$ fosse selecionado pelo algoritmo de minimização. Ao final do algoritmo o conjunto obtido seria $T^{\prime}=\{r a b b b, r a a b a b$, raabb\}. O conjunto $T^{\prime}$ não é $n$-completo, pois existe uma implementação diferente da MEF da Figura 4.1(a) que "responde" corretamente para o conjunto $T^{\prime}$. Essa implementação é ilustrada na Figura 4.1(b). Observa-se que a única diferença é em relação ao estado inicial.

Como visto, se a seqüência $\epsilon$ não estiver confirmada ao final do algoritmo, o conjunto $T^{\prime}$ produzido pelo algoritmo não garante a detecção de defeito de inicialização da MEF. Dessa forma, a sequiência $\epsilon$ sempre é escolhida para compor o conjunto state cover para que, no Passo 2, ela seja confirmada.

\subsubsection{Verificação dos Estados}

No Passo 2, o conjunto $T^{\prime}$ é inicializado com as sequiências de $Q$. Após a seleção do conjunto $Q$, têm-se as seqüências $\alpha \gamma, \beta \gamma \in \operatorname{pref}(T)$ a serem adicionadas ao conjunto $T^{\prime}$ para satisfazer Cond1 e minimizar o custo. Seja $B \subset \Omega_{M}$ um conjunto de casos de teste. O custo adicional de $B$ em relação à $A$ é definido como $c_{A}(B)=w(A \cup B)-w(A)$, ou seja, o custo adicional é o tamanho adicional que o conjunto $B$ agrega em $A$. O algoritmo encontra uma sequiência $\gamma$, tal que $\alpha \gamma, \beta \gamma \in$ pref $(T)$ e o custo adicional de $\{\alpha \gamma, \beta \gamma\}$ em relação a $T^{\prime}$ seja minimizado. Uma estratégia baseada no algoritmo guloso (greedy algorithm) (Cormen et al., 2001) foi utilizada para selecionar as sequiências $\alpha \gamma, \beta \gamma \in \operatorname{pre} f(T)$. Essa estratégia realiza a melhor escolha local, ou seja, as seqüências selecionadas são as que resultam no menor custo adicional $c_{T^{\prime}}(\alpha \gamma, \beta \gamma)$. É importante salientar que essa escolha local pode não resultar em uma solução global ótima. Após a adição das seqüências $\alpha \gamma$ e $\beta \gamma$ à $T^{\prime}$, observa-se que Cond1 é satisfeita. 
O Passo 2 é implementado pelo Algoritmo 1. Na função Confirm- $Q$ as seqüências $\alpha \gamma$ e $\beta \gamma$ são adicionadas à $T^{\prime}$. O algoritmo da função Find-Gamma é ilustrado mais adiante na Seção 4.4. Essa função encontra uma seqüência de separação $\gamma$ entre duas sequiências passadas como parâmetro.

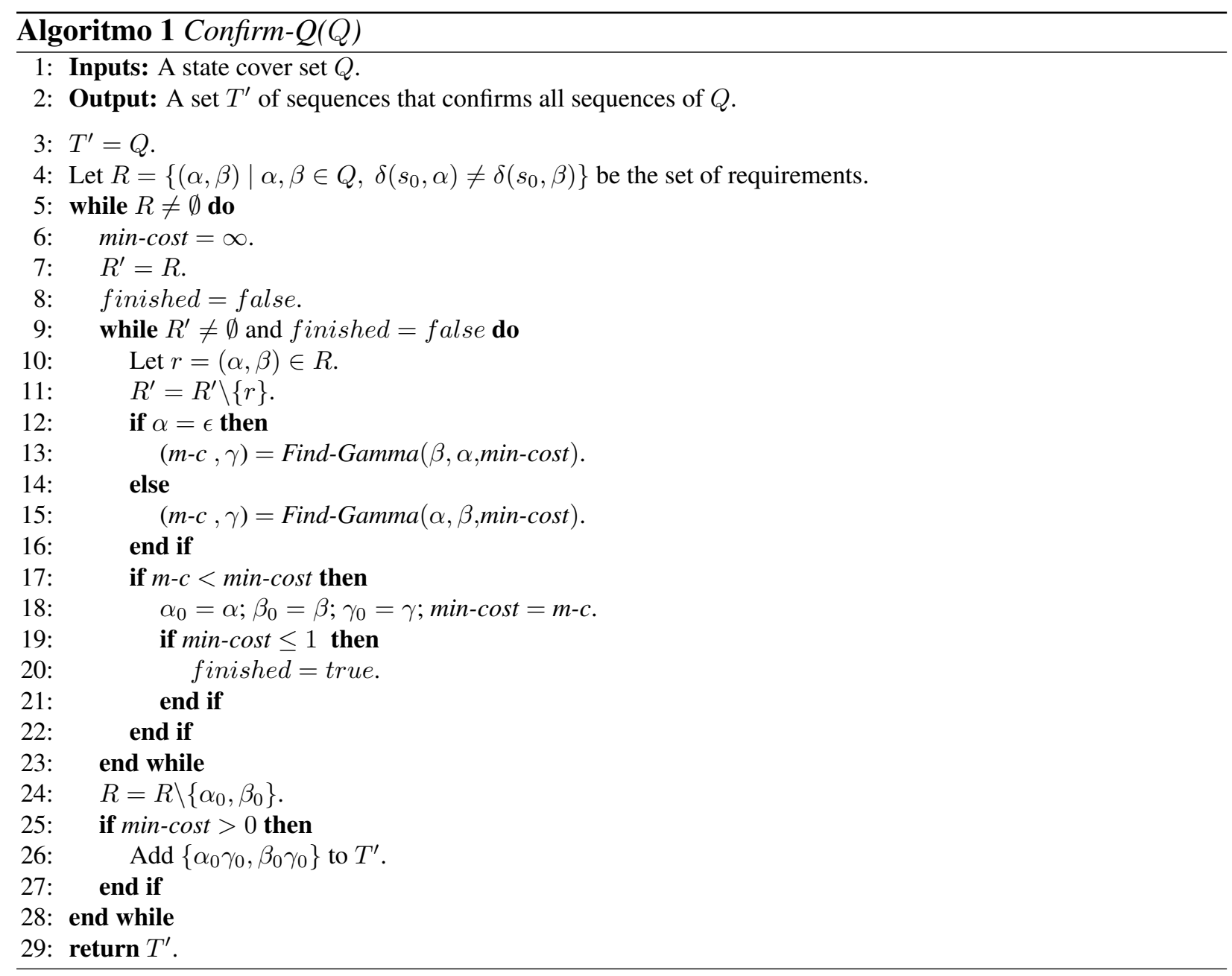

No Algoritmo 1 objetiva-se encontrar seqüências $\alpha \gamma, \beta \gamma \in \operatorname{pref}(T)$ e adicioná-las ao conjunto $T^{\prime}$. Inicialmente, o conjunto $T^{\prime}$ é inicializado com as seqüências do conjunto state cover $Q$ escolhido no Passo 1. Um conjunto de requisitos $R=\left\{(\alpha, \beta) \mid \alpha, \beta \in Q, \delta\left(s_{0}, \alpha\right) \neq \delta\left(s_{0}, \beta\right)\right\}$ é criado. Seja $R_{(\alpha, \beta)}$ um requisito de $R$. Para cada $R_{(\alpha, \beta)}$ uma sequiência $\gamma$, tal que $\alpha \gamma, \beta \gamma \in \operatorname{pre} f(T)$ é encontrada. Quando todos os requisitos são satisfeitos, conseqüentemente Cond1 é satisfeita.

Na Linha 6 um laço é iniciado e executado até que não existam requisitos em $R$. A variável min-cost representa o custo de se adicionar $\alpha \gamma$ e $\beta \gamma$ em $T^{\prime}$, ou seja, $c_{T^{\prime}}(\alpha \gamma, \beta \gamma)$. Uma cópia de $R$ é feita em $R^{\prime}$ e um segundo laço (Linhas 9 a 23) é iniciado. Para cada requisito $R_{(\alpha, \beta)}$ de $R^{\prime}$ a função Find-Gamma é invocada para se obter o custo adicional $(m-c)$ e a seqüência $\gamma$. Se $m-c$ for menor que o custo adicional encontrado até o momento (representado por min-cost) então os valores são armazenados, pois foi encontrado um custo adicional $c_{T^{\prime}}(\alpha \gamma, \beta \gamma)$ menor. Em seguida, se o custo adicional min-cost é menor ou igual a 1 então o custo adicional é o menor possível para o requisito $R_{(\alpha, \beta)}$ e os valores armazenados devem ser adicionados. Com isso, a variável finished é atualizada para verdadeiro, pois não há a necessidade de continuar o cálculo dos custos adicionais 
para os demais requisitos. Observa-se que nesse momento a estratégia gulosa é utilizada, pois o requisito escolhido para ser satisfeito é aquele que possuir o menor custo adicional $c_{T^{\prime}}(\alpha \gamma, \beta \gamma)$. Na Linha 24, o requisito é removido de $R$ e, em seguida, as seqüências $\alpha \gamma, \beta \gamma$ são adicionadas ao conjunto $T^{\prime}$. Esse procedimento é repetido até que todos os requisitos sejam satisfeitos.

\subsubsection{Verificação das Transições}

No Passo 3, um conjunto $R=\left\{\left(s, x, s^{\prime}\right) \mid s, s^{\prime} \in S, x \in X, \delta(s, x) \neq s^{\prime}\right\}$ de requisitos é criado. Esses requisitos representam os elementos que devem ser considerados para satisfazer Cond2. Para uma determinada transição $(s, x) \in D_{M}$, seja $R_{(s, x)} \subseteq R$ o conjunto de requisitos $\left(s, x, s^{\prime}\right)$, para algum $s^{\prime} \in S$. Para cada requisito $r=\left(s, x, s^{\prime}\right) \in R$, o algoritmo encontra em pref $f(T)$ seqüências $\alpha, \beta \in K$, tais que $\delta\left(s_{0}, \alpha\right)=s$ e $\delta\left(s_{0}, \beta\right)=s^{\prime}$, e uma seqüência de separação $\gamma$, tal que $\lambda\left(\delta\left(s_{0}, \alpha x\right), \gamma\right) \neq \lambda\left(\delta\left(s_{0}, \beta\right), \gamma\right)$. Quando todos os requisitos de $R_{(s, x)}$ são satisfeitos, conseqüentemente Cond2 é satisfeita para $(s, x)$. O algoritmo pode encontrar diversas seqüências $\alpha x \gamma$ e $\beta \gamma$ para cada requisito de $R$. Para a escolha dessas sequiências, uma estratégia gulosa também foi utilizada. Desse modo, as seqüências adicionadas ao conjunto $T^{\prime}$ são as que resultam em um menor custo adicional $c_{T^{\prime}}(\alpha x \gamma, \beta \gamma)$. Em seguida, o requisito $r$ é removido de $R$. Se $R_{(s, x)} \cap R=\emptyset$, ou seja, Cond2 é satisfeita para $(s, x)$, então $K$ é estendido da seguinte maneira. Para cada $\alpha \in K$, tal que $\delta\left(s_{0}, \alpha\right)=s$ e $\alpha x \in \operatorname{pre} f(T)$, a seqüência $\alpha x$ é adicionada ao conjunto $K$. Essa análise é repetida até que nenhuma nova seqüência possa ser adicionada em $K$ (Simão e Petrenko, 2007).

O Passo 3 é implementado pelo Algoritmo 2 que contém as etapas principais da minimização.

Na Linha 6, o Passo 1 do algoritmo é realizado, ou seja, um procedimento é chamado para que um conjunto state cover $Q$ seja selecionado. Na Linha 7, o Passo 2 do algoritmo é realizado, ou seja, o procedimento confirm- $Q$ é chamado. Inicialmente, as seqüências do state cover $Q$ são adicionadas ao conjunto confirmado $K$ (Linha 8). No trecho de código entre as Linhas 10 e 32 ocorre a verificação de Cond2. A variável min-cost representa o custo adicional $c_{T^{\prime}}(\alpha x \gamma, \beta \gamma)$. Quando o conjunto state cover selecionado é inapropriado para realizar a minimização, a variável badQ recebe o valor verdadeiro. A variável finished recebe o valor verdadeiro quando o requisito encontrado possui o menor custo adicional possível, ou seja, quando min-cost $\leq 1$ (Linha 25). Nesse momento, a busca por seqüências $\alpha x \gamma$ e $\beta \gamma$ não continua, pois o menor custo adicional foi encontrado para um determinado requisito e tais seqüências devem ser adicionadas ao conjunto $T^{\prime}$. Observa-se que nesse momento a estratégia gulosa é utilizada, pois o requisito escolhido para ser satisfeito é aquele que possuir o menor custo adicional $c_{T^{\prime}}(\alpha x \gamma, \beta \gamma)$.

Na Linha 9, um laço é iniciado para cada requisito $r=\left(s, x, s^{\prime}\right)$ de $R$. São encontradas seqüências $\alpha, \beta \in K$, tais que $\delta\left(s_{0}, \alpha\right)=s$ e $\delta\left(s_{0}, \beta\right)=s^{\prime}$ (Linha 14). O custo adicional $c_{T^{\prime}}(\alpha x \gamma, \beta \gamma)$ e uma seqüência de separação $\gamma$, tal que $\lambda\left(\delta\left(s_{0}, \alpha x\right), \gamma\right) \neq \lambda\left(\delta\left(s_{0}, \beta\right), \gamma\right)$ são encontrados (Linha 21). Se $m$ - $c$ for menor que o custo adicional encontrado até o momento (representado por min-cost) então os valores para o requisito $r$ são armazenados (Linha 23). Uma vez encontrados os valores 


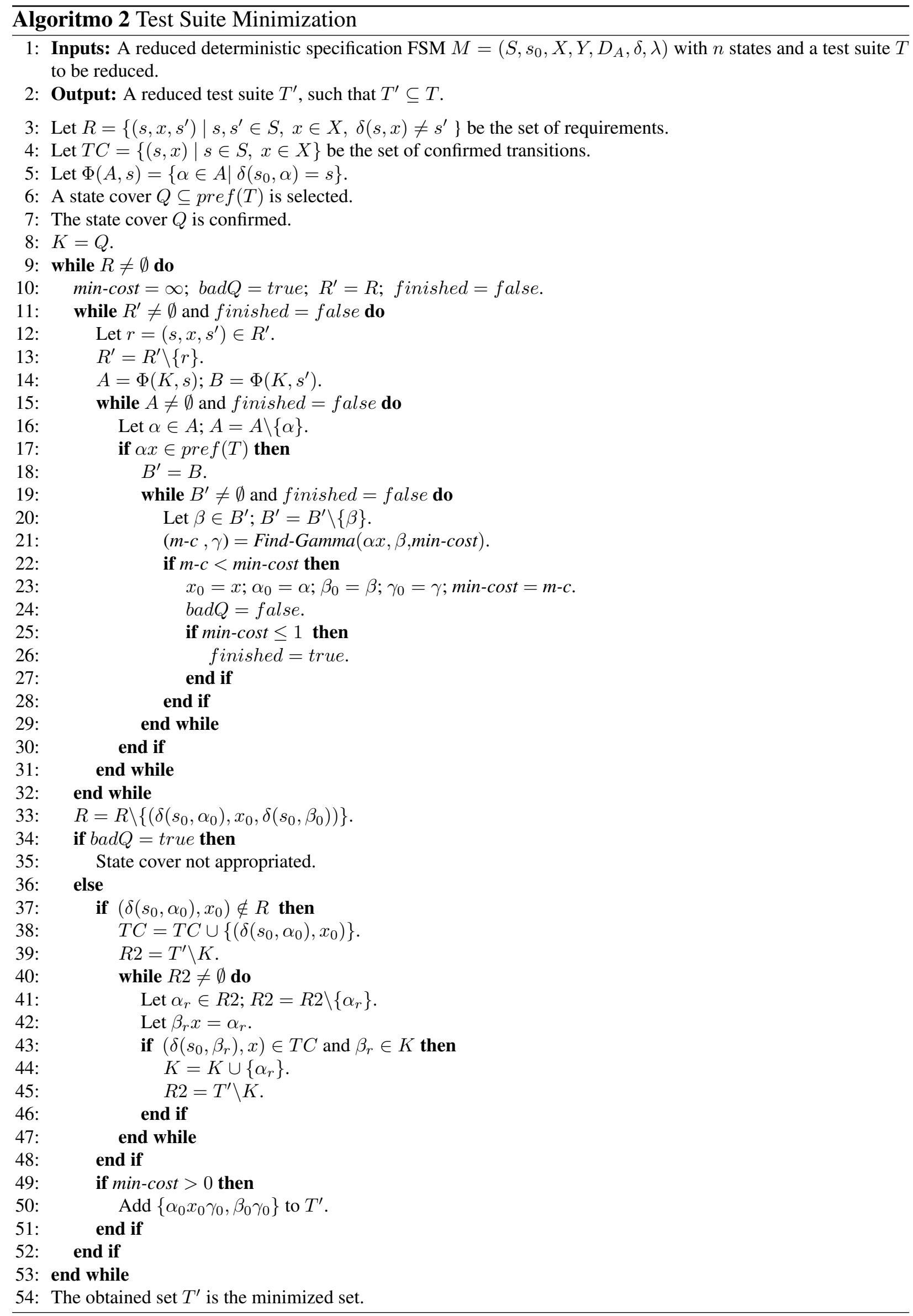


para o requisito $r$, retira-se $r$ de $R$ (Linha 33). Se a adição de $\alpha x \gamma$ e $\beta \gamma$ ao conjunto $T^{\prime}$ resultar em um custo adicional maior que zero (Linha 49), então essas seqüências são adicionadas. Se min-cost $=0$ significa que as seqüências $\alpha x \gamma$ e $\beta \gamma$ já estão em $T^{\prime}$ e não precisam ser adicionadas.

O código entre as Linhas 37 e 48 refere-se à melhoria proposta no trabalho de Simão e Petrenko (2007), ou seja, quando o conjunto confirmado $K$ é estendido. Se a transição $\left(\delta\left(s_{0}, \alpha_{0}\right), x_{0}\right) \notin R$, então significa que Cond2 é satisfeita para essa transição. A transição é adicionada ao conjunto $T C$ de transições confirmadas. Para cada sequiência $\alpha_{r}$ de $T^{\prime}$ que ainda não está confirmada, o algoritmo verifica se é possível confirmá-la para então adicioná-la ao conjunto confirmado $K$. A partir de $\alpha_{r}$, verifica-se a existência de um prefixo $\beta_{r}$, tal que $\beta_{r} x=\alpha_{r}$. Se a transição $\left(\delta\left(s_{0}, \beta_{r}\right), x\right)$ está confirmada $(\beta x \in K)$ e a sequiência $\beta_{r}$ pertence ao conjunto confirmado $K$, então a sequiência $\alpha_{r}$ também pode ser confirmada (Lema 1). Dessa forma, na verificação subseqüente de Cond2 a seqüência $\alpha_{r}$ pode ser utilizada. O conjunto final $T^{\prime}$ é obtido após todos os requisitos serem satisfeitos.

Com a expansão do conjunto state cover o algoritmo não seleciona apenas as sequiências $\alpha, \beta \in Q$, mas seleciona as seqüências $\alpha$ e $\beta$ do conjunto confirmado $K$. Com isso, existem mais sequiências $\alpha$ e $\beta$ para o algoritmo selecionar com o intuito de atender Cond2, o que pode melhorar o resultado da minimização.

\subsection{Exemplo de Minimização}

Para exemplificar a utilização do algoritmo de minimização, considere a MEF da Figura 3.2 e o conjunto $T=\{r x x y$, rxyyy, ryxy, ryyxx, ryyyyyy, rxxxyxyyy $\}$ de tamanho 34. No Passo 1 , o algoritmo de minimização procura selecionar seqüências de menor tamanho de forma a satisfazer Cond1. O algoritmo seleciona o conjunto state cover $Q=\{\epsilon, r y, r x$, ryy $\}$. O conjunto $T^{\prime}$ é inicializado com as sequiências de $Q$.

No Passo 2, a adição de sequiências $\alpha \gamma$ e $\beta \gamma$ é realizada. Por exemplo, para o par $(\alpha, \beta)=$ $(\epsilon, r x)$, o algoritmo encontra $\gamma=x$ de forma que $r x$ e $r x x$ são adicionadas à $T^{\prime}$. Para os pares $(\epsilon, r y),(r x, r y y),(r x, r y),(r y, r y y),(\epsilon, r y y)$ foram adicionadas as sequiências (ry, ryy), $(r x x, r y y x),(r x x, r y x),(r y y$, ryyy), (ryy, ryyyy), respectivamente. Ao final do Passo 2, é obtido o conjunto $T^{\prime}=\{r x x, r y x$, ryyx, ryyyy $\}$ de tamanho 15 .

Por fim, no Passo 3, a adição de seqüências $\alpha x \gamma$ e $\beta \gamma$ é realizada. Por exemplo, para o requisito $(S 3, x, S 1)$, o algoritmo encontra $\alpha=x, \beta=\epsilon, \gamma=y$ de forma que $r x x y$ e $r y$ são adicionadas à $T^{\prime}$. Ao final do Passo 3 , o algoritmo obteve como resultado o conjunto $n$-completo $T^{\prime}=\{$ rxxy, rxyyy, ryxy, ryyxx, ryyyyyy $\}$ de tamanho 25 .

É interessante observar que o algoritmo poderia produzir resultados diferentes se um outro conjunto state cover $Q$ fosse selecionado. Por exemplo, considere a mesma MEF da Figura 3.2 e o mesmo conjunto $T$. Considere também que o conjunto state cover $Q=\{\epsilon$, ry, rxxxyx, ryy $\}$ foi o conjunto escolhido no Passo 1 . O conjunto $T^{\prime}$ é inicializado com as sequiências de $Q$. 
No Passo 2, para os pares $(\epsilon, r y),(r y, r y y),(\epsilon, r y y),(r x x x y x, r y)$, e $(\epsilon, r x x x y x)$, são adicionadas as seqüências (ry, ryy), (ryy, ryyy), (ryy, ryyyy), (rxxxyxy, ryy), e (ryy, rxxxyxyy), respectivamente. Nesse momento, tem-se $T^{\prime}=\{$ ryyyy, rxxxyxyy $\}$. Para o par $(r y y, r x x x y x)$ tem-se, por exemplo, seqüências $\gamma=x \mathrm{e} \gamma=y y y$ como possíveis sequiências de separação. No entanto, o algoritmo seleciona $\gamma=$ yyy de maior tamanho e adiciona (ryyyyy, rxxxyxyyy) à $T^{\prime} \operatorname{com} c_{T^{\prime}}(\{$ ryyyyy, $r x x x y x y y y\})=2$. Isso ocorre, pois com $\gamma=x$ seriam adicionadas as sequiências $(r y y x, r x x x y x x)$, mas com $c_{T^{\prime}}(\{r y y x, r x x x y x x\})=11$. Ao final do Passo 2, o conjunto obtido é $T^{\prime}=\{$ ryyyyy, rxxxyxyyy $\}$ de tamanho 15 .

No Passo 3, após as adição de sequiências para atender aos requisitos de $R$, o resultado obtido é o conjunto $n$-completo $T^{\prime}=\{$ rxy, ryyyyyy, rxxxyxyy $\}$ de tamanho 19 .

Percebe-se que a escolha de um conjunto state cover $Q$ é importante, pois pode resultar em um conjunto $n$-completo de menor tamanho. Para a MEF da Figura 3.2, o algoritmo obteve um melhor resultado mesmo com um conjunto $Q$ de tamanho maior.

\subsection{Redução ao Problema do Clique}

O problema de selecionar um conjunto state cover $Q \in \operatorname{pref}(T)$ pode ser reduzido ao problema de se encontrar um clique em um grafo, que por sua vez é um problema NP-completo. Desse modo, a seleção de um conjunto state cover é também um problema NP-completo. Um clique de um grafo $G$ é um subconjunto de vértices onde cada vértice possui ligação com os demais, ou seja, é um subgrafo completo de $G$.

A redução ao problema do clique pode ser ilustrada como segue. A partir de um conjunto $T$, pode-se construir um grafo que representa o conjunto pre $f(T)$. Cada vértice do grafo representa uma sequiência $\alpha \in \operatorname{pref}(T)$. Sejam $a$ e $b$ dois vértices que representam as sequiências $\alpha$ e $\beta$, respectivamente. Se no grafo há uma aresta que conecta os vértices $a$ e $b$, então significa que no conjunto pref $(T)$ existe uma seqüência de separação entre $\alpha$ e $\beta$, ou seja, há uma sequiência $\gamma$ tal que $\alpha \gamma, \beta \gamma \in \operatorname{pref}(T)$ e $\lambda\left(\delta\left(s_{0}, \alpha\right), \gamma\right) \neq \lambda\left(\delta\left(s_{0}, \beta\right), \gamma\right)$.

Após a construção, um grafo $k$-partido é obtido. Um grafo $k$-partido (Garey e Johnson, 1979) é um grafo que pode ser dividido em $k$ conjuntos disjuntos sendo que os vértices de um mesmo conjunto não possuem arestas entre si. O grafo $k$-partido possui $k$ conjuntos, tal que $k=n$ onde $n$ é a quantidade de estados da MEF. Isso ocorre, pois todas as sequiências que atingem o mesmo estado não possuem arestas entre si. Desse modo, ao encontrar um clique no grafo $k$-partido, um conjunto state cover é encontrado.

Por exemplo, considere o conjunto $T=\{r x x y$, rxyyy, ryxy, ryyx $x$, ryyyy $\}$ de tamanho 23 para a MEF da Figura 3.2. Na Figura 4.2 é ilustrado o grafo 4-partido que representa o conjunto $\operatorname{pref}(T)$.

Observa-se que o grafo possui quatro conjuntos. Cada conjunto é formado pelas sequiências que atingem um determinado estado da MEF. Com isso, nota-se que as seqüências de um mesmo 


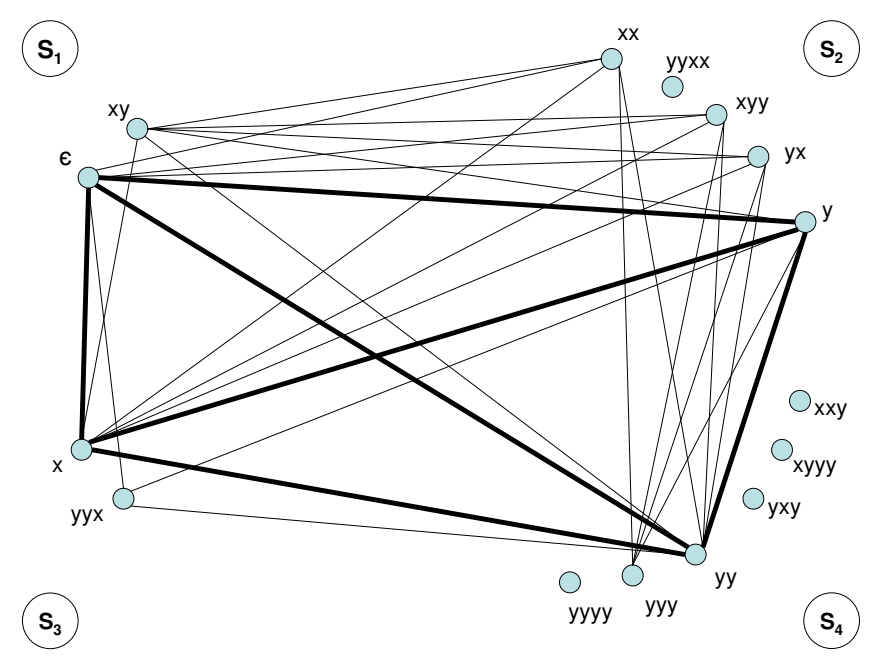

Figura 4.2: Representação de $\operatorname{pre} f(T)$ com o grafo 4-partido.

conjunto não possuem ligações entre si, pois não existe uma seqüência de separação $\gamma$ entre elas. No grafo estão ilustradas todas as ligações existentes entre os nós. Observa-se que há seqüências que não possuem nenhuma ligação. Essas seqüências não são prefixos de nenhuma outra seqüência $\alpha \in \operatorname{pref}(T)$ e, por isso, não há como encontrar uma seqüência de separação $\gamma$. O clique em destaque, formado pelas seqüências $\{\epsilon, x, y, y y\}$, representa um possível conjunto state cover.

Em um conjunto de teste podem existir diversos conjuntos candidatos a serem selecionados como state cover. O algoritmo de minimização procura selecionar um conjunto state cover formado com as seqüências de menor tamanho e que, ao mesmo tempo, satisfaça Cond1. Para o exemplo da Figura 4.2, o algoritmo seleciona exatamente o conjunto state cover $Q$ formado pelas sequiências $\{\epsilon, x, y, y y\}$.

\subsection{Limitações do Algoritmo}

Um ponto a considerar é que o conjunto state cover $Q$, selecionado no Passo 1, pode não ser apropriado para os próximos passos do algoritmo. Há situações em que o conjunto selecionado $Q$ não satisfaz as condições de suficiência, enquanto um outro conjunto poderia satisfazê-las. Uma solução seria encontrar todos os possíveis conjuntos state cover e executar o algoritmo com cada um deles. Essa solução, porém, apenas seria viável se houvesse uma pequena quantidade de conjuntos candidatos a state cover. A solução utilizada no algoritmo foi de selecionar as menores sequiências de transferência para compor o conjunto state cover. Se esse conjunto não é apropriado para os próximos passos, o algoritmo termina sem realizar a minimização. Para ilustrar um exemplo em que a minimização não ocorre, considere a MEF da Figura 4.1(a) e o conjunto de teste $n$-completo $T=\{r a b b b, r a a b a b, r a a b b, r b b\}$ de tamanho 19. 
No Passo 1, o algoritmo de minimização seleciona o conjunto state cover $Q=\{\epsilon, r b\}$. No Passo 2, a seqüência $r b b$ é adicionada para satisfazer Cond1. No Passo 3, as transições $(1, a)$ e $(1, b)$ são satisfeitas com a adição da seqüência $r a b$. Nesse momento, tem-se $T^{\prime}=\{r a b, r b b\}$ e $K=\{\epsilon, r a, r b\}$. Em seguida a transição $(2, a)$ não pode ser satisfeita no Passo 3, pois não há seqüências $\alpha, \beta \in K$, tal que $\delta\left(s_{0}, \alpha\right)=s$ e $\delta\left(s_{0}, \beta\right) \neq s$, e uma seqüência de separação $\gamma$, tal que $\lambda\left(\delta\left(s_{0}, \alpha x\right), \gamma\right) \neq \lambda\left(\delta\left(s_{0}, \beta\right), \gamma\right)$. Com isso, o algoritmo termina sem realizar a minimização.

\subsection{Aspectos de Implementação}

Como dito anteriormente, o algoritmo de minimização é executado a partir de um conjunto de teste inicial $T$. Desse modo, a minimização ocorre apenas com as sequiências existentes em $T$, ou seja, a minimização não encontra uma seqüência $\alpha \notin T$, mesmo que essa seqüência possa produzir um conjunto $T^{\prime} n$-completo menor.

Com isso, o algoritmo constrói uma estrutura de árvore para a representação do conjunto de teste $\operatorname{pref}(T)$ e realiza a minimização somente a partir dessa estrutura. O conjunto de teste pre $f\left(T^{\prime}\right)$ também é representado por uma árvore criada da seguinte forma. Os nós representam os estados da MEF $M$. O nó raiz representa o estado inicial $s_{0}$. As arestas representam as entradas. Cada caminho do nó raiz até um nó folha representa uma seqüência de $T^{\prime}$. Na Figura 4.3 um conjunto de teste $T^{\prime}=\{r x x y$, rxyyy, ryxy, ryyxx, ryyyyyy, rxxxyxyyy $\}$ de tamanho 34 é representado por uma árvore. Observa-se que o tamanho de pre $f(T)$, representado por $\mid$ pre $f(T) \mid$, corresponde ao número de nós da árvore.

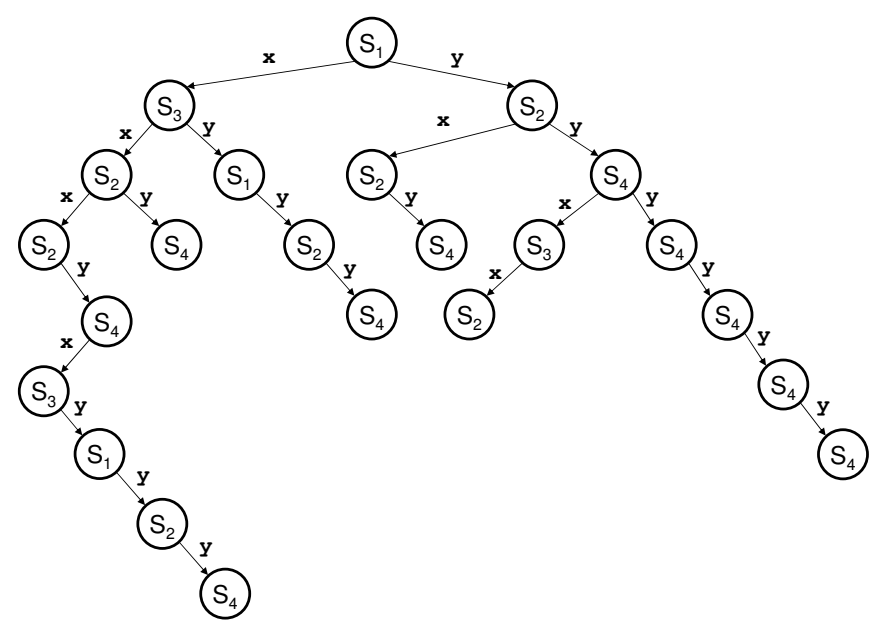

Figura 4.3: Representação do conjunto de teste por meio de uma árvore.

A árvore é utilizada para calcular o custo adicional que uma seqüência produz ao ser adicionada ao conjunto $T^{\prime}$. Para exemplificação, considere o conjunto de teste $T^{\prime}$ ilustrado na Figura 4.3 e as seqüências $\{r x x x, r y y y x x, r x x y y, r y x x\}$ a serem adicionadas.

Seja $d(\alpha)$ a profundidade de um nó atingido pela seqüência $\alpha$. Seja $\alpha x$ a seqüência a ser adicionada em $T^{\prime}$. O custo adicional $c_{T^{\prime}}(\{\alpha x\})$ é calculado como segue. Se $\alpha x \in \operatorname{pref}\left(T^{\prime}\right)$ então 
$c_{T^{\prime}}(\{\alpha x\})=0$, pois o conjunto de teste $T^{\prime}$ já contém a seqüência $\alpha x$ e não há a necessidade de se adicionar nenhum nó à árvore. Por exemplo, a sequiência $r x x x \in \operatorname{pre} f\left(T^{\prime}\right)$, portanto o custo adicional $c_{T^{\prime}}(\{r x x x\})=0$.

Se $\alpha x \notin$ pref $f\left(T^{\prime}\right)$ e $\alpha \notin$ pref $f\left(T^{\prime}\right)$ então $c_{T^{\prime}}(\{\alpha x\})=c_{T^{\prime}}(\alpha)+1$. O valor 1 representa o tamanho de $x$, pois esse é o custo para se adicionar $x$ ao final da seqüência $\alpha$. Por exemplo, a seqüência ryyyx $\notin \operatorname{pre} f\left(T^{\prime}\right)$ e seu prefixo ryyyx $\notin \operatorname{pref}\left(T^{\prime}\right)$ então $c_{T^{\prime}}(\{$ ryyyx $x\})=c_{T^{\prime}}(\{$ ryyyx $\})+1$, ou seja, $c_{T^{\prime}}(\{\operatorname{ryyyx} x\})=5+1=6$.

Para $\alpha x \notin \operatorname{pref}\left(T^{\prime}\right)$ e $\alpha \in \operatorname{pre} f\left(T^{\prime}\right)$ tem-se duas possibilidades: se $\alpha$ atinge um nó folha de pref $\left(T^{\prime}\right)$ então $c_{T^{\prime}}(\{\alpha x\})=1$, senão $c_{T^{\prime}}(\{\alpha x\})=d(\alpha)+1$. No primeiro caso, $\alpha$ atinge um nó folha, ou seja, somente $x$ deve ser adicionado ao final da sequiência $\alpha \in \operatorname{pre} f\left(T^{\prime}\right)$, por isso o custo adicional é 1. Por exemplo, a seqüência $r x x y y \notin \operatorname{pre} f\left(T^{\prime}\right)$ e seu prefixo $\operatorname{rxxy} \in \operatorname{pre} f\left(T^{\prime}\right)$. No entanto, a seqüência $r x x y$ atinge um nó folha, portanto o custo adicional $c_{T^{\prime}}(\{r x x y y\})=1$. No segundo caso, $\alpha$ não atinge um nó folha, ou seja, a seqüência inteira $\alpha x$ deve ser adicionada ao conjunto $T^{\prime}$. Isso significa que um novo caminho a partir do nó raiz até o nó atingido pela sequiência $\alpha x$ precisa ser adicionado à árvore. Desse modo, o custo adicional é calculado pela soma $d(\alpha)+1$, onde o valor 1 representa o tamanho de $x$. Por exemplo, a sequiência $r y x x \notin \operatorname{pref}\left(T^{\prime}\right)$ e seu prefixo $r y x \in \operatorname{pre} f\left(T^{\prime}\right)$. No entanto, a seqüência $r y x$ não atinge um nó folha, portanto o custo adicional $c_{T^{\prime}}(\{r y x x\})=d($ ry $x)+1$, ou seja, $c_{T^{\prime}}(\{r y x x\})=3+1=4$.

No Algoritmo 3 é ilustrada a função que calcula o custo adicional $c_{T^{\prime}}(\{\alpha x\})$.

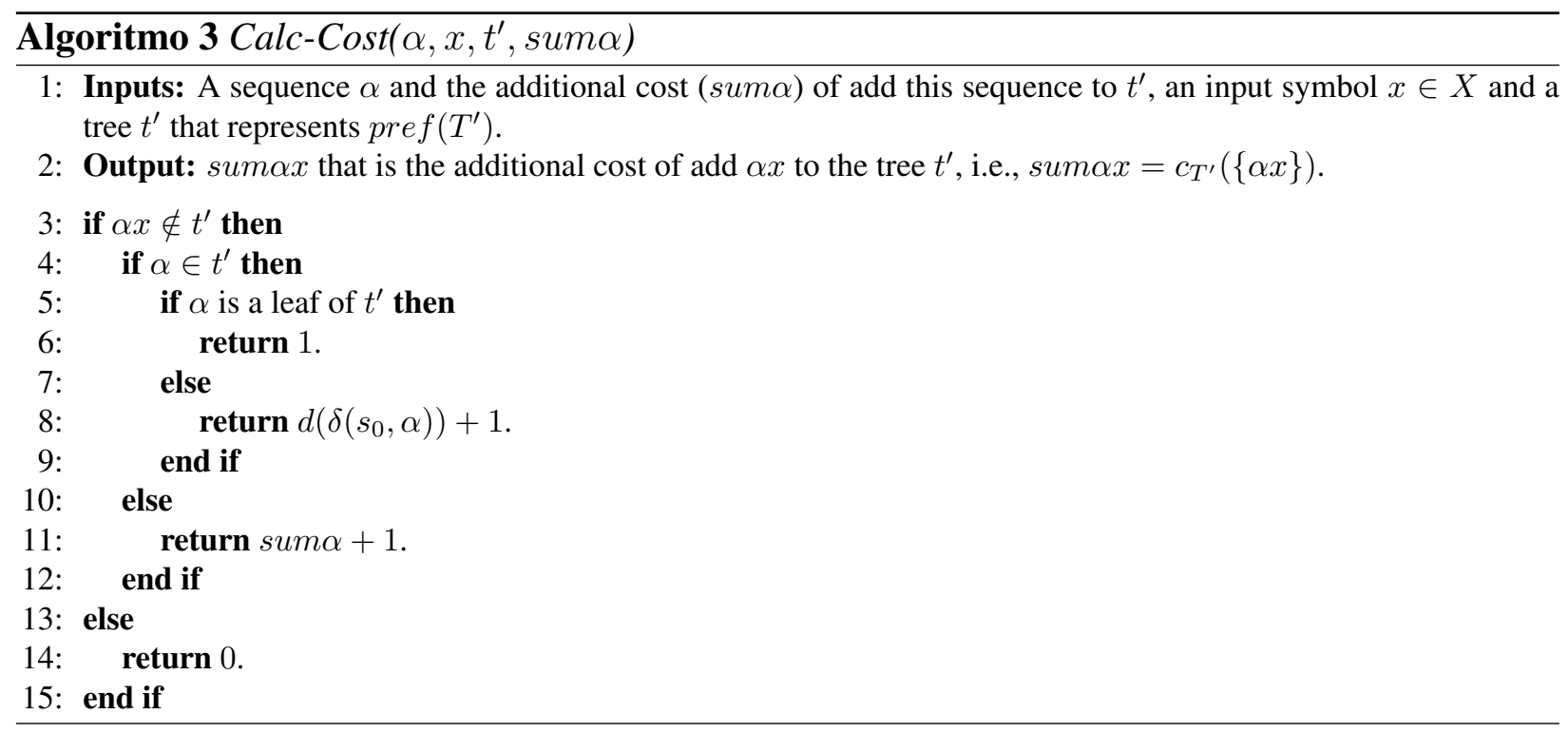

A representação dos casos de teste em uma árvore também é útil para se encontrar uma sequiência de separação $\gamma$ entre as seqüências $\alpha, \beta \in T$. A seqüência $\gamma$ é encontrada por uma busca em largura apresentada no Algoritmo 4. A tupla $\left(\alpha, c_{T^{\prime}}(\alpha), \beta, c_{T^{\prime}}(\beta)\right)$ é adicionada à fila $F$. Enquanto $F \neq \emptyset$, verifica-se para cada entrada $x \in X$, tal que $\alpha x, \beta x \in \operatorname{pre} f(T)$, se $\gamma$ é uma sequiência de separação para $\alpha$ e $\beta$. Se $\gamma$ é uma sequiência de separação então $\gamma$ é selecionada, senão a tupla $\left(\alpha x, c_{T^{\prime}}(\alpha x), \beta x, c_{T^{\prime}}(\beta x)\right)$ é adicionada à fila $F$. No Algoritmo 4 considera-se o valor de min-cost 
que representa a menor soma $c_{T^{\prime}}(\{\alpha \gamma\})+c_{T^{\prime}}(\{\beta \gamma\})$ encontrada até o momento. Dessa forma, a seqüência de separação $\gamma$ selecionada é aquela que produz o menor custo adicional.

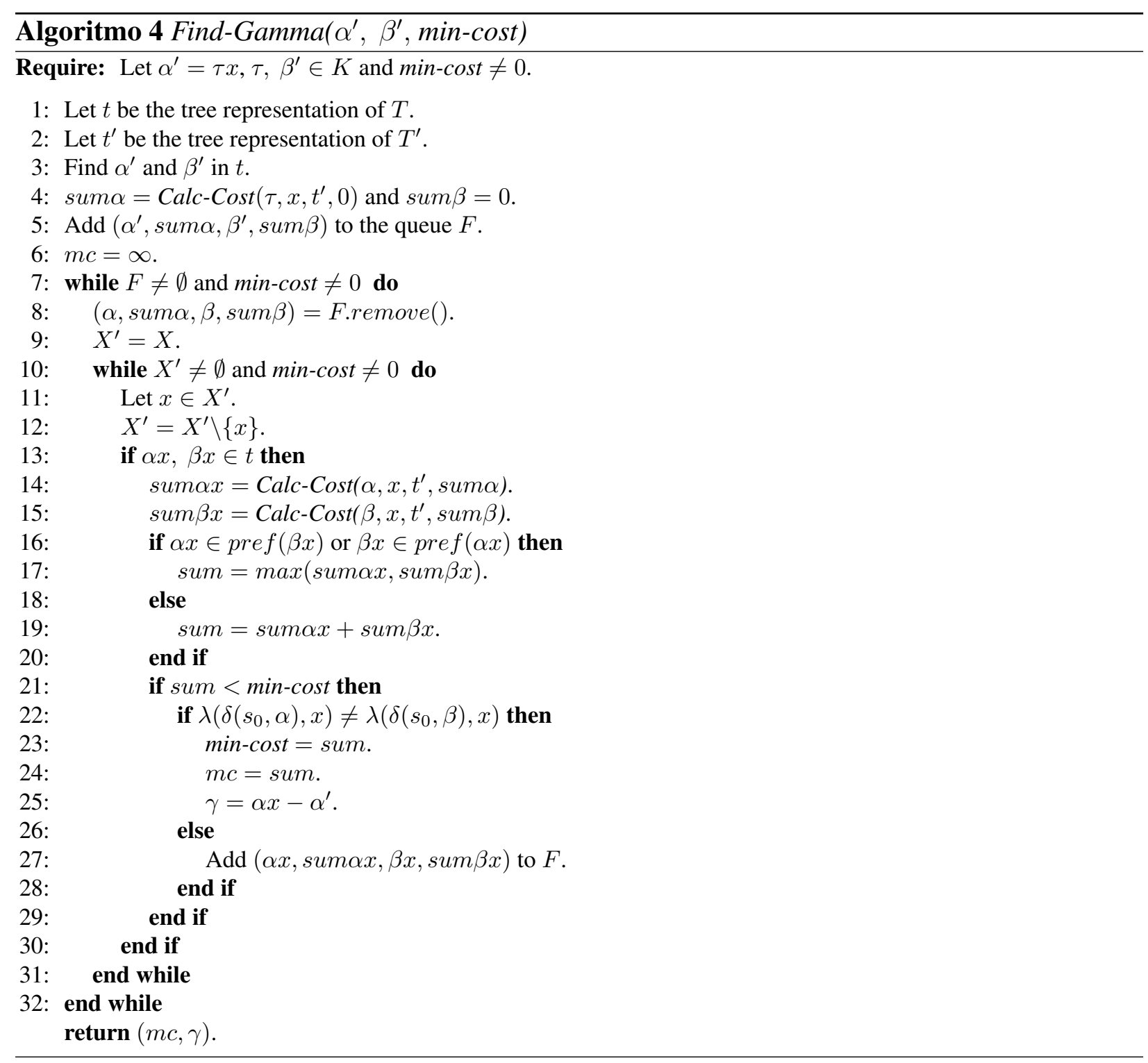

\subsection{Complexidade}

Nesta seção, uma análise da complexidade do algoritmo de minimização é realizada. Abordase a complexidade em relação ao tempo com a utilização da notação $O()$, ou seja, assume-se o pior caso durante a execução do algoritmo.

Seja $n$ o número de estados da MEF e $k$ o número de entradas. Como dito anteriormente, a seleção de um conjunto state cover é um problema NP-completo. Assim, o Passo 1 não é executado em tempo polinomial.

O Passo 2 é implementado pela função Confirm- $Q$. Um conjunto de requisitos $R=\{(\alpha, \beta) \mid \alpha, \beta \in$ $\left.Q, \delta\left(s_{0}, \alpha\right) \neq \delta\left(s_{0}, \beta\right)\right\}$ é criado. O conjunto $R$ é composto pela combinação de pares de seqüên- 
cias que formam o conjunto state cover $Q$. Observa-se que o conjunto $R$ possui tamanho $t=\frac{n^{2}-n}{2}$. Um conjunto auxiliar $R^{\prime}$ criado possui o mesmo tamanho que $R$ possuir em cada execução do laço. Em cada execução, um requisito do conjunto $R$ é retirado. Dessa forma, tem-se $\frac{t^{2}+t}{2}$ execuções. Realizando as respectivas substituições, o número máximo de execuções é $\frac{n^{4}-2 n^{3}+3 n^{2}-2 n}{8}=O\left(n^{4}\right)$. Para cada execução, há uma chamada da função Find-Gamma. Essa função encontra uma seqüência de separação $\gamma$ entre duas sequiências passadas como parâmetro. A busca pelo $\gamma$ é realizada nos nós da árvore criada. Seja $p=\mid$ pre $f(T) \mid$ o número de nós da árvore. Desse modo, tem-se $O(p)$. Pela propriedade da multiplicação, tem-se $O\left(n^{4}\right) O(p)=O\left(n^{4} p\right)$.

O Passo 3 é implementado pelo Algoritmo 2. Um conjunto de requisitos $R=\left\{\left(s, x, s^{\prime}\right) \mid s, s^{\prime} \in\right.$ $\left.S, x \in X, \delta(s, x) \neq s^{\prime}\right\}$ é criado. O conjunto $R$ é composto pelas combinações entre estado $s$, entrada $x$ e estado atingido $s^{\prime}$. Observa-se que o conjunto $R$ é formado pelas combinações $(n, k, n-1)$ e possui tamanho $r=k\left(n^{2}-n\right)$. Um conjunto auxiliar $R^{\prime}$ criado possui o mesmo tamanho que $R$ possuir em cada execução do laço. Em cada execução, um requisito do conjunto $R$ é retirado. Dessa forma, tem-se $\frac{r^{2}+r}{2}$ execuções. Realizando as respectivas substituições, o número de execuções é de $\frac{k^{2} n^{4}-2 k^{2} n^{3}+2 k n^{2}-k n}{2}=O\left(k^{2} n^{4}\right)$. Para cada execução, há uma chamada da função Find-Gamma. Assim, tem-se $p=|\operatorname{pre} f(T)|$ onde $p$ é o número de nós da árvore sendo $O(p)$. Pela propriedade da multiplicação, tem-se $O\left(k^{2} n^{4}\right) O(p)=O\left(k^{2} n^{4} p\right)$.

Pode-se observar que, com exceção do Passo 1 (problema NP-completo), os Passos 2 e 3 do algoritmo de minimização podem ser executados em tempo polinomial.

\subsection{Considerações Finais}

Neste capítulo foi apresentado o algoritmo de minimização de conjuntos de teste proposto neste trabalho. O algoritmo é aplicável para MEFs determinísticas, reduzidas e inicialmente conexas. Foram utilizadas condições de suficiência para guiar a minimização e manter a completude do conjunto de teste. Desse modo, o algoritmo produz um conjunto de teste minimizado que possui a mesma efetividade em revelar defeitos em relação ao conjunto de teste inicial.

Os três passos do algoritmo foram apresentados: Seleção do state cover, Verificação dos Estados e Verificação das Transições. Pela redução ao problema do clique, observou-se que a seleção de um conjunto state cover (Passo 1) é um problema NP-completo. No entanto, o Passo 1 é fundamental para o restante do algoritmo, pois é a partir do conjunto state cover que as sequiências são selecionadas para compor o conjunto final $T^{\prime}$. Pôde ser observado que, mesmo com a seleção de um conjunto state cover maior, um conjunto final $T^{\prime}$ menor pode ser obtido. Nos Passos 2 e 3 outras seqüências são selecionadas com a utilização de uma estratégia gulosa. Dessa forma, a melhor escolha local é realizada e não há garantia de que o conjunto final $T^{\prime}$ obtido seja o menor conjunto $n$-completo possível.

No próximo capítulo apresentam-se os experimentos realizados com o algoritmo de minimização. 


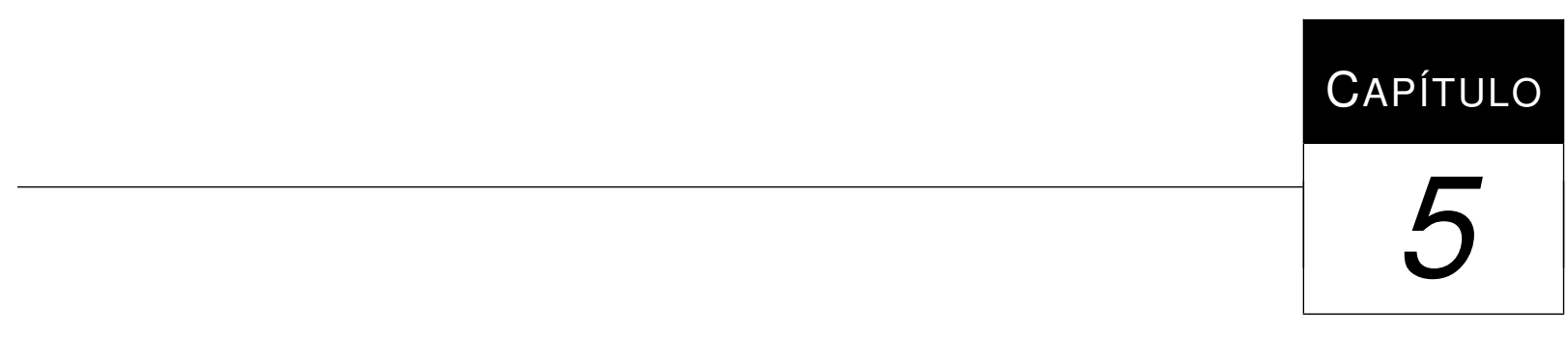

Experimentos

\subsection{Considerações Iniciais}

Neste capítulo são apresentados os experimentos realizados com o algoritmo de minimização. Foram conduzidos quatro experimentos com a utilização do algoritmo em dois diferentes contextos: (i) minimização a partir de conjuntos de teste e (ii) redução do esforço de se completar os conjuntos de teste. Na Seção 5.2, o primeiro experimento é conduzido para verificar a redução obtida a partir de conjuntos de teste gerados de forma aleatória. Na Seção 5.3, o segundo experimento é conduzido com o propósito de determinar o esforço de se completar um conjunto de teste utilizando MEFs geradas de forma aleatória. Na Seção 5.4, o terceiro experimento é conduzido para observar a redução obtida somente a partir de conjuntos gerados pelo método State Counting. $\mathrm{Na}$ Seção 5.5, o quarto experimento é conduzido no mesmo contexto do Experimento 2, ou seja, objetiva-se determinar o esforço de se completar um conjunto de teste, mas com MEFs obtidas a partir de um benchmark (Yang, 1991).

\subsection{Experimento 1}

Foi realizado um experimento com o algoritmo de minimização para verificar a redução obtida em conjuntos de teste $n$-completos. Nesse experimento, o algoritmo foi utilizado baseando-se apenas nas condições de suficiência apresentadas em Dorofeeva et al. (2005b), ou seja, sem utilizar uma das melhorias propostas em Simão e Petrenko (2007).

As MEFs foram geradas de forma aleatória em duas etapas. Na primeira etapa, um conjunto de estados era gerado e um estado era selecionado como estado inicial e marcado como "atingido". 
Para cada estado $s$ não marcado como "atingido", eram selecionados aleatoriamente um estado $s^{\prime}$, uma entrada $x$ e uma saída $y$, sendo que a transição $s^{\prime}-x / y \rightarrow s$ era adicionada à MEF e $s$ era marcado como "atingido". Ao final dessa etapa, uma MEF inicialmente conexa é obtida. Na segunda etapa, transições geradas aleatoriamente eram adicionadas para que a MEF se tornasse completa e, ao mesmo tempo, reduzida.

Os conjuntos de casos de teste também foram gerados de forma aleatória. Para cada MEF $A$ gerada, a quantidade e o tamanho das seqüências eram escolhidas. Em seguida, o conjunto de teste $T$ era criado com seqüências aleatórias que estavam definidas em $\Omega_{A}$. Após a minimização do conjunto $T$, o conjunto $T^{\prime} \subseteq T$ é obtido. Na Figura 5.1 são ilustrados os conjuntos $T$ e $T^{\prime}$.

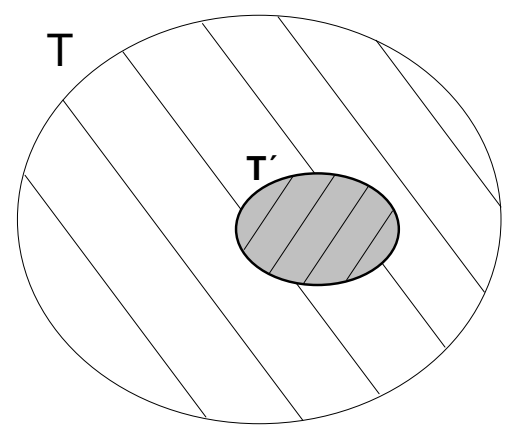

Figura 5.1: Conjuntos de Teste $T$ e $T^{\prime}$.

Para realizar o experimento com o algoritmo de minimização, foram utilizadas MEFs com três entradas, três saídas, reduzidas e completamente especificadas. Na Tabela 5.1 é apresentado um sumário dos resultados obtidos. Para cada linha da Tabela 5.1, foi utilizado um conjunto de 10 MEFs.

Tabela 5.1: Sumário dos resultados obtidos.

\begin{tabular}{|c|c|c|c|c|c|c|c|}
\hline $\begin{array}{c}\text { Qtde. } \\
\text { de } \\
\text { Estados }\end{array}$ & $\begin{array}{c}\text { Média } \\
\text { de } \\
w(T)\end{array}$ & $\begin{array}{c}\text { Qtde/Tam } \\
\text { de Seq. } \\
\text { em } T\end{array}$ & $\begin{array}{c}\text { Média } \\
\text { de } \\
w\left(T^{\prime}\right)\end{array}$ & Tempo & $\begin{array}{c}\text { Média } \\
\text { de } \\
w\left(T_{S C}\right)\end{array}$ & $\begin{array}{c}\% \text { em } \\
\text { relação } \\
\text { à } T\end{array}$ & $\begin{array}{c}\% \text { em } \\
\text { relação } \\
\text { à } T_{S C}\end{array}$ \\
\hline \hline 5 & 420 & $60 / 7$ & 73,4 & $0,113 \mathrm{~s}$ & 86,2 & $17,48 \%$ & $85,15 \%$ \\
\hline 10 & 2000 & $250 / 8$ & 217 & $0,637 \mathrm{~s}$ & 247,8 & $10,65 \%$ & $84,52 \%$ \\
\hline 15 & 8000 & $500 / 16$ & 396,9 & $10,493 \mathrm{~s}$ & 464 & $4,96 \%$ & $85,54 \%$ \\
\hline 20 & 16000 & $1000 / 16$ & 591 & $29,470 \mathrm{~s}$ & 682,9 & $3,69 \%$ & $86,54 \%$ \\
\hline
\end{tabular}

Para as MEFs de 5 estados, foram gerados conjuntos $T$ com 60 sequiências de tamanho sete. $\mathrm{O}$ algoritmo obteve, em média, um conjunto $T^{\prime}$ de tamanho 73,4. Para as MEFs de 10, 15 e 20 estados o conjunto obtido $T^{\prime}$, em média, foi de tamanho 217; 396,9 e 591, respectivamente. Em média, o conjunto $T^{\prime}$ obtido pelo algoritmo de minimização possui cerca de 17,48\%; 10,65\%; 4,96\% e 3,69\% do tamanho do conjunto inicial $T$ para as MEFs de 5, 10, 15 e 20 estados, respectivamente. 
Observa-se que a redução em relação ao conjunto de entrada $T$ é considerável. Contudo, isso se deve ao fato de que foi preciso gerar um conjunto inicial $T$ de alta cardinalidade de forma que $T$ tivesse maior probabilidade de ser $n$-completo.

Para efeito de comparação quanto ao tamanho do conjunto de teste obtido pelo algoritmo de minimização, foi utilizado o método de geração State Counting (Petrenko e Yevtushenko, 2005). Na Tabela 5.1 é fornecida a média dos tamanhos dos conjuntos de teste $T_{S C}$ obtidos pelo método State Counting para as mesmas MEFs. Observa-se que a minimização resultou, em média, conjuntos de teste $T^{\prime}$ com $85,15 \%, 84,52 \%, 85,54 \%$ e $86,54 \%$ do tamanho dos conjuntos de teste $T_{S C}$ gerados pelo State Counting para as MEFs de 5, 10, 15 e 20 estados, respectivamente.

\subsection{Experimento 2}

Um experimento foi realizado a fim de determinar o esforço de se completar um conjunto de teste. Para isso, o seguinte cenário foi considerado. Um conjunto de teste, chamado de $T_{a d-h o c}$, é obtido por alguma abordagem ad hoc. Em seguida, esse conjunto é completado com um conjunto $T_{n c} n$-completo obtendo-se o conjunto de teste $T=T_{a d-h o c} \cup T_{n c}$. Seja $T_{+}$o conjunto de seqüências de $T_{n c}$ que são, de fato, adicionadas ao conjunto $T_{a d-h o c}$, ou seja, seqüências que não estavam em $T_{a d-h o c}$. A partir de $T$, a minimização é realizada e o conjunto $n$-completo $T^{\prime}$ é obtido. Seja $T_{-}$o conjunto formado pelas seqüências de $T^{\prime}$ que não estão em $T_{a d-h o c}$. Observa-se que $T^{\prime}$ é $n$-completo e pode ser no máximo $T_{a d-h o c} \cup T_{-}$. Observa-se também que $T_{-} \subseteq T_{+}$. Desse modo, ao invés das seqüências de $T_{+}$serem adicionadas ao conjunto $T_{a d-h o c}$, pode-se completar $T_{a d-h o c}$ apenas com a adição das seqüências de $T_{-}$. Com isso, a redução do custo de se obter um conjunto de teste completo a partir de $T_{a d-h o c}$ pode ser medida pela razão entre os tamanhos de $T_{-}$e $T_{+}$. Para ilustrar esse contexto, na Figura 5.2 são ilustrados os conjuntos $T_{a d-h o c}, T_{n c}, T^{\prime}, T_{-}$e $T_{+}$.

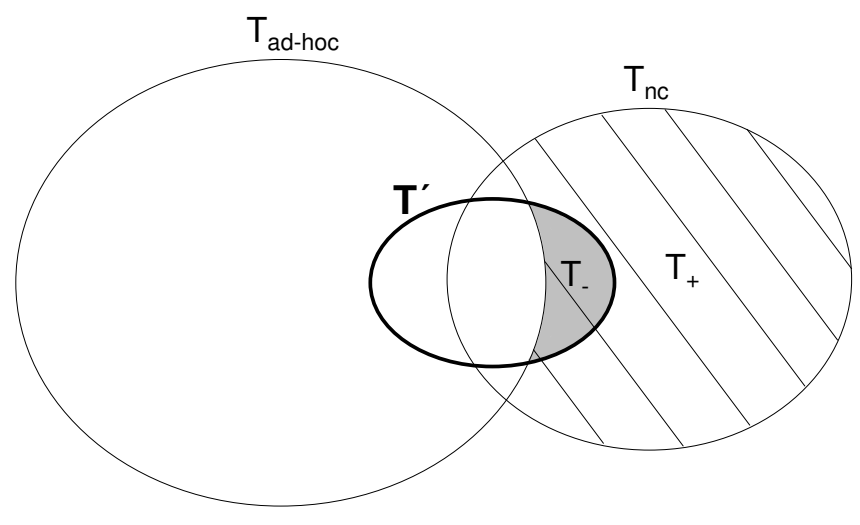

Figura 5.2: Conjuntos de Teste.

Após a minimização, o tamanho do conjunto $T^{\prime}$ pode ser no máximo igual à $T_{a d-h o c} \cup T_{-}$. Isso pode ocorrer se todo o conjunto $T_{a d-h o c}$ fosse selecionado pelo algoritmo e apenas uma parte das sequiências do conjunto $T_{n c}$ fosse selecionada. No entanto, quando a minimização é realizada, o algoritmo seleciona uma parte das seqüências de $T_{n c}$, mas também seleciona uma parte das 
sequiências de $T_{a d-h o c}$. Desse modo, o tamanho do conjunto obtido $T^{\prime}$, na maioria das vezes, é menor que $T_{a d-h o c} \cup T_{-}$.

Nos experimentos realizados, o conjunto $T_{a d-h o c}$ foi gerado de forma aleatória (descrito mais adiante) e $T_{n c}$ é um conjunto de teste $n$-completo gerado pelo método State Counting (Petrenko e Yevtushenko, 2005). Foram geradas MEFs inicialmente conectadas, completas e reduzidas da seguinte forma. Primeiramente, conjuntos de estados, entradas e saídas eram criados a partir do número de elementos requeridos. Em seguida, a geração era realizada em três etapas. Na primeira etapa, um estado era selecionado como estado inicial e marcado como "atingido". Para cada estado $s$ não marcado como "atingido", eram selecionados aleatoriamente um estado $s^{\prime}$, uma entrada $x \mathrm{e}$ uma saída $y$, sendo que a transição $s^{\prime}-x / y \rightarrow s$ era adicionada à MEF e $s$ era marcado como "atingido". Ao final dessa etapa, uma MEF inicialmente conectada é obtida. Na segunda etapa, o gerador adicionava à MEF, se necessário, mais transições (com a seleção aleatória de dois estados, uma entrada e uma saída). Essa adição de transições era realizada até que o número de transições, escolhido inicialmente, fosse atingido. Na terceira etapa, a distingüibilidade de cada par de estados da MEF é verificada. Se a MEF não for reduzida, ela é descartada e uma outra MEF é gerada.

Uma vez obtida uma MEF $A$, um conjunto de teste era gerado da seguinte forma. O número de sequiências e o comprimento de cada uma eram escolhidos. Em seguida, o conjunto de teste $T_{a d-h o c}$ era criado aleatoriamente com seqüências que estavam definidas em $\Omega_{A}$.

Por fim, o algoritmo de minimização era executado com o conjunto de teste $T=T_{a d-h o c} \cup T_{n c}$ como entrada. A saída obtida é o conjunto de teste $T^{\prime}$. Em seguida, era calculado o valor de $w\left(T_{-}\right) / w\left(T_{+}\right)$, onde $T_{-}=T^{\prime} \backslash \operatorname{pref}\left(T_{a d-h o c}\right)$ e $T_{+}=T_{n c} \backslash \operatorname{pref}\left(T_{a d-h o c}\right)$.

$\mathrm{O}$ conjunto $T_{+}$representa todas as seqüências de $T_{n c}$ que seriam adicionadas à $T_{a d-h o c}$ se a minimização não fosse realizada. $\mathrm{O}$ conjunto $T_{-}$representa todas as seqüências de $T_{n c}$ que seriam adicionadas à $T_{a d-h o c}$ se a minimização fosse realizada. Desse modo, a razão $w\left(T_{-}\right) / w\left(T_{+}\right)$ilustra a redução no custo de se completar $T_{a d-h o c}$. Foi investigado o impacto das variações do número de estados $(n)$, número de entradas $(k)$, número de saídas $(l)$, e tamanho de $T_{a d-h o c}$ sobre a razão $w\left(T_{-}\right) / w\left(T_{+}\right)$.

\subsubsection{Número de Estados}

Foram realizadas 20 iterações da seguinte forma. Foram geradas $48 \mathrm{MEFs}$ variando o número de estados de três à 50. Para cada MEF, foram selecionados os seguintes valores: $l=k=5 \mathrm{e}$ $w\left(T_{a d-h o c}\right)=2000$, onde $T_{a d-h o c}$ é composto por 200 sequiências de tamanho dez. Na Figura 5.3 é ilustrada a média de $w\left(T_{-}\right) / w\left(T_{+}\right)$para as 20 iterações.

Como ilustrado na Figura 5.3, a média de $w\left(T_{-}\right) / w\left(T_{+}\right)$situa-se entre 0,5 e 0,8, ou seja, o algoritmo seleciona de $50 \%$ à $80 \%$ das sequiências de $T_{+}$. Observa-se que o algoritmo seleciona mais seqüências a medida que o número de estados aumenta. Isso ocorre, devido ao tamanho do conjunto de teste $T_{n c}$. Enquanto $T_{n c}$ aumenta, o conjunto de teste $T_{a d-h o c}=2000$ possui o mesmo tamanho. Com isso, o algoritmo seleciona mais sequiências de $T_{n c}$ para garantir a completude. 


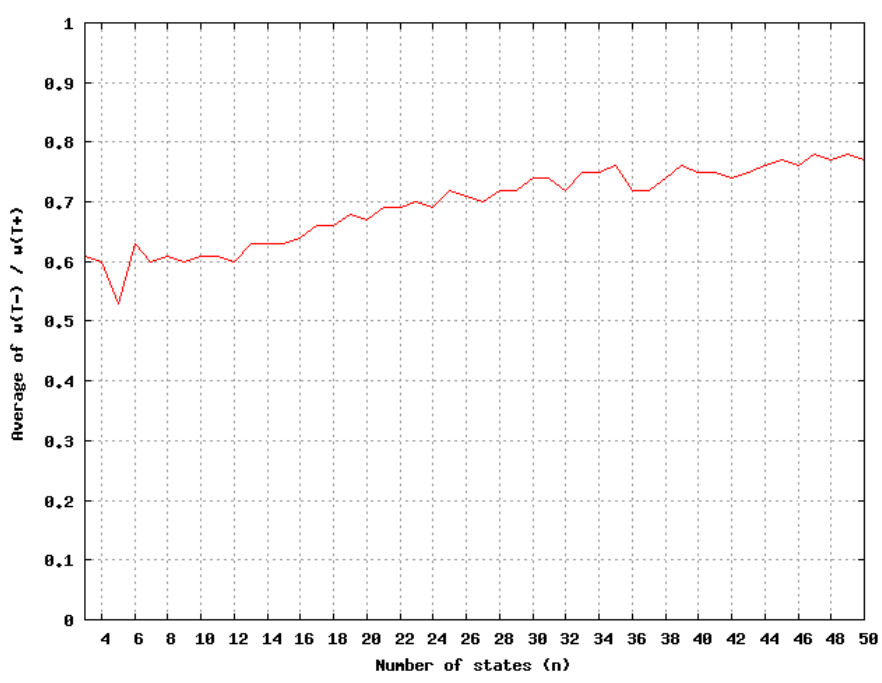

Figura 5.3: Variação de $n$.

\subsubsection{Número de Saídas}

Foram realizadas 20 iterações da seguinte forma. Foram geradas nove MEFs variando o número de saídas de dois à dez. Para cada MEF, foram selecionados os seguintes valores: $n=20$, $k=5$ e $w\left(T_{a d-h o c}\right)=2000$, onde $T_{a d-h o c}$ é composto por 200 sequiências de tamanho dez. Na Figura 5.4 é ilustrada a média de $w\left(T_{-}\right) / w\left(T_{+}\right)$para as 20 iterações.

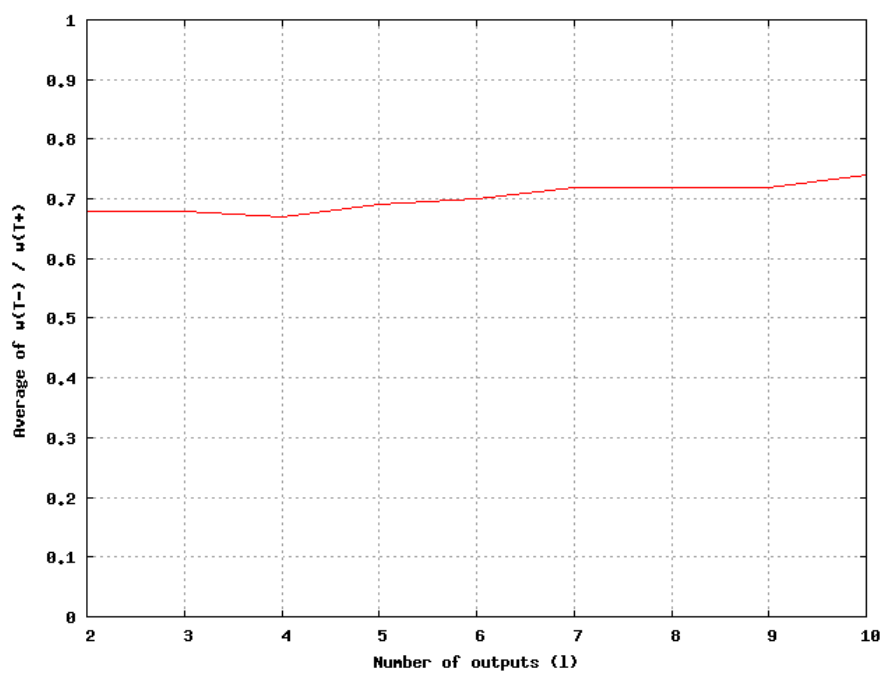

Figura 5.4: Variação de $l$.

Como ilustrado na Figura 5.4, a média de $w\left(T_{-}\right) / w\left(T_{+}\right)$situa-se entre 0,67 e 0,74 e aumenta a medida que o número de saídas aumenta. No entanto, observa-se que houve pouca variação da média, ou seja, o número de saídas tem menor impacto no comportamento do algoritmo.

\subsubsection{Número de Entradas}

Foram realizadas 20 iterações da seguinte forma. Foram geradas nove MEFs variando o número de saídas de dois à dez. Para cada MEF, foram selecionados os seguintes valores: $n=20$, 
$l=5$ e $w\left(T_{a d-h o c}\right)=2000$, onde $T_{a d-h o c}$ é composto por 200 seqüências de tamanho dez. Na Figura 5.5 é ilustrada a média de $w\left(T_{-}\right) / w\left(T_{+}\right)$para as 20 iterações.

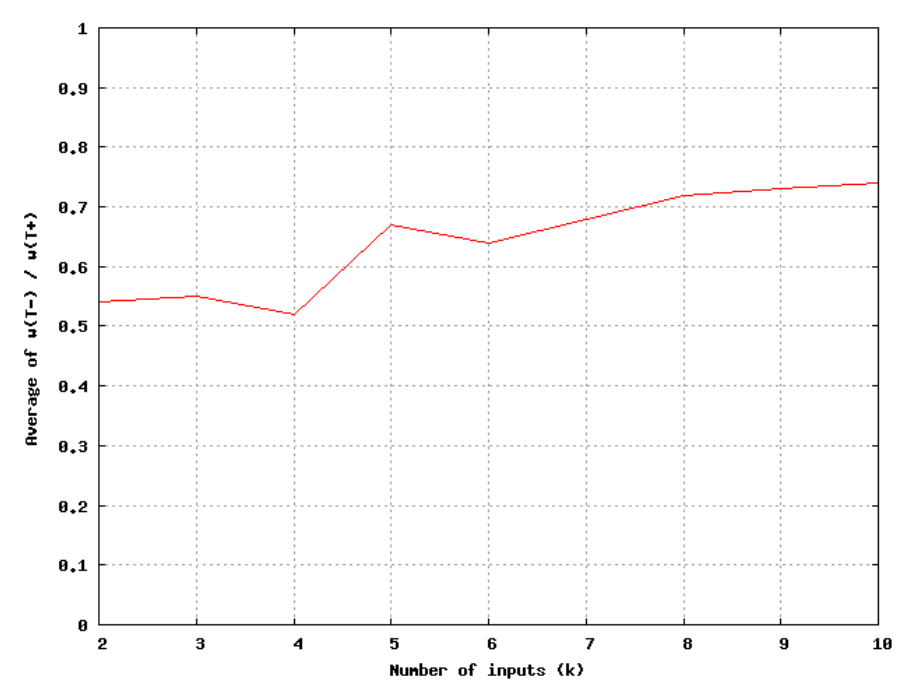

Figura 5.5: Variação de $k$.

Como ilustrado na Figura 5.5, a média de $w\left(T_{-}\right) / w\left(T_{+}\right)$situa-se entre 0,5 e 0,75 e aumenta a medida que o número de entradas aumenta. Isso ocorre, pois pre $f\left(T_{a d-h o c}\right)$ contém diversas sequiências de $T_{n c}$ para MEFs com apenas duas entradas. Dessa forma, uma quantidade pequena de seqüências de $T_{n c}$ precisa ser selecionada. O conjunto de teste $T_{n c}$ é maior a medida que o número de entradas aumenta e, com isso, o algoritmo precisa selecionar mais sequiências de $T_{+}$ para garantir a completude.

\subsubsection{Tamanho de $T_{a d-h o c}$}

Foram realizadas 20 iterações da seguinte forma. Foram geradas 11 MEFs com $n=20, k=5$, e $l=5$. Para cada MEF, variou-se o tamanho de $T_{a d-h o c}$. O conjunto de teste $T_{a d-h o c}$ é composto por seqüências de tamanho dez com $w\left(T_{a d-h o c}\right)$ entre 100 e 10000. Na Figura 5.6 é ilustrada a média de $w\left(T_{-}\right) / w\left(T_{+}\right)$para as 20 iterações.

Como ilustrado na Figura 5.6, a média de $w\left(T_{-}\right) / w\left(T_{+}\right)$situa-se entre 0,95 e 0,5 e decresce consideravelmente a medida que $w\left(T_{a d-h o c}\right)$ aumenta. Considerando uma mesma MEF, quanto maior $w\left(T_{a d-h o c}\right)$, maior a probabilidade de $T_{a d-h o c}$ ser $n$-completo. Desse modo, uma pequena quantidade de seqüências de $T_{n c}$ deve ser selecionada para garantir a completude.

\subsection{Experimento 3}

Nos experimentos anteriores foi observado que o conjunto de teste $T_{n c}$ gerado pelo método State Counting é formado por muitas sequiências de tamanho reduzido. Isso ocorre porque o método seleciona um conjunto state cover formado pelas menores seqüências possíveis. Dessa forma, o método inicia sua construção tendo como base essas seqüências menores e, consequientemente, 


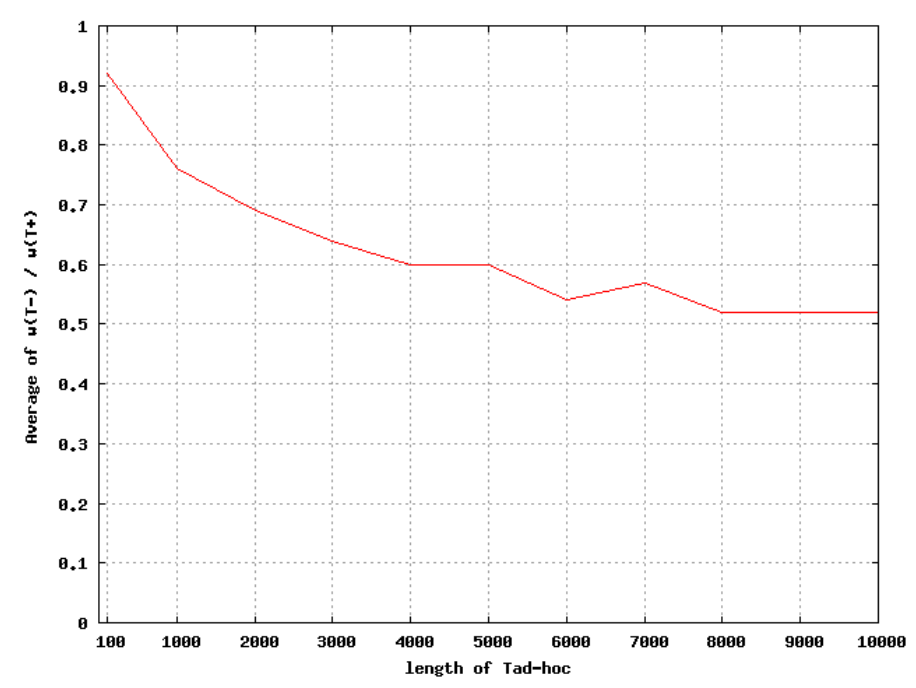

Figura 5.6: Variação de $w\left(T_{a d-h o c}\right)$.

as seqüências finais geradas possuem comprimento reduzido. O método só produzirá seqüências de maior comprimento se as seqüências selecionadas para compor o conjunto state cover forem maiores.

Um outro experimento foi conduzido para observar a redução obtida somente a partir de $T_{n c}$ gerado pelo método State Counting. Foram utilizadas 300 MEFs completas, determinísticas, reduzidas e geradas de forma aleatória com o número de estados variando de três a cinco e o número de entradas e saídas variando de dois a cinco. O conjunto $T_{n c}$ foi gerado pelo método State Counting para cada MEF. A partir de $T_{n c}$ o algoritmo realizava a minimização.

O conjunto state cover foi composto com as menores seqüências sendo que a seqüência vazia $\epsilon$ foi escolhida para o estado inicial. A média da redução obtida foi de 7,15\%. É importante observar que o algoritmo realizou a minimização em $100 \%$ dos casos, pois o conjunto state cover escolhido pelo algoritmo foi o mesmo conjunto state cover escolhido pelo método State Counting. Nesse contexto, podem existir situações em que o algoritmo selecione todas as sequiências do conjunto $T_{n c}$, ou seja, $T^{\prime}=T_{n c}$. A minimização realizada a partir de $T_{n c}$ não produz resultados satisfatórios, ou seja, a redução é pequena ou nenhuma. Isso ocorre, pois o algoritmo não tem muitas possibilidades de escolha no momento de selecionar uma sequiência para testar uma determinada transição. Desse modo, a sequiência selecionada pelo algoritmo, para compor o conjunto final $T^{\prime}$, é a mesma seqüência de $T_{n c}$ que o State Counting selecionou no processo de geração.

Apesar da minimização não ser eficiente, o resultado pode ser considerado relevante, pois demonstra que a minimização ainda pode ocorrer em um conjunto gerado com o propósito de ser $n$-completo.

O mesmo experimento foi conduzido, mas com a seleção de outras sequiências para compor o conjunto state cover a fim de verificar a redução obtida. Para a composição do conjunto state cover foi escolhida a seqüência vazia $\epsilon$ para o estado inicial e, para os demais estados, foram escolhidas seqüências aleatórias $\alpha \in \operatorname{pref}\left(T_{n c}\right)$. Nesse contexto, o algoritmo realizou a minimização em $46 \%$ dos casos (138 MEFs). Em 54\% dos casos (142 MEFs) o algoritmo selecionou um conjunto state 
cover inapropriado. Essa redução da aplicabilidade do algoritmo se deve ao fato da seleção de sequiências maiores para a composição do conjunto state cover. Desse modo, o algoritmo encontra dificuldades para a seleção de seqüências $\gamma$, uma vez que o conjunto de teste $T_{n c}$ é formado por sequiências de tamanho reduzido. A média da redução obtida foi de 7,21\%. Observa-se que a redução obtida pelo algoritmo com seqüências aleatórias foi semelhante à média obtida pelo algoritmo com a seleção das menores seqüências.

Em resumo, a redução é pequena quando o algoritmo é aplicado a partir de um conjunto $n$ completo gerado pelo State Counting. Esse método produz um conjunto $T_{n c}$ construído a partir de um state cover específico. Desse modo, o algoritmo limita-se a poucas possibilidades de escolha de seqüências, sendo que as mesmas seqüências de $T_{n c}$ são selecionadas para compor $T^{\prime}$. Em outras palavras, o algoritmo de minimização "tende" a selecionar as mesmas seqüências que o método State Counting produziu.

É importante ressaltar que a minimização realizada a partir de um conjunto $n$-completo $T_{a d-h o c}$ é satisfatória (Seção 5.2), pois existem mais possibilidades de escolha para a seleção das seqüências. Desse modo, seqüências de tamanho maior em relação às seqüências contidas em $T_{n c}$ podem ser selecionadas pelo algoritmo e um número maior de transições são testadas.

\subsection{Experimento 4}

Realizou-se também um experimento com exemplos de MEFs ${ }^{1}$ obtidas do International Workshop on Logic Synthesis (LGSynth91) realizado em 1991.

Há um total de 53 exemplos de MEFs no formato KISS2. Inicialmente as MEFs foram convertidas para o formato aceito pelo algoritmo de minimização. Na Figura 5.7 é ilustrado um exemplo de uma MEF no formato KISS2 e no formato aceito pelo algoritmo de minimização.

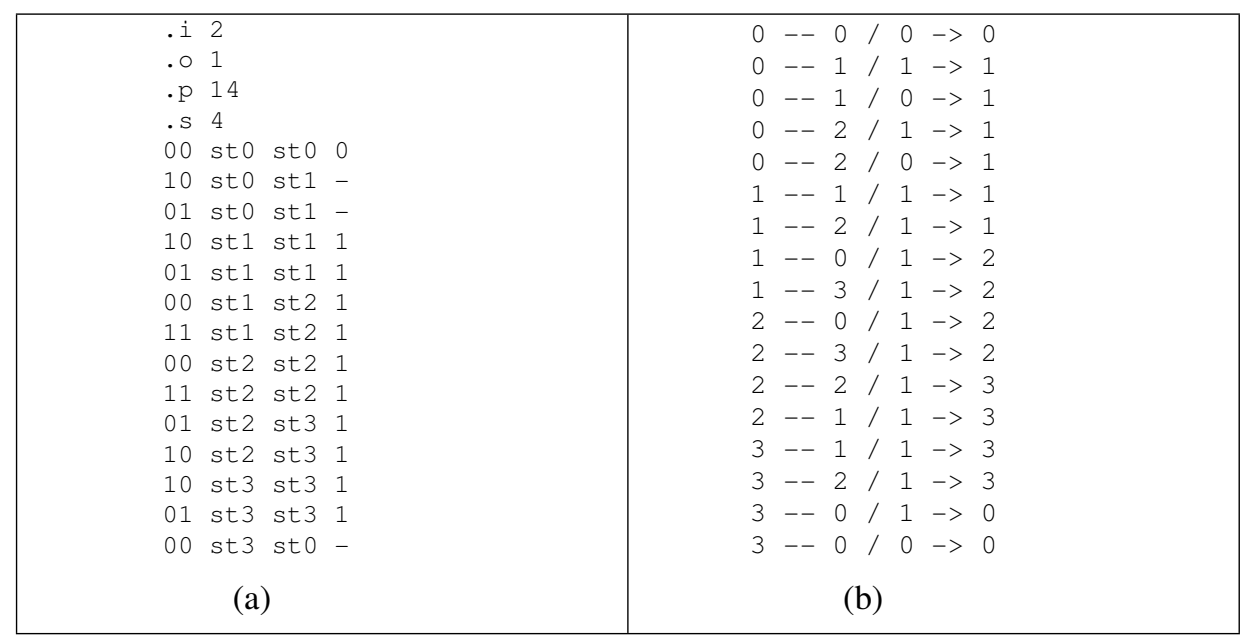

Figura 5.7: Representações da MEF.

\footnotetext{
${ }^{1}$ Disponíveis em http://www.cbl.ncsu.edu:16080/benchmarks/LGSynth91/fsmexamples/
} 
Observa-se que o formato aceito pelo algoritmo necessita que cada transição seja representada em uma linha, enquanto o formato KISS2 pode representar uma maior quantidade de transições ao mesmo tempo devido ao símbolo “-”. Cada símbolo representa os valores 0 e 1 . Com isso, 12 MEFs foram descartadas do experimento após a conversão, pois eram MEFs que continham mais de 15 mil transições ou mais de 100 estados. Essas MEFs resultaram em arquivos com tamanho entre 5 a 520MB que, conseqüentemente, inviabilizaram a execução do algoritmo. Outras 19 MEFs também foram descartadas por não serem reduzidas. Não foi possível aplicar a implementação do método State Counting para $14 \mathrm{MEFs}$ que também foram descartadas. Na Tabela 5.2 estão ilustradas as MEFs do benchmark e o motivo pelo qual algumas foram descartadas.

Nesse experimento, o algoritmo de minimização foi utilizado no mesmo contexto do experimento descrito na Seção 5.3, ou seja, em relação ao esforço de se completar um conjunto de teste.

O conjunto $T_{n c}$ foi gerado pelo método State Counting. O conjunto $T_{a d-h o c}$ foi gerado de forma aleatória de tamanho 1100 composto por 100 sequiências de comprimento 11. Para a composição do conjunto state cover foi escolhida a seqüência vazia $\epsilon$ para o estado inicial e, para os demais estados, foram escolhidas seqüências aleatórias.

Foram utilizadas oito MEFs determinísticas e reduzidas e o algoritmo realizou a minimização para todos os casos. Na Tabela 5.3 é ilustrado o sumário dos resultados obtidos.

Observa-se que o algoritmo obteve diferentes resultados devido às características das MEFs e à seleção do conjunto state cover. Para a MEF bbtas todas as sequiências de $T_{+}$foram selecionadas para se completar o conjunto $T_{a d-h o c}$, pois $w\left(T_{-}\right)=w\left(T_{+}\right)$. Já na MEF train4 apenas $7 \%$ das seqüências de $w\left(T_{+}\right)$foram selecionadas. Em média, a razão $w\left(T_{-}\right) / w\left(T_{+}\right)$obtida foi de 0,52 , ou seja, o esforço em se completar o conjunto de teste foi reduzido pela metade. 
Tabela 5.2: Exemplos de MEFs.

\begin{tabular}{|c|c|c|c|c|c|c|}
\hline $\begin{array}{l}\text { Nome } \\
\text { da } \\
\text { MEF }\end{array}$ & Estados & Entradas & Utilizada & Não Reduzida & $\begin{array}{l}\text { State Counting } \\
\text { Não Executou }\end{array}$ & $\begin{array}{c}\text { MEF com } \\
\text { mais de } \\
15 \text { mil transições }\end{array}$ \\
\hline bbara & 10 & 16 & & $\checkmark$ & & \\
\hline bbsse & 16 & 128 & & $\checkmark$ & & \\
\hline bbtas & 6 & 4 & $\checkmark$ & & & \\
\hline beecount & 7 & 8 & & $\checkmark$ & & \\
\hline cse & 16 & 128 & & & $\checkmark$ & \\
\hline dk14 & 7 & 8 & & & $\checkmark$ & \\
\hline dk15 & 4 & 8 & & & $\checkmark$ & \\
\hline dk16 & 27 & 4 & $\checkmark$ & & & \\
\hline dk17 & 8 & 4 & $\checkmark$ & & & \\
\hline dk27 & 7 & 2 & $\checkmark$ & & & \\
\hline dk512 & 15 & 2 & $\checkmark$ & & & \\
\hline donfile & 24 & 4 & & $\checkmark$ & & \\
\hline ex1 & 20 & 512 & & $\checkmark$ & & \\
\hline ex2 & 19 & 4 & & $\checkmark$ & & \\
\hline ex3 & 10 & 4 & & $\checkmark$ & & \\
\hline ex4 & 14 & 64 & & & $\checkmark$ & \\
\hline ex5 & 9 & 4 & & $\checkmark$ & & \\
\hline ex6 & 8 & 32 & & & $\checkmark$ & \\
\hline ex7 & 10 & 4 & & $\checkmark$ & & \\
\hline keyb & 19 & 128 & & & $\checkmark$ & \\
\hline kirkman & 16 & 4096 & & & & $\checkmark$ \\
\hline lion & 4 & 4 & $\checkmark$ & & & \\
\hline lion9 & 9 & 4 & & $\checkmark$ & & \\
\hline mark1 & 15 & 32 & & & & $\checkmark$ \\
\hline $\mathrm{mc}$ & 4 & 8 & & & $\checkmark$ & \\
\hline modulo12 & 12 & 2 & & $\checkmark$ & & \\
\hline opus & 10 & 32 & & $\checkmark$ & & \\
\hline planet & 48 & 128 & & & & $\checkmark$ \\
\hline planet1 & 48 & 128 & & & & $\checkmark$ \\
\hline pma & 24 & 256 & & 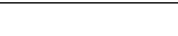 & $\checkmark$ & \\
\hline s1 & 20 & 256 & & 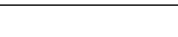 & $\checkmark$ & \\
\hline s1a & 20 & 256 & & $\checkmark$ & 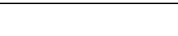 & \\
\hline s8 & 5 & 16 & & $\checkmark$ & & \\
\hline s820 & 25 & 262144 & & & & $\checkmark$ \\
\hline s1494 & 48 & 256 & & & $\checkmark$ & \\
\hline s208 & 18 & 2048 & & & $\checkmark$ & \\
\hline s27 & 6 & 16 & & $\checkmark$ & & \\
\hline $\mathrm{s} 420$ & 18 & 524288 & & & & $\checkmark$ \\
\hline s832 & 25 & 262144 & & & & $\checkmark$ \\
\hline s1488 & 48 & 256 & & & $\checkmark$ & \\
\hline s510 & 47 & 524288 & & & & $\checkmark$ \\
\hline s386 & 13 & 128 & & 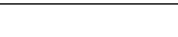 & $\checkmark$ & \\
\hline s298 & 218 & 8 & & 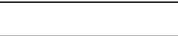 & & $\checkmark$ \\
\hline sand & 32 & 2048 & & & & $\checkmark$ \\
\hline scf & 121 & $2^{27}$ & & & & $\checkmark$ \\
\hline shiftreg & 8 & 2 & $\checkmark$ & & & \\
\hline sse & 16 & 128 & & $\checkmark$ & & \\
\hline styr & 30 & 512 & & & & $\checkmark$ \\
\hline tav & 4 & 16 & & & $\checkmark$ & \\
\hline tbk & 32 & 64 & & $\checkmark$ & & \\
\hline tma & 20 & 128 & & $\checkmark$ & & \\
\hline train11 & 11 & 4 & & $\checkmark$ & & \\
\hline train4 & 4 & 4 & $\checkmark$ & & & \\
\hline
\end{tabular}


Tabela 5.3: Sumário dos resultados obtidos.

\begin{tabular}{|c|c|c|c|c|c|c|c|c|c|c|}
\hline $\begin{array}{c}\text { Nome } \\
\text { da } \\
\text { MEF }\end{array}$ & Estados & Entradas & Saídas & $w(T)$ & $w\left(T_{a d-h o c}\right)$ & $w\left(T_{n c}\right)$ & $w\left(T^{\prime}\right)$ & $w\left(T_{+}\right)$ & $w\left(T_{-}\right)$ & $\begin{array}{c}w\left(T_{-}\right) / \\
w\left(T_{+}\right)\end{array}$ \\
\hline \hline bbtas & 6 & 4 & 4 & 1288 & 1100 & 211 & 214 & 188 & 188 & 1 \\
\hline dk16 & 27 & 4 & 5 & 1978 & 1100 & 974 & 784 & 878 & 626 & 0,71 \\
\hline dk17 & 8 & 4 & 5 & 1249 & 1100 & 258 & 209 & 149 & 88 & 0,59 \\
\hline dk27 & 7 & 2 & 3 & 1008 & 1100 & 64 & 109 & 7 & 0 & 0 \\
\hline dk512 & 15 & 2 & 4 & 1186 & 1100 & 238 & 272 & 97 & 65 & 0,67 \\
\hline lion & 4 & 4 & 2 & 1171 & 1100 & 129 & 113 & 71 & 59 & 0,83 \\
\hline shiftreg & 8 & 2 & 2 & 1104 & 1100 & 69 & 125 & 48 & 16 & 0,33 \\
\hline train4 & 4 & 4 & 2 & 1167 & 1100 & 108 & 82 & 67 & 5 & 0,07 \\
\hline
\end{tabular}




\subsection{Considerações Finais}

Neste capítulo foram apresentados quatro experimentos com o algoritmo de minimização. O algoritmo foi utilizado em dois diferentes contextos. Nos Experimentos 1 e 3, o algoritmo foi utilizado para verificar a redução obtida a partir de conjuntos de teste. Foi observado que a minimização obteve resultados satisfatórios a partir de conjuntos de teste aleatórios. No entanto, a minimização foi pequena a partir de conjuntos de teste gerados pelo método State Counting, pois o algoritmo não possui muitas possibilidades para a seleção de seqüências. Desse modo, o algoritmo de minimização "tende" a selecionar as mesmas seqüências que o método State Counting produziu.

Nos Experimentos 2 e 4, o algoritmo foi utilizado para verificar a redução do esforço de se completar conjuntos de teste. Foi possível observar que o comportamento do algoritmo de minimização foi semelhante tanto com MEFs do benchmark quanto com MEFs geradas de forma aleatória. 


\section{CAPítulo \\ 6}

Conclusões

A minimização de conjuntos de casos de teste pode viabilizar e agilizar a etapa de teste, uma vez que menos casos de teste são aplicados. Para que a qualidade dos testes não seja prejudicada é importante que o conjunto de teste resultante da minimização ofereça a mesma efetividade na detecção de defeitos em relação ao conjunto de teste inicial. Com isso, a atividade de teste se torna menos onerosa, mas com a manutenção de sua efetividade.

Neste trabalho, um algoritmo de minimização de conjuntos de teste para MEFs foi proposto. Com base nas condições de suficiência apresentadas em Dorofeeva et al. (2005b) e Simão e Petrenko (2007), a minimização mantém a $n$-completude de um conjunto de teste. O algoritmo possui três passos principais e utiliza uma estratégia baseada no algoritmo guloso para determinar quais casos de teste devem ser selecionados. Experimentos foram conduzidos tanto para verificar a redução obtida em conjuntos de teste quanto para verificar a redução obtida em relação ao esforço para se completar um conjunto de teste. A seguir, apresentam-se as contribuições de forma mais detalhada, as limitações e as possibilidades de trabalhos futuros.

\subsection{Contribuições}

A principal contribuição deste trabalho foi o desenvolvimento de um algoritmo de minimização de conjuntos de teste para MEFs. O algoritmo baseia-se nas condições de suficiências apresentadas nos trabalhos de Dorofeeva et al. (2005b) e Simão e Petrenko (2007). É importante salientar que o algoritmo utiliza as melhorias propostas por Simão e Petrenko (2007) que, atualmente, são as condições de suficiência mais abrangentes para o caso particular $m=n$. 
Um experimento com MEFs reduzidas, completas e geradas aleatoriamente foi realizado para verificar a redução obtida com a minimização. No entanto, esse experimento foi realizado com o algoritmo de minimização baseando-se apenas nas condições de suficiência apresentadas no trabalho de Dorofeeva et al. (2005b), ou seja, sem utilizar uma das melhorias propostas por Simão e Petrenko (2007). Os resultados apontam uma redução significativa de conjuntos de teste que foram obtidos de forma aleatória. A redução também foi obtida quando comparou-se os conjuntos de teste obtidos pela minimização e os conjuntos de teste obtidos a partir de um método clássico de geração. A minimização resultou, em média, conjuntos com 85,15\%, 84,52\%, 85,54\% e 86,54\% do tamanho dos conjuntos gerados pelo método de geração para MEFs de 5, 10, 15 e 20 estados, respectivamente.

Outros experimentos foram realizados com o objetivo de verificar a redução no esforço de se completar um conjunto de teste. Em um primeiro momento, foram utilizadas MEFs reduzidas, completamente especificadas e geradas de forma aleatória. Os resultados apontam uma redução da razão $w\left(T_{-}\right) / w\left(T_{+}\right)$de até 0,5 . Isso significa que o esforço adicional para se completar um conjunto de teste pode ser reduzido pela metade. O algoritmo de minimização também foi utilizado com um benchmark de MEFs. Em média, a razão $w\left(T_{-}\right) / w\left(T_{+}\right)$obtida foi de 0,52.

Além da minimização, pode-se utilizar o algoritmo com o intuito de verificar se um conjunto de teste $T$ é $n$-completo para uma determinada MEF. Nesse cenário, se a minimização for realizada sabe-se que o conjunto inicial $T$ é $n$-completo.

\subsection{Limitações}

A minimização não é realizada em duas situações. A minimização não ocorre quando o conjunto de teste a ser minimizado não satisfaz as condições de suficiência, pois não atende as suposições iniciais estabelecidas pelo algoritmo. A minimização também não ocorre quando o conjunto state cover selecionado não é apropriado para os próximos passos do algoritmo. Em outras palavras, há situações que o conjunto state cover selecionado não satisfaz as condições de suficiência, enquanto um outro conjunto poderia satisfazê-las.

A seleção de um conjunto state cover é o passo mais importante do algoritmo, pois é a partir desse conjunto que as sequiências de teste são selecionadas. Essa seleção não é trivial, pois o problema para selecionar um conjunto state cover é um problema NP-completo. Podem existir diversos subconjuntos candidatos a state cover em um conjunto de teste. Por exemplo, um conjunto de teste para uma MEF de 20 estados pode conter um número excessivo de diferentes subconjuntos state cover que poderiam ser utilizados pelo algoritmo, ou seja, que atenderiam Cond1. 


\subsection{Trabalhos Futuros}

Como trabalho futuro pode-se citar a investigação de uma melhor forma de se selecionar um conjunto state cover. Outras heurísticas podem ser utilizadas na seleção para melhorar os resultados da minimização. Um passo nessa direção foi a utilização de um conjunto state cover composto com seqüências selecionadas de forma aleatória. Essa seleção, ainda de forma não conclusiva, aponta uma maior redução do esforço para se completar um conjunto de teste. Essa melhoria pode ser explicada pelo maior comprimento das seqüências escolhidas de forma aleatória. Com isso, a seqüência maior pode checar mais transições de uma vez e menos seqüências precisam ser selecionadas para se checar as demais transições.

Uma outra possibilidade em relação à composição do conjunto state cover seria com a seleção de prefixos de uma sequiência state tour. Essa seqüência atinge todos os estados da MEF. Desse modo, apenas a seqüência state tour seria a base inicial para a minimização.

Uma linha de pesquisa com o algoritmo de minimização poderia ser explorada no contexto de geração de sequiências, ou seja, o algoritmo poderia ser utilizado para a geração de casos de teste. Por exemplo, suponha que o conjunto de teste $T$ (conjunto de entrada do algoritmo) seja formado por todas as combinações possíveis de símbolos de entrada $x \in X$. Nesse cenário, o algoritmo teria maior possibilidade de escolha para adicionar seqüências ao conjunto final $T^{\prime}$. Dessa forma, um conjunto de teste reduzido e $n$-completo $T^{\prime}$ poderia ser obtido. Nesse contexto, uma comparação quanto ao tamanho do conjunto gerado pelo algoritmo e dos conjuntos gerados pelos métodos clássicos de geração poderia ser realizada.

Maior investigação quanto à extensão do algoritmo de minimização pode ser realizada na medida em que as condições de suficiência forem estendidas. Dessa forma, o algoritmo poderá ser aplicado para verificar a $m$-completude de conjuntos de teste, ou seja, quando $m \geq n$ e para verificar a $m$-completude de MEFs não determinísticas.

\subsection{Publicações}

A seguir, são apresentados os trabalhos publicados resultantes das atividades desenvolvidas durante o mestrado.

- MEllo NETO, L. F.; SIMÃO, A. S.; Minimização de Conjuntos de Casos de Teste por meio de Condições de Suficiência. In: 1st Brazilian Workshop on Systematic and Automated Software Testing, João Pessoa, 2007. p. 55-62.

- MELlO NETO, L. F.; SIMÃO, A. S.; Test Suite Minimization Based on FSM Completeness Sufficient Conditions. In: 9th IEEE Latin-American Test Workshop, Puebla, 2008. 

Barbosa, D. L.; Andrade, W. L.; Machado, P. D. L.; Figueiredo, J. C. A. SPACES - uma ferramenta para teste funcional de componentes. In: XI Sessão de Ferramentas do Simpósio Brasileiro de Engenharia de Software, Brasília, DF, 2004, p. 55-60.

BARrocA, L. M.; MCDERmid, J. A. Formal methods: Use and relevance for the development of safety-critical systems. The Computer Journal, v. 35, n. 6, p. 579-599, 1992.

BEIZER, B. Software testing techniques. 2 ed. New York: Van Nostrand Eeinhold, 1990.

BINDER, R. V. Testing object-oriented systems: Models, patterns, and tools, v. 1. Addison Wesley Longman, Inc., 1999.

Broy, M.; Jonsson, B.; Katoen, J.-P.; Leucker, M.; Pretschner, A. Model-based testing of reactive systems. 1 ed. Berlin Heidelberg: Springer-Verlag, 2005.

Bueno, P. M. S.; JinO, M. Automated test data generation for program paths using genetic algorithms. In: 13th International Conference on Software Engineering \& Knowledge Engineering - SEKE'2001, Buenos Aires, Argentina, 2001, p. 2-9.

Candolo, M. A.; Simão, A. S.; Maldonado, J. C. Mgaset - uma ferramenta para apoiar o teste e validação de especificações baseadas em máquinas de estado finito. In: Anais do XV Simpósio Brasileiro de Engenharia de Software, 2001, p. 386-391.

Chaim, M. L. Poke-tool-uma ferramenta para suporte ao teste estrutural de programas baseado em análise de fluxo de dados. Dissertação de Mestrado, DCA/FEEC/UNICAMP, Campinas, SP, 1991.

Chen, J.; Hierons, R. M.; Ural, H.; Yenigün, H. Eliminating redundant tests in a checking sequence. In: 17th IFIP Int. Conference on Testing of Communicating Systems (TESTCOM 2005), Springer, 2005, p. 146-158 (Lecture Notes in Computer Science, v.3502). 
Chen, W.-H.; TANG, C. Y.; VuOnG, S. T. Improving the uiov-method for protocol conformance testing. Computer Communications, v. 18, n. 9, p. 609-619, 1995.

CHOw, T. S. Testing software design modeled by finite-state machines. IEEE Transactions on Software Engineering, v. 4, n. 3, p. 178-187, 1978.

Cormen, T. H.; Leiserson, C. E.; Rivest, R. L.; Stein, C. Introduction to algorithms. 2nd ed. Mit Press, 2001.

DAVIS, A. M. A comparison of techniques for the specification of external system behavior. Communications of the ACM, v. 31, n. 9, 1988.

Delamaro, M. E. Proteum - um ambiente de teste baseado na análise de mutantes. Dissertação de Mestrado, ICMC/USP, São Carlos, SP, 1993.

DeMillo, R. A. Progress toward automated software testing. In: ICSE'91: Proceedings of the 13th international conference on Software engineering, Los Alamitos, CA, USA: IEEE Computer Society Press, 1991, p. 180-183.

DeMillo, R. A.; OffutT, A. J. Constraint-based automatic test data generation. IEEE Transactions on Software Engineering, v. 17, n. 9, p. 900-910, 1991.

Dorofeeva, R.; El-Fakih, K.; MaAg, S.; Cavalli, A. R.; Yevtushenko, N. Experimental evaluation of fsm-based testing methods. In: Third IEEE International Conference on Software Engineering and Formal Methods, 2005a, p. 23-32.

Dorofeeva, R.; El-Fakih, K.; Yevtushenko, N. An improved conformance testing method. In: Formal Techniques for Networked and Distributed Systems (FORTE 2005), 2005b, p. 204-218.

Fabbri, S. C. P. F.; Maldonado, J. C.; Delamaro, M. E.; Masiero, P. C. Proteum/fsm: A tool to support finite state machine validation based on mutation testing. In: In XIX SCCC - International Conference of the Chilean Computer Science Society, IEEE Computer Society, 1999, p. 96-104.

FonseCA, R. P. Suporte ao teste estrutural de programas fortran no ambiente poke-tool. Dissertação de Mestrado, DCA/FEE/UNICAMP, Campinas, SP, 1993.

Frankl, P.; Weyuker, E. A data flow testing tool. In: Proceedings of IEEE Softfair II Conference on Software Development Tools, Techniques, and Alternatives, 1985, p. 46-53.

FRAnKL, P. G.; WeyUKer, E. J. Testing software to detect and reduce risk. Journal of Systems and Software, v. 53, n. 3, p. 275-286, 2000. 
FrASER, G.; WotAWA, F. Using model-checkers for mutation-based test-case generation, coverage analysis and specification analysis. Los Alamitos, CA, USA: IEEE Computer Society, 2006, p. 16.

Fujiwara, S.; Bochman, G. V.; Khendek, F.; Amalou, M.; Ghedamsi, A. Test selection based on finite state models. IEEE Transactions on Software Engineering, v. 17, n. 6, p. 591603, 1991.

FURBACH, U. Formal specification methods for reactive systems. Journal of Systems and Software, v. 21, n. 2, p. 129-139, 1993.

GAREY, M.; Johnson, D. Computers and intractability: a guide to the theory of npcompleteness. 1 ed. Freeman, 1979.

GILL, A. Introduction to the theory of finite-state machines. New York: McGraw-Hill, 1962.

Gönenc, G. A method for design of fault detection experiments. IEEE Transactions on Computers, v. 19, n. 6, p. 551-558, 1970.

HAREL, D. Statecharts: A visual formalism for complex systems. Science of Computer Programming, v. 8, n. 3, p. 231-274, 1987.

Harrold, M. J. Testing: A roadmap. In: Future of Software Engineering, $22^{\text {nd }}$ International Conference on Software Engineering, ACM Press, 2000, p. 61-72.

Herculano, P. F. R. Análise de cobertura de critérios de teste estruturais a partir de conjuntos derivados de especificações formais: Um estudo comparativo no contexto de aplicações espaciais. Dissertação de Mestrado, ICMC/USP, São Carlos, SP, 2007.

Hierons, R. M.; UraL, H. Reduced length checking sequences. IEEE Transactions on Computers, v. 51, n. 9, p. 1111-1117, 2002.

Hierons, R. M.; UrAL, H. Optimizing the length of checking sequences. IEEE Transactions on Computers, v. 55, n. 5, p. 618-629, 2006.

Holzmann, G. J. Design and validation of protocols. Englewood Cliffs, New Jersey: PrenticeHall Software Series, 1991.

Horgan, J. R.; Mathur, A. P. Assessing testing tools in research and education. IEEE Software, v. 9, n. 3, p. 61-69, 1992.

Howden, W. E. Theoretical and empirical studies of program testing. IEEE Transactions on Software Engineering, v. 4, n. 4, p. 293-298, 1978.

HSIEH, E. Checking experiments for sequential machines. IEEE Transactions on Computers, v. C-20, n. 10, p. 1152-1166, 1971. 
IEEE IEEE standard glossary of Software Engineering terminology. Padrão 620.12, IEEE, 1990.

KoHAVI, I.; KoHaVI, Z. Variable-length distinguishing sequences and their application to the design of fault-detection experiments. IEEE Transactions on Computers, v. 17, n. 8, p. 792$795,1968$.

KOREL, B. Automated software test data generation. IEEE Transactions on Software Engineering, v. 16, n. 8, p. 870-879, 1990.

LeE, D.; YAnnaKaKis, M. Testing finite-state machines: State identification and verification. IEEE Transactions on Computers, v. 43, n. 3, p. 306-320, 1994.

LEITÃO, P. S. J. Suporte ao teste estrutural de programas cobol no ambiente poke-tool. Dissertação de Mestrado, DCA/FEE/UNICAMP, Campinas, SP, 1992.

Leveson, N. G.; Stolzy, J. L. Safety analysis using petri nets. IEEE Transactions on Software Engineering, v. 13, n. 3, p. 386-397, 1987.

LiU, S.; MCDERMid, J. A. A model-oriented approach to safety analysis using fault trees and its support system. The Journal of Systems and Software, v. 35, n. 2, p. 151-164, 1996.

Luo, G.; Petrenko, A.; Bochmann, G. Selecting test sequences for partially-specified nondeterministic finite state machines. In: 7th IFIP WG 6.1 international workshop on Protocol test systems, London, UK, UK: Chapman \& Hall, Ltd., 1995, p. 95-110.

Maldonado, J. C. Critérios potenciais usos: Uma contribuição ao teste estrutural de software. Tese de doutoramento, Campinas, SP, 1991.

Maldonado, J. C.; Barbosa, E. F.; Vincenzi, A. M. R.; Delamaro, M. E.; Souza, S. R. S.; JinO, M. Introdução ao teste de software. Relatório Técnico 65, ICMC/USP, São Carlos, SP, notas Didáticas do ICMC, Série Computação, 2004.

Maldonado, J. C.; Chaim, M. L.; Jino, M. Arquitetura de uma ferramenta de teste de apoio aos critérios potenciais usos. In: Anais do XXII Congresso Nacional de Informática, São Paulo, SP, 1989.

Martins, E.; Ambrosio, A. M.; Mattielo-Francisco, M. F. Atifs: a testing toolset with software fault injection. In: Proceedings of York Computer Science Yellow Report 2003 Workshop SofTest: UK Testing Research II, 2003.

Martins, E.; Sabião, S. B.; Ambrosio, A. M. Condata: a tool for automating specificationbased test case generation for communication systems. Software Quality Journal, v. 8, n. 4, p. 303-319, 1999. 
Morell, L. J. A theory of fault-based testing. IEEE Transactions on Software Engineering, v. 16, n. 8, p. $844-857,1990$.

Myers, G. J. The art of software testing. 2 ed. Hoboken, New Jersey: John Wiley \& Sons, Inc., 2004.

NAIK, K. Efficient computation of unique input/output sequences in finite state machines. IEEE/ACM Transactions on Networking, v. 5, n. 4, p. 585-599, 1997.

NAito, S.; Tsunoyama, M. Fault detection for sequential machines by transition tours. In: Proceedings of the 11th IEEE Fault Tolerant Computing Conference (FTCS 1981), IEEE Computer Society Press, 1981, p. 238-243.

OfFUtT, J.; PAN, J.; VOAS, J. Procedures for reducing the size of coverage-based test sets. 1995, p. 111-123.

Peterson, J. L. Petri nets. ACM Computing Surveys, v. 9, n. 3, p. 223-252, 1977.

Petrenko, A.; Bochmann, G.; Yao, M. Y. On fault coverage of tests for finite state specifications. Computer Networks and ISDN Systems, v. 29, n. 1, p. 81-106, 1996.

Petrenko, A.; Yevtushenko, N. Testing from partial deterministic fsm specifications. IEEE Transactions on Computers, v. 54, n. 9, p. 1154-1165, 2005.

Petrenko, A.; Yevtushenko, N.; Lebedev, A.; Das, A. Nondeterministic state machines in protocol conformance testing. In: Protocol Test Systems, 1993, p. 363-378.

PLAVIS Plavis - platform for software validation \& integration on space systems. Online em: http://www.labes.icmc.usp.br/plavis/index.html, último acesso: 21/04/2006, 2005.

Pressman, R. S. Software engineering - a practitioner's approach. 6 ed. McGraw-Hill, 2005.

RAPPS, S.; WEYUKER, E. J. Data flow analysis techniques for program test data selection. In: 6th International Conference on Software Engineering, Tokyo, Japan, 1982, p. 272-278.

RAPPS, S.; WEYUKer, E. J. Selecting software test data using data flow information. IEEE Transactions on Software Engineering, v. 11, n. 4, p. 367-375, 1985.

Sabnani, K. K.; Dahbura, A. A protocol test generation procedure. Computer NetWorks and ISDN Systems, v. 15, n. 4, p. 285-297, 1988.

Simão, A. S. Aplicação da análise de mutantes no contexto do teste e validação de redes de petri coloridas. Tese de doutoramento, ICMC/USP, São Carlos, SP, 2004. 
Simão, A. S.; Ambrósio, A. M.; Fabbri, S. C. P. F.; Amaral, A. S. M. S.; Martins, E.; Maldonado, J. C. Plavis/fsm: an environment to integrate fsm-based testing tools. In: Caderno de Ferramentas do XIX Simpósio Brasileiro de Engenharia de Software, Uberlândia, MG, 2005.

Simão, A. S.; Petrenko, A. Checking fsm test suite completeness based on sufficient conditions. Relatório Técnico CRIM-07/10-20, Centre the Recherche Informatique de Montreal, 2007.

Simão, A. S.; Petrenko, A. Generating checking sequences for partial reduced finite state machine. In: 20th IFIP Int. Conference on Testing of Communicating Systems (TESTCOM 2008), Tokyo, Japan, (accepted), 2008.

Tan, Q.; Petrenko, A.; Bochmann, G. A test generation tool for specifications in the form of state machines. In: IEEE International Conference on Communications (ICC'96), 1996, p. 225-229.

UrAL, H.; WU, X.; ZhANG, F. On minimizing the lengths of checking sequences. IEEE Transactions on Computers, v. 46, n. 1, p. 93-99, 1997.

Vincenzi, A. M. R. Orientação a objeto: Definição e análise de recursos de teste e validação. Tese de Doutoramento, ICMC/USP, São Carlos, SP, 2004.

Vincenzi, A. M. R.; Wong, W. E.; Delamaro, M. E.; Maldonado, J. C. JaBuTi: A coverage analysis tool for Java programs. In: XVII SBES - Simpósio Brasileiro de Engenharia de Software, Manaus, AM, Brasil, 2003, p. 79-84.

Vuong, S. T.; Chan, W. W. L.; Ito, M. R. The uiov-method for protocol test sequence generation. In: Proc. of the IFIP TC6 2nd IWPTS, North-Holland, 1989, p. 161-175.

WeyUKer, E. J. Axiomatizing software test data adequacy. IEEE Transactions on Software Engineering, v. 12, n. 12, p. 1128-1138, 1986.

WING, J. M. A specifier's introduction to formal methods. IEEE Computer, v. 23, n. 9, p. 8,1022,24, 1990.

YANG, S. Logic synthesis and optimization benchmarks user guide version 3.0. Online em: http://www.cbl.ncsu.edu/xBed/datasets/BCSP/LogSynth91/ 1991 -IWLSUG-Saeyang/1991-IWLSUG-Saeyang.pdf, último acesso: 18/03/2008, 1991.

YAnNAKAKIS, M.; LEE, D. Testing finite state machines: Fault detection. J. Computer and System Science, v. 50, n. 2, p. 209-227, 1995. 
Yao, M. Y.; Petrenko, A.; Bochmann, G. Fault coverage analysis in respect to an fsm specification. In: IEEE INFOCOM`94, Toronto, Canadá, 1994, p. 768-775.

Yevtushenko, N.; CAVAlli, A.; Anido, R. Test suite minimization for embedded nondeterministic finite state machines. Relatório Técnico, 1999.

Disponível em: citeseer.ist.psu.edu/yevtushenko99test.html

Yevtushenko, N.; Cavalli, A. R.; Lima, L. P. Test minimization for testing in context. In: 11th IWTCS, 1998, p. 127-145.

Zhu, H.; Hall, P. A. V.; MAY, J. H. R. Software unit test coverage and adequacy. Computer Survey, v. 29, n. 4, p. 367-427, 1997. 

APÊNDICE

\section{$A$}

Detalhes do Código

Neste apêndice, são ilustrados os detalhes do código e a formatação dos arquivos de entrada para a execução do algoritmo de minimização.

\section{A.1 Estrutura de Dados}

$\mathrm{O}$ algoritmo foi implementado com a linguagem C++ e a biblioteca STL (Standard Template Library $^{1}$ ). A implementação contém aproximadamente 2.400 linhas de código composta por cerca de 47 procedimentos.

A principal estrutura de dados utilizada foi a árvore. A árvore foi criada a partir do conjunto de teste $T$ a ser minimizado. Na Figura A.1 são ilustrados os campos do nó da árvore utilizada.

Observa-se que a mesma árvore foi utilizada para representar o conjunto final $T^{\prime}$ por meio do campo sel. Se em um nó $a$ o campo sel possui o valor true, significa que a seqüência $\alpha$, que atinge o nó $a$, pertence ao conjunto $T^{\prime}$, ou seja, $\alpha \in T^{\prime}$. Da mesma forma ocorre com o campo conf. Se conf possui o valor true, significa que a seqüência $\alpha$, que atinge o nó $a$, pertence ao conjunto $K$, ou seja, $\alpha \in K$.

O campo level contém o valor da profundidade do nó. Esse valor é utilizado no cálculo do custo para se adicionar uma seqüência $\alpha$ ao conjunto $T^{\prime}$. O campo numChildren contém a quantidade de nós filhos que o nó pai possui. Esse valor é, no máximo, igual ao número de entradas da MEF.

\footnotetext{
${ }^{1}$ http://www.sgi.com/tech/stl/index.html
} 


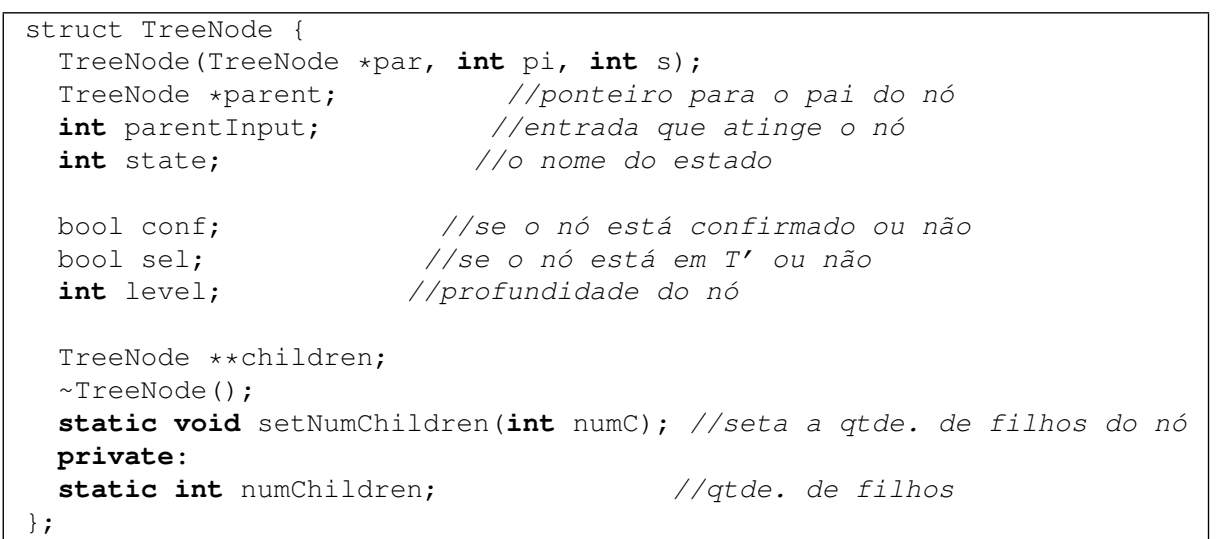

Figura A.1: Campos do nó da árvore.

\section{A.2 Formatação dos Arquivos}

Para a execução do algoritmo de minimização são necessários dois arquivos de entrada. $\mathrm{O}$ primeiro arquivo deve conter a especificação da $\mathrm{MEF} M$ composta com transições no formato $s_{i}--x / y \rightarrow s_{j}$, ou seja, a MEF $M$ no estado $s_{i}$ produz $y$ como saída e realiza uma transição para o estado $s_{j}$ quando a entrada $x$ é aplicada. Desse modo, cada linha do arquivo contém uma transição e todas as transições da MEF devem ser declaradas. O primeiro estado da primeira linha do arquivo é considerado o estado inicial. Na Figura A.2(b) é ilustrada a representação da MEF (Figura A.2(a)) pelo arquivo de entrada.

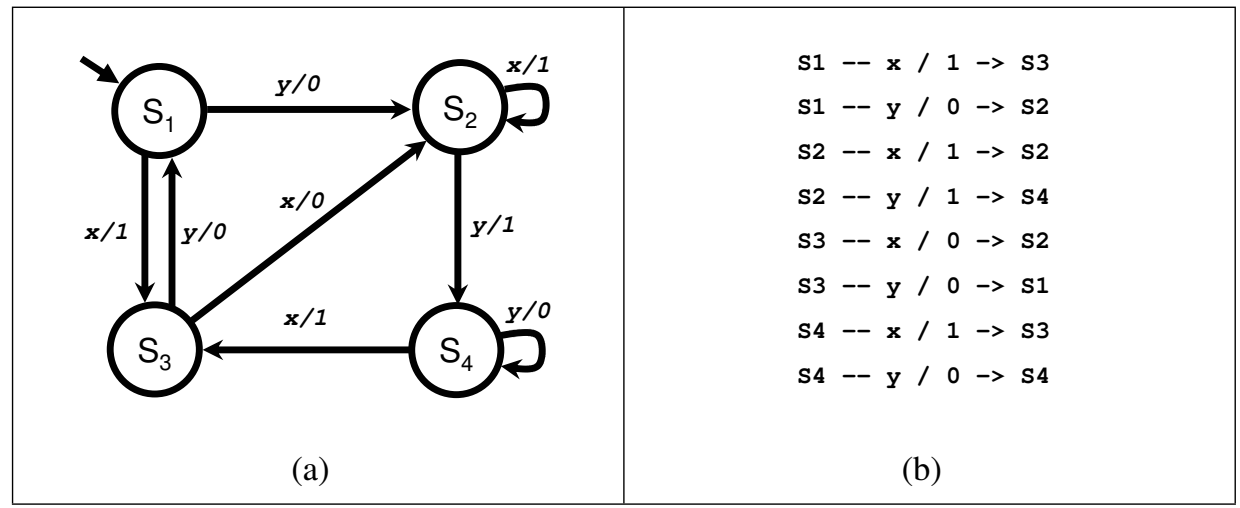

Figura A.2: Representação da MEF no arquivo de entrada.

O segundo arquivo deve conter o conjunto de teste $T$ a ser reduzido. Em cada linha do arquivo um caso de teste é descrito sem o símbolo " $r$ ". No entanto, a existência do símbolo " $r$ ", no início de cada caso de teste, é considerada. Na Figura A.3(a) é ilustrado o formato do arquivo de entrada que representa o conjunto de teste $T=\{r x x y$, rxyyy, ryxy, ryyxx, ryyyyyy, rxxxyxyyy $\}$ de tamanho 34.

Todos os casos de teste são lidos e representados em uma estrutura de árvore para que a minimização possa ser iniciada. Ao final da minimização, um conjunto de teste $n$-completo $T^{\prime} \subseteq T$ é 


\begin{tabular}{|l|l|}
\hline$x x y$ & $x x y$ \\
XYYY & xyYy \\
YXY & YXY \\
YYXX & YYXX \\
YYYYYY & YYYYYY \\
XXXYXYYY & \\
\multicolumn{1}{|c|}{ (a) } & (b) \\
\hline
\end{tabular}

Figura A.3: Representações dos conjuntos de teste $T$ e $T^{\prime}$.

obtido. Na Figura A.3(b) é ilustrado o formato do arquivo de saída que representa o conjunto de teste $T^{\prime}=\{r x x y$, rxyyy, ryxy, ryyx $x$, ryyyyyy $\}$ de tamanho 25 .

O algoritmo deve ser executado da seguinte forma: "fsm-minimization < MEF.txt T.txt [T'.txt]" onde MEF.txt e T.txt são os arquivos que possuem a MEF e o conjunto de teste a ser reduzido, respectivamente. Um terceiro arquivo (opcional) pode ser passado como parâmetro para que o conjunto final $T^{\prime}$ seja salvo. 